\title{
Diskursive Veränderungen in Psycho zwischen Horrorsensation und Autorenkino
}

Alfred Hitchcocks Film Psycho gilt als einer der meistanalysiertesten Filme der Filmgeschichte. Von einem zu Entstehungszeiten als umstritten aufgenommenen Film hat sich Psycho über die Jahre zu einem Klassiker der Filmkunst und des Genrekinos entwickelt, wo er unter zahlreichen Bestenlisten reiht: 2007 landete Psycho in der vom American Film Institute organisierten Umfrage auf Platz 14 der 100 besten Filme der Filmgeschichte (AFI, „10th Anniversary“), ${ }^{1}$ bei der vom britischen Magazin Sight \& Sound 2012 initiierten Wahl dagegen ,nur' auf Platz 35, aber wie die Redaktion betont: „Hitchcock's low budget , shocker' paved the way for the modern horror film." (Christie) Es ist insbesondere dieser Diskurs zum Genre, in dem Psycho als „quintessential horror film“ (Modleski 104) und „ancestor“ des Slasherfilms (Clover 23) eine herausragende Stellung zugeschrieben bekommt, die zu einer psycho-sexuellen Neuausrichtung des Genres beigetragen hat. In seiner wegweisenden Studie Monsters and Mad Scientists. A Cultural History of the Horror Movie betrachtet Andrew Tudor 1989 Psycho als Wendepunkt des Genres, an dem statt von einem aus entlegener Ferne kommenden Monster die Gefahr nun von der sexuell repressiven, psychotischen Natur des Menschen selbst ausgeht (47).

In earlier horror movies, most ,mad' characters were glossed as simply evil, their madness (if it was even given the name) an autonomous feature of a constantly malevolent world. After 1960, however, and most particularly in the seventies, madness becomes psychosis: a secular, dependent and internally articulated threat. (57)

\footnotetext{
${ }^{1}$ Gegenüber der ersten Abstimmung von 1998 wurde Psycho 2007 sogar 4 Plätze höher gelistet (AFI 1998). 
Auch für Carol J. Clover hat Psycho mit der Figur des psychopathischen Mörders ein neues populäres Muster eingeführt, das zu einer Psychologisierung der Horrorthemen und einer Sexualisierung von Motiv und Mord geführt hat, die insbesondere für den Slasherfilm der 1970er und 1980er Jahre genrebildend waren (24). ${ }^{2}$ Doch Psycho greift nach Jancovich auch die bereits Horrorfilme der 1950er Jahre prägende Tendenz auf, statt ,exotischer' Schauplätze vermehrt Räume des Alltäglichen zu besetzen und den Horror innerhalb der Gesellschaft zu platzieren (,Rational Fears“ 303). Diese Tendenz nimmt in der Duschszene eine radikale Form an (S. Koebner 147) und hat Psycho für das Genre prototypisch werden lassen. Ebenso im Kriminalfilm und Thriller wird Psycho richtungsweisend für die Herausbildung des Psychothrillers geführt. ${ }^{3}$

Als Psycho am 16. Juni 1960 in New York anläuft, ist dieses ,revolutionäre` Genrepotential des Films für etablierte Filmeliten, auch im Kontext des damaligen Genrekinos von Hollywood und des abseitigen Low-Budget-Genrekinos, in der Form nicht absehbar. ${ }^{4}$ Die Filmkritik reagiert überaus negativ auf den Film, den sie als ,unsinniges Spektakelkino' mit gruseligen Schockeffekten und einer ,reißerischen “ Werbekampagne ablehnt. Die Werbekampagne sorgt trotz der schlechten Kritiken letztlich nicht nur für ein großes Publikum, sondern trägt erheblich dazu bei, dass Psycho zu Hitchcocks erfolgreichstem Film wird. Nur wenige ,abseitige' Besprechungen erkennen das Potential dieses Films, das zu der obigen Sonderstellung sowohl im autorenbezogenen Kanon der Filmkunst als auch in wissenschaftlichen Genrediskursen führen soll. Auf der Ebene der Genreproduktion liegt mit Psycho also ein überaus facettenreich diskursivierter Film vor, der nicht nur eine fast 70-jährige (Diskurs-)Geschichte aufweist, sondern innerhalb dieser auch mehreren (Genre-)Verschiebungen unterliegt, wie es entlang der historischen Dynamik von Genrebezeichnungen zuvor problematisiert wurde. Einerseits hat sich Psycho filmhistorisch von einem von Kritik

\footnotetext{
${ }^{2}$ Die stete Zunahme an Horrorfilmen erhält vor allem Ende der 1970er Jahre einen auffälligen Sprung, den Tudor auf den enormen Erfolg von Halloween zurückführt (67), der auch den Ausgangspunkt von Clovers Untersuchungskorpus zum Slasherfilm bildet. In beiden Horrortheorien wird hierbei Psycho als Vorläufer gesetzt. Siehe auch Vossen 22; S. Koebner 147; Seeßlen/Jung 352 und Wood, „An Introduction to“ 173.

${ }^{3}$ In der Reclam-Reihe der Filmgenres wird Psycho als Schlüsselfilm nicht nur im Horrorfilm (Vossen), sondern auch im Kriminalfilm (Hickethier, ,Einleitung“ 23) und Thriller (Koebner/Wulff 12 f.) besprochen; ebenso setzt Seeßlen ihn als Grundmodell dieses Sub-Genres (,Filmwissen: Thriller“ 149). Dabei sind diese Einzelgenres keineswegs als abgegrenzte Konzepte zu verstehen, sondern beweisen insbesondere am Fall von Psycho fließende Grenzüberschneidungen und Genrevermischungen auf.

${ }^{4}$ Zum Low-Budget-Genrekino siehe Doherty und Heffernan.
} 
und Hollywood abgelehnten Projekt zu Hitchcocks erfolgreichstem Film entwickelt, den nicht nur Bestenlisten als Meisterwerk preisen, sondern auch die mit der Institutionalisierung der Film Studies exponentiell zunehmenden (film-) wissenschaftliche Veröffentlichungen. ${ }^{5}$ Zudem griff Hitchcock auf eine außergewöhnliche und umfangreiche Werbekampagne zurück, die nicht nur den Presseund Publikumszugang steuerte, sondern auch einen entscheidenden Genrediskurs setzte, der sich auf die nachfolgenden generischen Diskursivierungen des Films und der dazugehörigen Genrekonzepte auswirkte.

Im Gegensatz zu seiner heutigen prototypischen Stellung stellt Psycho 1960 genrehistorisch betrachtet ein Randphänomen des Horrorfilms dar, das zudem noch abseits Hitchcocks gängiger ,Thrill and Suspense'-Geschichten ein ungewöhnliches Szenario aufweist und als Low-Budget-Produktion eigenfinanziert werden muss. Dabei war 1960 eine Genretheorie in einem systematischen Verständnis noch nicht vorhanden. Auch fehlte dem Horrorfilm ein Theoriediskurs, wie ihn beispielsweise Robert Warshow zum Gangsterfilm und Western skizziert (,Westerner“ und „Gangster“), sodass Psycho gewissermaßen in einen ,diskursiven Leerraum“ eintritt. Dennoch wird Psycho 1960 im Kontext von Genrekonzepten wahrgenommen, die für Hollywood- wie Low-Budget-Produktionen, das Publikum und die Kritik von praktischer Relevanz und kultureller Wertigkeit sind. Inwiefern sich diese Genrekontexte in den Filmkritiken und den Materialien der Werbekampagne widerspiegelt und die Genrediskurse als ,praktische“ Diskurse avant la lettre prägen, wird in dieser Fallanalyse zu Psycho aufgezeigt.

Den Fokus der Untersuchung bildet Psycho's genrehistorische Entwicklung von einer randseitigen Genreposition hin zum Klassiker und Prototypen des Horrorfilms, die über die Autorenpolitik, die Filmkritik, die Materialien der Werbekampagne, den Film Criticism und die Genretheorie bewirkt wird. Sie leisten vor allem in Bezug auf den Status von Psycho als Genreproduktion eine bemerkenswerte diskursive Arbeit, an der sich auf der Ebene der Genreproduktion der dynamische und multiple Verlauf von Genres veranschaulichen lässt. Zugleich deutet sich als ein Nebenprodukt die Ebene des Genrekonzepts in ihrer theoriehistorischen Genese aus der politique des auteurs heraus an, wie es bereits theoriegeschichtlich skizziert wurde.

\footnotetext{
${ }^{5}$ Während Hitchcock ab Mitte der 1960er Jahre zum präferierten Regisseur autorenbezogener Studien wird, die mit Robin Woods Hitchcock's Films den Anfang der „Hitchcock Studies“ (Belton, „Hitchcock“) bilden, avanciert Psycho in den 1970er Jahren zum präferierten Analyseobjekt der psychoanalytisch orientierten Filmtheorie (Williams, „Discipline and fun“ 353$)$.
} 
Auch was zuvor als ,strukturelle Lücke“ der Genretheorie beschrieben wurde, wird hier exemplarisch: Obgleich Psycho im Horrorfilm eine diskurshistorisch prominente Stellug zukommt, gehen Psycho's Genrediskurse nicht vollständig im Horrorfilm auf. Ebenso wenig wie sich Psycho auf den Horrorfilm reduzieren lässt, wird der Horrorfilm in seiner Gänze über Psycho abbildbar. ${ }^{6}$ Psycho ist weniger im Sinne eines Präzedenzfalls als vielmehr als ein besonders umfangreich diskutiertes Fallbeispiel zu verstehen, an dem in typischer Weise die zuvor herausgestellte Dynamik, Flexibilität und Varianz von Genres aufgezeigt werden können. Die herausgearbeiteten generischen Verschiebungen und Neuverortungen besitzen wiederum in der Form ihrer Zusammenhänge, Kontexte und Diskurse durchaus einen repräsentativen Charakter für Filme, die in ähnlicher Weise generischen Veränderungen unterlagen.

Die folgende diskursanalytische Betrachtung von Psycho und seinen (Genre-) Diskursen nähert sich in einem ersten Schritt überblicksartig den zahlreichen textbasierten Materialien zu Hitchcock und Psycho, um aus diesen diskursanalytische Schwerpunkte für die nachfolgenden Betrachtungen zu entwickeln. In einem Exkurs wird dabei die Rolle der Cahiers du Cinéma-Kritiker und späteren Nouvelle Vague-Filmemacher skizziert, die Hitchcock zum auteur erheben und damit einen Kanonisierungsprozess einleiten. Dieser legt den Grundstein für die anschließenden systematischen Genrediskurse, in denen Psycho schließlich als Genreklassiker positioniert wird. Anschließend werden die generischen Diskurse von Psycho innerhalb der Filmkritiken und der Materialien der Werbekampagne untersucht. Während die Kontroverse, die sich in den Filmkritiken widerspiegelt, nicht zuletzt Ausdruck der damaligen kulturellen Geringschätzung der Filmpresse gegenüber dem Genre des Horrorfilms ist, ziehen sich durch die Materialien mehrere Genremarkierungen, die einen deutlichen Bezug zum Horrorgenre und seinen damaligen Kinopraktiken herstellen. Inwiefern diese einerseits einer Sensationalisierung im Sinne von Linda Williams (,Discipline and fun“) entsprechen und anderseits ein jüngeres, horroraffines Publikum ansprechen, wird hier aufgezeigt. Schließlich wird in einem letzten Schritt eine genrespezifische Analyse des Films selbst vorgenommen, die ausgewählte film- und genretheoretische close readings von Psycho einbezieht, um den inzwischen überwiegend wissenschaftlichen Genrediskurs zu Psycho herauszuarbeiten. Dabei kann allerdings auf nur wenige dezidiert genretheoretische Analysen zurückgegriffen werden, weil die

\footnotetext{
${ }^{6}$ Psycho ließe sich gleichermaßen produktiv als schwarze Komödie lesen, wie es Naremore bereits in Ansätzen skizziert (,Hitchcock and humor“ 33-35). Auch William Paul entdeckt in Psycho Elemente, die ,strikingly conflate the horror film with comedy.“ (412)
} 
Genretheorie erst nach Psycho systematische Konzeptualisierungen und Horrordiskurse herausbildet. Diese zementieren zwar, wie oben eingeführt, Psycho's prototypischen wie ikonischen Genrestatus, operieren aber genreanalytisch meist an anderen, gegenwärtigeren Beispielen. Der genrespezifischen Vormachtstellung von Psycho fehlt es also ungewöhnlicherweise an einer entsprechenden Diskursivierung auf der Mikroebene exemplarischer Genreanalysen. Diese soll hier nicht nur eingelöst werden, sondern auch methodisch als, diskursanalytische Genreanalyse" im Spiegel der umfangreichen Diskurse umgesetzt werden. In diesem Vorgehen zeigt sich, wie über die vielfältigen Diskursivierungen Psycho als ,generischer Text' im Derrida'schen Sinn entsteht und eine semantische Einheit bildet. Indem die Diskurse Markierungen identifizieren und Bezüge herstellen, konstruieren sie ein dynamisches Bezugsfeld an Semantiken, das Genres auf der Ebene der Genreproduktion kennzeichnet und im Folgenden exemplarisch in seinen diskursiven Bestandteilen untersucht wird.

\section{1 Überblick und diskursanalytische Schwerpunkte}

In der 2013 herausgegebenen deutschen Übersetzung des Hitchcock-Buchs von Éric Rohmer und Claude Chabrol, die 1957 im französischen Original erscheint, stellt Robert Fischer fest: „Es gibt mit Sicherheit keinen Filmschaffenden, über den soviel veröffentlicht wurde wie über Hitchcock.“ (7) Bereits in den 1980ern verzeichnet Hans Jürgen Wulff etwa 3.000 Artikel und Bücher, davon 79 selbständige Schriften über Hitchcock (,All about Hitchcock“). Fischer kommt 30 Jahre später auf über 100 Bücher, die allein auf Englisch erschienen sind. ${ }^{7}$ Bis heute werden unaufhörlich weitere Reader, Einführungen und Companions nicht nur zu

\footnotetext{
${ }^{7}$ Eine vollständige Wiedergabe des Diskurses zu Psycho ist angesichts dieses Umfangs nicht mehr möglich. Zugleich leistet der Diskurs diese Arbeit bereits selbst durch kommentierte Bibliographien (zu Psycho siehe Naremore, „Filmguide“; zu Hitchcock siehe Wulff, „All About“ und Sloan), über Reader, Companions und Handbücher (zu Hitchcock siehe Allen/Ishii-Gonzalès; Deutelbaum/Poague; Gottlieb; Gottlieb/Allen; Heller, „Hitchcock“; zu Psycho siehe Naremore, ,Filmguide“ und Kolker), Metaanalysen zu Psycho (Bordell, ,Making Meaning“ 224-248; Jancovich, ,Rational Fears“ 220-234; Williams, „Discipline and fun“) und kritische Besprechungen (Belton, „Hitchcock“). Neben den theoretischanalytischen Diskussionen finden sich hierbei auch populärwissenschaftliche Veröffentlichungen wie Janet Leighs Psycho. Behind the Scenes of the Classic Thriller, Stephen Rebellos Hitchcock and the Making of Psycho und Robert Graysmiths The Girl in Alfred Hitchcock's Shower.
} 
Hitchcock, sondern auch zu Psycho herausgegeben. ${ }^{8}$ Wie Bordwell bereits 1989 aufzeigt, lässt sich entlang des Diskurses zu Psycho die sukzessive Herausbildung eines theoriegeleiteten Film Criticism nachzeichnen, die er von den ersten PsychoKritiken in den Cahiers du Cinema bis zu den Analysen der psychoanalytischen Filmtheorie zieht.

If one takes this survey of Psycho criticism as a record of changes in the interpretative institution, one historical trend stands out. The appeal of ,theory is at first nonexistent (Douchet), then tentative (Wood's quiet invocation of Freud), then explicit (Bellour), then tacit (Klinger), and again explicit (Poague, who wants to confute the reigning theory). (247)

Die zunehmende Institutionalisierung der Filmwissenschaft führt vor allem zwischen 1965 und 1975 zu einem erheblichen Anstieg an Filmseminaren, die einen steigenden Bedarf an akademischer Filmliteratur nach sich ziehen (Elsaesser, „New Film History“ 246). Mit Robin Woods wegweisender Autorenstudie Hitchcock's Films erscheint 1965 die erste englische Monographie zu Hitchcock. ${ }^{9}$ Bald folgen darauf weitere, die die steigende Popularität autorenbezogener Filmanalysen widerspiegeln. ${ }^{10}$ Woods einführende Frage „Why should we take Hitchcock seriously?“ (29) zeichnet dabei den rhetorischen Weg, dem nicht nur weitere Arbeiten folgen, sondern der dem Autorendiskurs auch eine neue Deutungshoheit zuschreibt, wie Bordwell bei Wood herausliest: ,[...] we can trust Hitchcock when he explains the mechanics of suspense, but when it comes to implicit meanings, one should put one's faith in critical interpretations.“(,Making Meaning“ 229). Diese ,Ernsthaftigkeit”,

\footnotetext{
${ }^{8}$ In den letzten zehn Jahren erschienen unter anderem eine weitere Monographie zu Hitchcock von William Rothman, „Must We Kill“; die englischen Companions über Hitchcock von Leitch/Poague und Freedman, die deutsche Einführung von Heller, „Hitchcock“, sowie die deutsche Übersetzung von Éric Rohmers und Claude Chabrols Hitchcock-Buch als auch Stephen Rebellos Psycho-Buch.

${ }^{9}$ Woods Hitchcock's Films wird 1969 und 1977 in erweiterter Form sowie 1989 als Hitchcock's Films Revistited mit acht zusätzlichen Artikeln neu aufgelegt. Die vorliegende Studie zitiert aus der 3. Auflage von 1977.

${ }^{10}$ Auf Englisch erscheint 1973 das erste Handbuch zu Psycho, in dem James Naremore eine ausführliche Szenenanalyse, kommentierte Bibliographie sowie Hintergrundinformationen zu Hitchcock und der Produktion bereithält („Filmguide“), 1974 dann die Monographie von Raymond Durgnat, The Strange Case of Alfred Hitchcock, und $1976 \mathrm{u}$. a. Jean Douchets Alfred Hitchcock, Robert A. Harris' und Michael S. Laskys The Films of Alfred Hitchcock sowie Donald Spotos The Art of Alfred Hitchcock. Neben Übersetzungen entstehen deutschsprachige Studien erst ab Mitte der 1980er (siehe u. a. Fründt; Schnelle).
} 
die als Legitimierungsstrategie die autorenbezogenen Analysen vor allem in Bezug auf Filme kommerzieller Regiegrößen des Genrekinos durchzieht, findet sich 1960 in den Filmkritiken zu Psycho polemisch gegen das Genre des Horrorfilms gewendet wieder. Denn der Film, darin implizit als Horrorfilm gemeint, sei als Witz zu verstehen und keineswegs ernst zu nehmen (Wood, „Hitchcock's Films“ 106). Um die Verbindung dieser Diskurse zu verdeutlichen, wird der Analyse der Filmkritiken diese Frage rhetorisch überstellt und die Filmkritiken werden, gegen den Strich ' auf ihre Diskursivierung der Horror- und Schockelemente gelesen.

Noch zu Hitchcocks Lebzeiten gestaltet sich Psycho damit von einem randseitigen Low-Budget-Horrorfilm, der von Hitchcocks gängigen ,Thrill and Suspense'-Geschichten abweicht, zu einem der meist analysiertesten Filme des neuen Film Criticism, der den Diskurs zu Psycho ab Mitte der 1970er Jahre endgültig in den Bereich akademischer Forschung verschiebt: „From now on, Psycho criticism would be unremittingly academic.” (Bordwell, ,Making Meaning” 235) Insbesondere innerhalb des psychoanalytischen Paradigmas der Filmtheorie wird Psycho zum bevorzugten Analyseobjekt. ${ }^{11}$ Hierbei kritisiert Williams allerdings, dass die psychoanalytischen und feministischen Analysen, indem sie Psycho's Schlüsselposition nur voraussetzen, eine entscheidende Qualität des Films übergehen: „what was missing from such interpretations is a quality mentioned by Hitchcock himself and cited in an epigraph to Robin Wood's influential auteur study: this quality is ,fun“." („Discipline and fun“ 353). Wurde dieser ,fun“ von den Filmkritiken noch als Witz gedeutet, der eine ausführliche Auseinandersetzung mit dem Film an sich blockierte, interessiert sich Williams für diesen „sensational fun“ (ebd.) als eine ,ernsthaft" auszumachende visuelle Lust, die das Publikum damals derart erfolgreich anzog. Statt dieser sensationsgeladenen Form visueller Lust nachzugehen, die Psycho so erfolgreich beim Publikum zu befriedigen schien, war für viele der psychoanalytischen und feministischen Studien das ,endlessly deferred, unsatisfiable desire“ (ebd.) zentral. Wie Williams vergleichend in Bezug auf den ,klassisch-realistischen' Ansatz bei Kaja Silverman in The Subject of Semiotics und den von David Bordwell, Kristin Thompson und Janet Staiger beschriebenen klassischen Hollywoodstil ausführt (ebd. 353 ff.), argumentieren die Studien zwar mit unterschiedlichen Konzepten des ,Klassischen', aber jeweils mit dem gleichen Ergebnis, dass Psycho mit ,klassischen“

${ }^{11}$ Siehe vor allem Bellour; Jameson; Klinger; Silverman, ,Subject of Semiotics“ und Žižek, aber auch Bronfen und Modleski. 
Formen filmischer Narrationen breche. ${ }^{12}$ Dabei kommt für Williams der Aspekt des Sensorisch-Sinnlichen zu kurz:

What is missing from both Bordwell's and Silverman's account of Psycho's deviance from ,classical' norms is any sense of the popular, sensory pleasures of either the mainstream cinema from which it supposedly deviates or the specific nature of the different and ,deviant' pleasures of Psycho itself. (Ebd. 354)

Demgegenüber bietet Williams einen neuen Zugang auf Psycho an, der die Intensivierung visueller Formen und Sensationalisierung der sinnlichen Erfahrungen in das Zentrum rückt; all dies ,,were already evident in what is more properly called the popular modernism of mainstream Hollywood cinema" (ebd. 355). ${ }^{13}$ Diese grundsätzliche Sensationalisierung der Kinoerfahrung markiert aber nicht nur die Filmwahrnehmung von Psycho, sondern fängt bereits vor dem Kino selbst an. Wie gezeigt wird, durchzieht die Materialien der Werbekampagne eine Sensationalisierung, die sich insbesondere in den Aufführungspraktiken der Kinos, dem Trailer und auf den Plakaten wiederfindet und den genrespezifischen Diskurs der Psycho Policy-Werbekampagne als New Sensationalism prägt.

Neben diesem Sensationsgestus ist der genrespezifische Diskurs der Psycho Policy aber auch durch Hitchcocks mediale Persona geprägt. Seit der frühen britischen Produktionszeit sind Hitchcocks Filme, wie auch die späteren Autorenstudien, mit seinen zahlreichen öffentlichen Auftritten verbunden, die er über Interviews, Pressetouren, Werbekampagnen und Cameo-Auftritte geschickt zu inszenieren wusste.

From early years in England [...] to his final years in Hollywood [...], Hitchcock attempted to produce a direct critical response to himself and to his work, [...] Hitchcock remained actively engaged in the publicity for and promotion of his films throughout his career, personally conducting national press tours. ${ }^{14}$ (Belton, „Hitchcock“ 16)

\footnotetext{
${ }^{12}$ Williams verweist dabei in einer Fußnote auf die Problematik, den ihre Kritik am Terminus des Klassischen birgt, für den sie angesichts der allgemeinen Akzeptanz des ,Klassischen keine alternative Bezeichnung an der Stelle anbringen kann (,Discipline and fun“ 355, siehe Endnote 5).

${ }^{13}$ Williams beschreibt Psycho als ,a roller-coaster concept“ der Filmwahrnehmung, womit er dem Konzept des Blockbusters vorausgreift, das nach Schatz das New Hollywood prägt (,Discipline and fun“ 358).

${ }^{14}$ Für Psycho ging er sogar auf internationale Pressetour (Rebello 163 f.).
} 
Um die so herausgebildete mediale Persona von Hitchcock entstanden eine Reihe an Legenden, wie Hitchcocks panische Angst vor der Polizei: Sein Vater habe ihn als Fünfjähriger mit einem Brief zur Polizei geschickt, wo man ihn (angeblich) als Strafe für sein ungezogenes Verhalten einige Minuten lang in eine Zelle sperrte, wie es der Vater im Brief forderte. Diese Geschichte spiegelt Hitchcocks gezielte Selbstvermarktung wider, die als Teil der sensationsgeladenen Psycho Policy-Werbekampagne hinsichtlich ihres generischen branding beleuchtet wird. Zusammen mit den theoretisch-analytischen Studien und den populärwissenschaftlichen Veröffentlichungen fügen sich diese medialen Diskurse in ein fast unüberschaubares „Geflecht von sich überlagernden Anekdoten, Legenden, Selbstinszenierungen und multimedialen Sekundärverwertungen“ (Heller, „Hitchcock“7) ein. Und dennoch haben insbesondere die theoretisch-analytischen Diskurse Psycho entgegen der Erwartung nicht jedes Mal neu ,geformt', wie Bordwell resümiert:

Still, despite the divergences and struggles for novelty, the interpretations of Psycho display a high degree of consensus. All critics treat Marion and Norman as the primary characters, all accept the break in point of view and plot action, all take the parlor dialogue and the shower murder as pivotal segments, and most are obliged to interpret the psychiatrist's speech. All assume that, whatever semantic fields will be brought into play, they must be mapped onto principal characters [...]. One might reply that this is a result of Psycho's obviousness. Yet the critical tradition [...] also exhibits a remarkable consensus about what cues and passages are worth attention, and how they are best interpreted.“(,Making Meaning“ $247 \mathrm{f}$.)

Ähnlich diesem Konsens werden in einem letzten Schritt ausgewählte Filmanalysen von Psycho diskursanalytisch für eine genrespezifische Analyse des Films herangezogen. Bereits Bordwell sieht in Genrekonventionen Gründe für den erstaunlichen interpretativen Konsens zum Film (ebd. 248). Über die filmbezogene Neubetrachtung des wissenschaftlichen Diskurses zu Psycho wird verdeutlicht, wie bereits seit Woods wegweisender Autorenstudie generische Diskursivierungen angelegt sind, bevor Genretheorien in den 1980er Jahren Psycho innerhalb des Horror- und Slashergenres positionieren (u. a. Clover; Tudor, „Monsters"; Jancovich, „Rational Fears"). So bildet Psycho schon bei Wood „one of the key works of our age“ (,Hitchcock’s Films“ 150), der sich durch eine neue Intensität und einen neuen Horror auszeichnet und in der Lage ist, ,to contemplate the ultimate horror without hysteria, with poised, almost serene detachment" (ebd. 151). Inwiefern den Diskurs neben diesen allgemeinen vor allem detaillierte Genresemantiken durchziehen, die sich auf spezifische Markierungen beziehen, wird entlang des Films chronologisch erarbeitet. Der wissenschaftliche Diskurs zu 
Psycho entwickelt sich zwar wie oben skizziert im Kontext des Film Criticism aus der Tradition der Filmkritik heraus, von dieser ist er aber zu unterscheiden. Denn genretheoretisch unterliegen diese Diskurse unterschiedlichen Zielen, Praktiken und Normen: Während die Filmkritiken Psycho zuerst ablehnen und darin ihrer Aufgabe als Empfehlungsinstanzen nachkommen, betonen die akademischen Studien die semantische Vielschichtigkeit des Films und operieren darin losgelöst von Publikumsempfehlungen. Statt einer prospektiven Anbindung an den wissenschaftlichen Diskurs lassen sich die Filmkritiken über die Differenz zur politique des auteurs erklären, die in den USA erst ab 1962 Einfluss nimmt (siehe Sarris, „Auteur Theory“). Als Psycho zum Ende des Jahres 1960 von Bosley Crowther in die Jahresbestliste der New York Times aufgenommen wird (nach Kolker 59), hat die Filmkritik in der Zwischenzeit einen ersten wichtigen Schritt genommen, um Psycho im Nachklang der aufkommenden Autorentheorie als Genreklassiker zu kanonisieren. Indem die jungen Autoren der Cahiers du Cinéma Hitchcock den Status eines Auteurs zuerkennen, lösen sie eine Autorenpolitik des Genrekinos aus. Bevor auf die Filmkritiken zu Psycho eingegangen wird, zeigt der folgende kurze Exkurs auf, wie die politique des auteurs als Brückenschlag zu den Genrediskursen von Psycho verstanden werden kann.

\section{Exkurs: Autorenpolitik für ein Genrekino}

Um die genrehistorische Verschiebung von Psycho zum Klassiker der Filmgeschichte und des Genrekinos nachzuvollziehen, erweitert der Exkurs den Fokus auf Hitchcock und die Kanonisierung seiner Filme, die in den 1950er Jahren anzusetzen ist. Die heute selbstverständlich erscheinenden Würdigungen Hitchcocks als ,filmhistorische Legende' sind das Ergebnis eines Kanonisierungsprozesses, der nicht nur sein filmisches Werk sondern auch die öffentliche Persona ,Hitchcock' sukzessive zu einem der bekanntesten Auteurs aufbaut. ${ }^{15}$ Entscheidend erwirkt haben dies die jungen Autoren der französischen Filmkritikzeitschrift Cahiers du Cinéma, die die Ausfechtung um Alfred Hitchcock als ernstzunehmenden Autor in den 1950er Jahren in Gang setzen und mit Éric Rohmers und Claude Chabrols Hitchcock-Buch von 1957 noch vor der Produktion von Psycho 1960 die erste Monografie über Hitchcocks 44 Filme umfassendes Werk hervorbringen. Während sich spätere Veröffentlichungen wie Woods Hitchcock's Films auf wenige Filme beschränken (müssen), profitieren Rohmer

\footnotetext{
15 Sowohl die University of California (1968) als auch die Columbia University (1973) verleihen Hitchcock noch zu Lebzeiten Ehrendoktorwürden. Hitchcocks Rede von 1973 ist hierbei eine häufig zitierte Anekdote (siehe unter anderem Harris/Lasky und Rebello).
} 
und Chabrol von einer der frühen Retrospektiven, die 1956 in der Cinemathèque Française auch das frühe britische Werk Hitchcocks zeigt. ${ }^{16}$ Rohmer und Chabrols Buch legt erste Zugänge zu einer autorenbezogenen Betrachtung des kommerziellen Genrekinos. Es verwundert daher nicht, dass 1960 eine der wenigen positiven Filmkritiken zu Psycho statt in der britischen Sight and Sound in den französischen Cahiers du Cinéma erscheint (Wood, „Psychanalyse“) - dem Forum, das Hitchcock in der aufkommenden Tradition der politique des auteurs bereits als stilistisch herausragenden ,Auteur" ansieht.

Die jungen Autoren und späteren Filmemacher Éric Rohmer, Claude Chabrol, François Truffaut und Jean-Luc Godard liefern sich, wie Fischer ausführt, bereits seit März 1952 einen Schlagabtausch mit der älteren Generation der etablierten, vornehmlich hollywood-kritischen Filmkritik, die für das Konkurrenzmagazin Positif schreibt. Auch mit André Bazin, dem damaligen Chefredakteur der Cahiers du Cinéma und intellektuellen Vordenker, streiten sie sich regelmäßig über das Werk Hitchcocks. Dabei veröffentlicht Bazin allerdings seine Beiträge innerhalb dieser Auseinandersetzung in anderen Zeitschriften (8 ff.). Wie Fischer des Weiteren skizziert, gilt Hitchcock in den Augen der traditionellen Kritik in Frankreich, bis Anfang der 1960er Jahre auch in den USA, als handwerklich begabter Hollywood-Regisseur, der aber die Technik nur zum Selbstzweck einsetzt (8). Demgegenüber lancieren die jungen Kritiker Hitchcock erstmals als ernstzunehmenden Autoren, der mehr als nur ein geschickter Techniker ist, wie Rohmer, hier noch unter seinem gebürtigen Namen Maurice Schérer, in der Mai-Ausgabe von 1952 schreibt:

Non, Hitchcock n'est pas seulement un très habile technicien - et au nom de quoi ériger la maladresse en vertu? - mais un des plus originaux et profonds auteurs de toute l’histoire du cinéma. (,Le Soupçon“ 66)

In den zahlreichen Kritiken zu seinen Filmen feiern sie immer wieder sein schöpferisches Genie, das es innerhalb des kommerziellen Studiosystems Hollywoods schafft, eine eigene Handschrift und einen wiedererkennbaren Stil zu pflegen. Sein Umgang mit der Kameratechnik, Mise en Scène und Schauspielführung dient dabei keinem Selbstzweck, sondern schafft selbst Inhalt und Ausdruck.

\footnotetext{
${ }^{16}$ Retrospektiven wie diese ermöglichen als Sonderprogramme nicht nur der Filmkritik eine Wiederaufführung und Relektüre älterer Filme, sie grenzen sich als spezifische Sonderformate auch vom herkömmlichen Kinoprogramm ab. Sie tragen in ihrem einmaligen Ereignischarakter und in ihrer Programmkohärenz zu einer identitätsfördernden Wahrnehmung als Autorenwerkschau bei, womit sie Autor und Film nobilitieren und die Autorenpolitik weiter voranbringen. Zum Programm siehe Klippel.
} 
Bereits nach einigen Jahren widmen sie 1954 die 39. Ausgabe ganz Hitchcock. ${ }^{17}$ Für Rohmer bildet Hitchcock einen ,virtouse au doigté savant“ (Schérer, „A qui la faute?“ 6) und den ,cinéaste le plus moderne“ (ebd. 9). Truffaut setzt Hitchcock nicht nur in eine Reihe mit großen europäischen Regisseuren - ,un cinéaste que [...] je place après Renoir, Rossellini et Hawkes“ (,Un trousseau“ 45), sondern sieht ihn auch als „génie“ an, das sich seiner selbst bewusst ist: ,[...] nous ne voulons pas un génie inconscient. Je tiens Alfred Hitchcock pour plus conscient que Renoir et Rossellini“" (ebd. 47). Chabrol spricht bereits vom „univers hitchcockien“ (18), das er im gemeinsamen Buch mit Rohmer weiterentwickelt. Da Rohmers und Chabrols Buch erst 1979 in englischer Übersetzung erscheint, bleibt die Debatte noch lange eine französische. Ihnen kommt Truffauts Hitchcock-Buch zuvor, das bereits 1967 nur ein Jahr nach der französischen Erstveröffentlichung auf Englisch erscheint. Auf einem 1962 mit Hitchcock geführten Interview beruhend, ist es vor allem Truffauts Buch, das den Diskurs zusammen mit den Artikeln von Andrew Sarris nach Amerika trägt. ${ }^{18}$ Sie tragen erheblich zur Etablierung der Autorentheorie als kritische Analysemethode bei, die das amerikanischen Hollywood-Kino neu bewertet und Hitchcocks künstlerische Leistungen im Besonderen anerkennt.

Für mich überragt Hitchcock sie alle, weil er der kompletteste ist. [...] Weil er alle Elemente eines Films beherrscht und in allen Stadien der Realisierung eines Films seine persönlichen Ideen durchsetzt, hat Alfred Hitchcock wirklich einen eigenen Stil [...]. (,Mr. Hitchcock“ 16)

Die Auseinandersetzung um Hitchcock kann im Vorfeld von Psycho als Brückenschlag angesehen werden. Mit der ernsthaften Betrachtungsweise Hitchcocks als Auteur werden seine Genreproduktionen innerhalb eines Kinos der Autoren positioniert, das nicht mehr nur seine Filme als ,Hitchcock-Filme‘ ausweist, sondern ihnen einen expliziten und wiedererkennbaren künstlerischen Stil zugesteht. Für Psycho öffnet dies eine erste Tür für ausführlichere Analysen, wie sie Robin Wood und Jean Douchet 1960 in ihren Kritiken für die Cahiers du Cinéma vollführen. Dass sie aber mit ihren Ansätzen angesichts der vor allem in den USA überwiegend negativen Reaktionen noch eine diskursive Nische bedienen, wird vor dem Hintergrund der historischen Entwicklung der politique des auteurs deutlich: Die Errungenschaften dieser Auseinandersetzungen führen erst Ende der 1960er Jahre in der methodischen Weiterführung als Autorentheorie umfassender

\footnotetext{
171956 folgt ein zweites Sonderheft zu Hitchcock.

${ }^{18}$ Siehe vor allem Sarris“ einflussreichen Artikel „Notes on the Auteur Theory in 1962“, der zuerst in Film Culture erschien.
} 
dazu, dass auch Hollywood-Produktionen den Status originärer Kunstwerke zuerkannt bekommen und hinsichtlich bedeutsamer künstlerischer Kohärenzen und Kontinuitäten eingehender untersucht werden. ${ }^{19}$ Damit werden sie nicht mehr nur als ,bloße Massenware" der Filmindustrie abgetan, denen eine Gleichförmigkeit und Formelhaftigkeit vorgeworfen wird, sondern sie werden in ihren stilistischen Besonderheiten und künstlerischen Gestaltungsweisen hervorgehoben und den Regisseuren innerhalb dem industriellen Produktionssystem von Hollywood zugeschrieben. Dieser Weg zeichnet sich bereits 1963 in der 48-seitigen Broschüren ab, die Peter Bogdanovich zu der von ihm organisierten Retrospektive zu Hitchcock im Museum of Modern Art in New York erstellt:

In the history of cinema, Alfred Hitchcock holds a unique position: he is the only director (with the possible exception of DeMille) whose name conjures up a specific image in the average filmgoer's mind [...]. Today, he is the only director whose movies were sold on his name alone - a name that has become synonymous in everyone's mind with a certain kind of film. The phrase, , a Hitchcock picture,' has become less noun than adjective.

The sort of movies he makes - thrillers, mysteries, macabre comedies, suspense films - are considered by American critics as lowbrow and non-art. In England, the genre is a sophisticated, respected one. [...] By any criteria (except his wryly bizarre sense of humorous), he is an American artist, as much as Chaplin is, despite his birthplace. („Cinema of Alfred Hitchcock“ 3)

An diesem Exkurs zeigt sich, das der Umweg über die politique des auteurs einen autorenbezogenen Zugang zu Hitchcock und zum Genrekino Hollywoods legt, der zwar wie bereits zuvor ausgeführt nicht ohne eine gewisse Widersprüchlichkeit auskommt, aber dessen Leistung darin besteht, die Filme aus dem Bereich des ,Formelhaften ' und ,Trivialen' herauszuholen und für eine ,offenere ' Auseinandersetzung mit Genreproduktionen einzustehen. Die Autorenpolitik hat damit Hitchcock, seinen Filmen und Psycho den Weg bereitet, im Kanon der Filmkunst aufgenommen zu werden und erste Grundsteine für systematische Genrediskurse gelegt, in denen Psycho zum ,mehrfachen' Genreklassiker werden kann. Bevor dies aber erfolgt, stößt der Film 1960 auf vehemente Kritik.

${ }^{19}$ Siehe Sarris, ,,The American Cinema“. 


\subsection{Horror, seriously? Filmkritik um 1960}

Hitchcock bringt mit Psycho 1960 wider Erwarten einen überaus erfolgreichen Film in die Kinos. Zwar hatte er sich in den 1930er Jahren international einen Namen als Regisseur von ,Thrill and Suspense'-Filmen gemacht, an deren Erfolg auch die meisten seiner Hollywood-Filme anknüpften, und war durch seine Fernsehsendung Alfred Hitchcock Presents inzwischen auch dem weniger filmaffinen Publikum bekannt. Entgegen der hohen Publikumsresonanz, Einspielergebnisse und Prominenz, löst der Film bei der Filmkritik jedoch sehr gespaltene Reaktionen aus. Diese werden hier in den wesentlichen Positionen beleuchtet, um den Nährboden zu skizzieren, aus dem sich die nachfolgenden Auseinandersetzungen um Psycho entwickelt haben.

Die Filmkritik zu Psycho spaltet sich in zwei Lager. Die überwiegende Mehrheit lehnt Psycho als nicht ernstzunehmende Variante eines nur auf Schockeffekte zielenden Spektakels komplett ab, wohingegen ihn nur einige wenige, allen voran Andrew Sarris, Robin Wood und Jean Douchet, als symbolisch dichtes und technisch raffiniert inszeniertes Meisterwerk feiert. Trotz der Differenzen besteht in einem Punkt Einigkeit: Der dargestellten Drastik an Horror- und Schockelementen innerhalb der Mordszenen, allen voran innerhalb der Duschszene, wird selbst von den positiven Kritiken eine neue Widerwärtigkeit und enorme Brutalität bescheinigt. Sarris schreibt von ,the grisliest murder scenes ever filmed“ (,Movie Journal“ 6) und Wood sieht in der Unsinnigkeit des Mordes das eigentliche Grauen: „Suit le plus horrible meurtre jamais montré sur un écran: horrible, non seulement par sa hideur physique, mais dans son inutilité“ („Psychanalyse“ 4). Ernest Callenbach in Film Quarterly bezeichnet die Duschszene als ,the goriest thing seen on film in a long time“ (48), ebenso schreibt Peter John Dyer in Sight and Sound von „one of the bloodiest murders ever filmed“ (195) und auch die anonyme Kritik in der Time spricht von „one of the messiest, most nauseating murders ever filmed“ (o.A. 51). Gerade auch die katholisch geprägten Magazine heben die blutige Gewalt hervor, die für Moira Walsh in America „the bloodiest bathtub murder in screen history“ (443) darstellt und für Philip T. Hartung in Commonweal „one of the bloodiest scenes ever shown in a movie“ (469) bedeutet. Newsweek betrachtet den Film sogar nur als ,gimmick movie whose suspense depends on a single specific twist“. Ebenso schockiert über die ausgestellten Schauereffekte fallen Kritiken in linksliberaleren Zeitschriften aus. Stanley Kauffman in New Republic sieht den Mord als ,the most vicious I have ever seen in films" (22). Bosley Crowther von The New York Times warnt sogar, ,(y)ou had better have a pretty strong stomach and be prepared for a couple of grisly shocks when you go to see Alfred Hitchcock's Psycho“ (37), 
wohingegen sich Robert Hatch in Nation nicht nur schockiert, sondern gar angewidert zeigt: „I am shocked, in the sense that I am offended and disgusted.“ (18) Auch deutsche Kritiken urteilen drastisch in Bezug auf die ausgestellte Gewalt. „Wenig geschmackvolle Zutaten füllen den Hintergrund: Muttermord, eine konservierte Leiche und Gemetzel in der Badewanne mit im Ablauf gurgelndem Blut“, beschreibt der Film-Dienst dieses „Kintopp-Grusel“-Erlebnis (Ev. 366). Mit diesen „blutunterlaufenen Effekte(n)“ ergibt dies für den Evangelischen Filmbeobachter nur einen „Hitchcock-Reißer, der seine Wirkung weniger durch eine spannende Geschichte als durch blutrünstige Mätzchen zu erzielen sucht.“ (Fr. 549). Enno Patalas urteilt ähnlich in der Filmkritik: „So nötigt dieses Drehbuch den Regisseur schließlich, wider seine Gewohnheit den Mord selbst auszumalen und daraus den Schauer zu ziehen, den er sonst auf subtilere Weise beschwört.“ (331)

Als der Film im Anschluss an die amerikanische Filmpremiere nach Europa, Südamerika und Asien geht, erscheinen weltweit weitere Filmbesprechungen zu Psycho, die ähnlich gemischt ausfallen, wie Stephen Rebello in seinem Buch Alfred Hitchcock \& the Making of Psycho beschreibt (295-305). Sowohl in den USA als auch kurz darauf in Großbritannien, Frankreich und Deutschland, auf die die Analyse hier begrenzt wird, erscheinen Filmbesprechungen in den etablierten Filmfeuilletons und -magazinen wie der New York Times, Sight and Sound, aber auch der deutschen Filmkritik, wobei diese mehrheitlich negativ ausfallen und besonders vernichtende Kritiken abdrucken. Besonders die bürgerlichen Filmeliten sind sich einig, dass der Film ,zu weit gegangen“ ist (Kapsis 62 f.).

Demgegenüber werden nur wenig positive Kritiken veröffentlicht, wie die im Diskurs als wegweisend hervorgehobenen von Sarris, Wood und Douchet, die in dem alternativen New Yorker Stadtmagazin Village Voice und in den französischen Cahiers du Cinéma erscheinen. Beide Zeitschriften bildeten prädestinierte Orte der Filmavantgarde und ideale Foren für alternative, abweichende Filmlektüren: Das New Yorker Stadtmagazin Village Voice, das Artikel über Politik, Kunst und Kultur veröffentlicht, hatte sich einen Namen als alternative Wochenzeitschrift gemacht, in dem Jonas Mekas eine regelmäßige Filmkolumne betreibt und bei Abwesenheit immer wieder von jungen Autorinnen und Autoren wie Maya Deren oder Andrew Sarris vertreten wird. Als am 11. August die Kritik zu Psycho veröffentlicht wird, hat Sarris im Sommer 1960 gerade zeitweise die Filmkolumne übernommen, weil Mekas einen Film dreht (Hoberman). In seiner Lobeshymne erhebt Sarris Hitchcock zu einem der wagemutigsten Avantgarde-Filmemacher Amerikas, der mit Psycho nicht einfach nur einen beliebigen Horrorfilm inszeniert, sondern eine vielseitige Symbolik und Ausdruckskraft entwickelt, die die moderne Gesellschaft als einen Sumpf menschlicher Gefühle und Sehnsüchte 
zeichnet, die sich buchstäblich darstellt als „flushed down the drain“ („Movie Journal“ 6). In der kurzen Besprechung (sie umfasst gerade einmal etwas mehr als eine schmale Spalte) betont Sarris neben der Prospektion auf den zu erwartenden besonderen filmhistorischen Status (,the first American film since Touch of Evil to stand in the same creative rank as the great European films", ebd.) die Neuerung des Horrors, die eben auch die schaurigste aller Mordszenen (,the grisliest murder scenes ever filmed", ebd.) hervorbringt. Nicht weniger als dreimal sei der Film zu sehen, empfiehlt Sarris in seiner Kritik, um neben dem Horror auch die Elemente einer makabren Komödie und schließlich die versteckten Symbole entdecken zu können (ebd.).

Dass die Filmkritik von Wood ihren Weg nur über einen Umweg erst im November 1960 zu den Cahiers du Cinéma findet, zeigt letztlich den Sonderstatus, den diese ausführliche Filmbesprechung einnimmt. Wood hat seine Filmbesprechung zuerst der Redaktion von Sight and Sound in Großbritannien angeboten, welche sie aber mit der Begründung ablehnte, dass seine Kritik sich bei der Tragweite des Films verschätze - sei doch der Film als Witz zu verstehen und keineswegs ernst zu nehmen (Wood, „Hitchcock's Films Revisited“ ix). Statt eines Scherzes sieht Wood in dem Film aber eine ernsthafte Inszenierung am Werk, welche besondere Raffinessen aufweist. In seiner überaus anerkennenden und positiven Filmkritik, die schließlich sogar den ersten Beitrag in der Novemberausgabe der Cahiers du Cinéma bildet, spiegelt sich die in Frankreich zunehmende und bei den Cahiers-Autoren längst etablierte Bedeutsamkeit von HollywoodRegisseuren als Auteurs wider. Der Titel seiner Kritik „Psychanalyse de Psycho“ ist dabei doppelt konnotiert: als eigene Methode des filmkritischen Umgangs, auf das Genaueste die tieferliegenden Symbolschichten des Films hervorzuholen, sowie als psychoanalytische Komponente des Films selbst, die Wood - dem späteren Horrordiskurs quasi vorweggreifend - in Verbindung mit generischen Strukturen, insbesondere dem Horror des Films, bringt. In dem die Geschichte zwischen Normalität und Wahnsinn angesiedelt ist, aber im weiteren Verlauf sukzessive zum Wahn tendiert (1 f.), situiert der Film seinen Schrecken innerhalb einer uns nahen Alltäglichkeit und Vorstellungswelt: „(L)'extrême anormalité n'est pas si éloignée de nous que nous l'imagions." (6) Diese Deutung setzt Wood besonders bei der Duschszene an, die für ihn als furchterregendster Mord der Kinogeschichte gilt:

Suit le plus horrible meurtre jamais montré sur un écran: horrible, non seulement par sa hideur physique, mais dans son inutilité. Marion meurt sans raison, victime du désir impudique de l'esclave de détruire la chose pure et libre. Le meurtre est aussi irrationnel que le vol d'argent. Il est essentiel pour la thématique hitchcockienne de 
montrer la continuité entre le normal et l'anormal. Après la mort de Marion, l'enquête devient une enquête de la personnalité psychosée d'un être en permanence incapable de choisir. (4 f.)

Mit der von Wood herausgearbeiteten psychisch-metaphysischen Ebene des Films, „un niveau plus profond, psychologico-métaphysique“ (5), greift er dem späteren genrehistorischen Diskurs von Psycho voraus, der in der Psychologisierung der Geschichte wie oben eingeführt einen Wendepunkt innerhalb des Genrekonzepts des Horror- wie Kriminalfilms und Thrillers ausmacht.

Ebenso begeistert wie lobend fällt auch die Kritik von Jean Douchet aus, die in derselben Ausgabe wie Woods Beitrag erscheint. Beide Artikel bilden die ersten Beiträge der Ausgabe. In seiner detaillierten Filmanalyse legt Douchet den Fokus auf die „formes-forces“ als essentielle Mittel der geheimen Sehnsüchte: „Ces formes-forces du désir constituent l'élément capital de tout film d'Hitchcock“ („Hitch“ 9). Im Unterschied zu Wood hebt Douchet dabei verstärkt die Wirkungen auf das Publikum hervor, mit dessen Ängsten bewusst gespielt wird und dessen Blicke eine gezielte Komplizenschaft mit Norman herstellen. Unter der Überschrift „Hitch et son public“ schreibt Douchet:

[...] nous sommes devenus complices d'un crime. Nous avons gravi une marche sur l'échelle de la culpabilité. Je ne crois pas qu'il soit utile de continuer à résumer le film en détail. Ce qu'il importe de saisir, avant tout, c'est le processus même de l'imagination hitchcockienne: comment Hitch se sert du spectateur pour la progression interne de son film, comment il joue de ses craintes et de ses désirs. (Ebd. 13)

Gegenüber diesen positiven Besprechungen fallen die negativen Kritiken zwar wesentlich kürzer, aber, wie folgende Beispiele zeigen, zahlreicher aus. Besonders drastisch ist hierbei die Kritik von Bosley Crowther, die bereits einen Tag nach der Kinopremiere in der New York Times am 17. Juni erscheint und dem Film neben „old-fashioned melodramatics“ (37) eine fehlende Raffinesse vorwirft, die sich nicht nur in „a couple of grisly shocks“ (ebd.) zeigt, sondern auch in eine flache Auflösung am Ende mündet.

That's the way it is with Mr. Hitchcock's picture - slow buildups to sudden shocks that are old-fashioned melodramatics, however effective and sure, until a couple of people have been gruesomely punctured and the mystery of the haunted house has been revealed. [...] The consequence of his denouement falls quite flat for us. (Ebd.) 
Ebenfalls im New Yorker beschreibt John McCarten am 25. Juni in ähnlicher Weise wie Crowther Psycho als ,heavy-handed“, womit er eigentlich nicht mit den sonstigen hervorragenden Arbeiten Hitchcocks vergleichbar ist.

Hitchcock does several spooky scenes with his usual éclat, and works diligently to make things as horrible as possible, but it's all rather heavy-handed and not in any way comparable to the fine jobs he's done in the not so distant past. [...] a dawdling Alfred Hitchcock apparently uncertain what to do with a young lady who has pinched forty thousand dollars. (70)

Dieser Sichtweise schließt sich auch die anonyme Kritik vom 27. Juni in der Time an, die Psycho als ,a spectacle of stomach-churning horror" zusammenfasst und vom schrecklichsten aller Mörder der Kinogeschichte schreibt: „What is offered instead is merely gruesome. The trail leads to a sagging, swamp-view motel and to one of the messiest, most nauseating murders ever filmed." (o.A. 51). Die somatischen Beschreibungsrhetoriken finden sich auch bei Robert Hatch in Nation wieder, der den Film als ,,an offense against taste” ansieht: ,it makes you feel unclean”. Hitchcock stellt für Hatch ,not an entertainer, but a pander of vicarious perversion" dar (18). Detailliert spitzt er dies auf eine klinische Perversion zu:

The clinical details of psychopathology are not material for trivial entertainment; when they are used so they are an offense against taste and an assault upon the sensibilities of the audience. Psycho puts you in the position of rubbernecking at the horrors of the diseased mind; it makes you feel unclean. I am sorry to lecture so, but on all sides, I see statements to the effect that good old ,Hitch“ has done it again. If that means that he has repeated the happy thrills and mystifications of The Lady Vanishes and The 39 Steps, it is nonsense. In, Psycho, Hitchcock is not an entertainer, but a pander of vicarious perversion. (18)

Auch einige Monate später, als der Film im September und Oktober in Europa anläuft, fallen die Kritiken weiterhin überwiegend schlecht aus. Peter John Dyers in Sight and Sound erscheinende Kritik stuft Psycho als schlechten Film ein, der einer unsinnigen Story folgt und alles zu einem Witz macht. Für ihn bleibt die obsessive Besessenheit der Hauptfigur mit der Mutter unbegreiflich: ,[...] the only mystery Hitchcock's solution seems unable to explain is why the critics should have even tried to believe such arrant nonsense, and what happened to their sense of humour in the first place." (195) Zwar würdigt er die Duschszene als „one of the bloodiest murders ever filmed“ (ebd.), doch der Weg dahin ist absurd und nicht nachzuvollziehen. Für Dyer ist Hitchcock mit dem Film nicht mehr als ernsthafter Regisseur wahrzunehmen (196). Auch für Callenbach weicht Psycho 
mit dem „out-and-out horror“ (47) deutlich von den bisherigen kommerziellen Filmen Hitchcocks ab, wie er in Film Quarterly schreibt. Zwar schätzt auch er Psycho als „surely the sickest film ever made“ ein, aber er gesteht ihm durchaus formale Finesse zu: „It is also one of the most technically exciting films of recent years, and perhaps an omen [...].“ (48)

In Deutschland, wo der Film erst im Oktober herauskommt, erscheinen in den bekannten Rezensionsorganen vorwiegend negative Kritiken. In der Filmkritik bemängelt Enno Patalas das fehlende für Hitchcock übliche Niveau und wirft ihm ein schlechtes Drehbuch vor („Psycho“ 329 f.). Gleichwohl erkennt er eine gute Regieleistung an, die eine „Aura des Fatalen“ (ebd. 330) und eine „Atmosphäre des Grauen“ (ebd. 331) erzeugt, aber die Grenze zur Filmkunst dennoch nur fast erreicht:

Wie so häufig in seinen besseren Filmen nähert sich Hitchcock immer wieder der Grenze, hinter der das Gebiet der wirklichen Kunst beginnt, bei deren Überschreiten er der ,E.A. Poe des Films' oder der ,Kafka des Films “ werden könnte, den man einmal in ihm sehen möchte. (Ebd. 331)

Ebenso schreibt der Film-Dienst von einem „Gruselstück“, das „,so mäßig interessant, so gequält pseudowissenschaftlich, so lächerlich“ und ,allzu sehr in seinen Klischees verfangen“" ist (Ev. 366). Der Evangelische Film-Beobachter rät ganz ab: „So witzlos wie wüst. Wir raten ab.“ (Fr. 549)

Es fällt insgesamt auf, dass trotz der gleichen Wahrnehmungen in Bezug auf die Mordszene(n) eine gravierende Uneinigkeit darin existiert, wie der Film ganz grundsätzlich als solcher zu bewerten ist: ob als „Scherz“, als „fun picture“, wie ihn auch Hitchcock selbst beschreibt (Wood, „Hitchcock's Films“ 106), als ,absonderliche" Abweichung von seinen bisherigen Erfolgsformeln oder doch als formales und symbolreiches Meisterwerk. Der Film polarisiert 1960 die Filmkritik und spaltet in zwei konträre Lager: die abwertenden Haltungen, die den Film als „Scherz“ und „widerwärtigen Irrtum“ ohne längere Analysen ablehnen, und die anerkennenden Bewunderungen, die in ausführlichen Analysen nicht nur die vielschichtige Symbolik und meisterliche Gestaltung loben, sondern auch den bisher schaurigsten Horror der Filmgeschichte. Gründe für diese Spaltung und vor allem die Negativkritiken sieht Robert E. Kapsis in seiner Studie Hitchcock: The Making of a Reputation im Umgang mit der Presse begründet, bei der Hitchcock nicht den üblichen Gepflogenheiten folgt. Unter anderem weicht Hitchcock von dem ungeschriebenen, ästhetischen Vertrag ' mit der Presse ab, da er Psycho nicht mit der gewöhnlichen ,Hitchcock'schen“ Mischung aus „Supense, Romance and 
Humor“ versieht (Kapsis 63). Auch Rebello sieht den Auslöser für die schlechten Kritiken in der Verärgerung der Presse (164 f.). Im Vorfeld der offiziellen Kinopremiere herrscht für Pressevertreter eine restriktive Vorberichterstattung, die weder Pressevorführungen vor dem Kinostart noch Interviews mit den Stars des Films erlaubt. Mit der ungewöhnlichen Pressepolitik geht zudem noch eine derart erfolgreiche Werbekampagne einher, die trotz schlechter Kritiken das nationale sowie internationale Interesse an dem Film steigert und für ein ausverkauftes Prerelease in New York sorgt (Kapsis 59). Der Filmpresse ist ihre Vorrangstellung als primäre Sichtungs- und Wertungsinstanz entzogen wurden. Inwiefern die Vermarktung und Distribution von Psycho von üblichen Kino- und Pressepraktiken abweicht und als Psycho Policy einen sensationellen Ruf erhält, wird im folgenden Kapitel detaillierter untersucht.

In Bezug auf den Diskurs der Filmkritik lässt sich aber bereits hier festhalten, dass der Umgang mit der Filmkritik einer, Degradierung' gleichkommt. Nicht nur ist die Pressevertretung gezwungen, sich den Film zusammen mit dem ,gewöhnlichen' Publikum anzuschauen; ihre Funktion, dem Publikum Lektürehinweise zu geben und Sehempfehlungen auszusprechen, ist obsolet geworden. Dass dies gerade den etablierten bürgerlichen Filmeliten nicht passt, die zudem noch von einer breit und reißerisch angelegten Werbekampagne quasi ,mundtot ' gemacht werden, klingt bei einigen Kritiken bereits durch. Dyer distanziert sich gleich zu Beginn seiner Kritik nicht nur von der Effekthascherei der Werbung, sondern auch von dem Publikum, das auf solches anspringt:

What keeps the public happy is undoubtedly their obsession with craftsmanship. Your
average critic, on the other hand, tends to be more concerned with the story itself
than with its telling; and when, as in Hitchcock's Psycho (Paramount), he finds an
outrageous story allied with a portentously irregular press-show and publicity, his
conditioned reflexes automatically cause him to hiss and jeer. (195)

In gleicher Weise bewertet der Evangelische Film-Beobachter die Pressepolitik vielmehr als ein kalkuliertes Manöver, das über die ersten 20 Minuten des Films hinwegzutäuschen versucht:

Ein Kritiker, der die Pointe eines Kriminalfilms mitteilt, gilt als humorlos. Nun liest man im Programm gar, Mister Hitchcock habe die Journalisten verpflichtet, über den Inhalt des Filmes und den Ausgang der Handlung nichts zu veröffentlichen und auch kein Sterbenswörtchen darüber zu verraten. Wer sich so schäumend ins Zeug legt, der kann kaum ein großes Zutrauen zu seinem Opus haben. Und gleich der Anfang gibt der Skepsis recht. [...] Nun, die langweiligen ersten zwanzig Minuten könnte man sich getrost schenken.“ (549) 
Der deutsche Film-Dienst steigt mit gleicher Rhetorik in seine Rezension ein: „Je lautstärker die Werbung, um so schwächer der Film.“ (366) Auch bei weiteren Kritiken lassen sich immer wieder Verweise auf die irregulären Presse- und Werbepraktiken finden, die implizit den unüblichen Presseumgang anprangern (siehe Rebello 164 f.). Dass Psycho auf eine derartige Ablehnung bei der Filmkritik stößt, lässt sich unter anderem darauf zurückführen: Die fehlenden Pressevorführungen, die große Marketingkampagne und die Auswertungspolitik schürten Vorbehalte gegenüber dem Film, die sich in den Kritiken niederschlagen. Einige Aussagen beziehen sich daher auch stärker auf die veränderten Presse- und Werbepraktiken als auf analytische Betrachtungen des Films. Das Publikum zeigte sich national wie international von diesem Diskurs der Filmkritik unbeeindruckt.

Relentlessly and adroitly, the director continued to promote the movie around the world. Wherever the movie played, the scene was the same: long lines, audiences on the knife-edge of screams and laughter, and Hitchcock stoking his newly minted legend as a master of shock. (Rebello $163 \mathrm{f}$.)

Psycho bescherte Hitchcock einen unvorhergesehenen Kassenerfolg, der im Vergleich zu seinen anderen Filmen mit Abstand am erfolgreichsten lief (ebd. 164). Vor dem Hintergrund dieses Publikumserfolgs, aber insbesondere in Bezug auf die Presse- und Werbepraktiken, kann der diskursive Umschwung erklärt werden, dem viele Kritiker noch bis Ende des Jahres 1960 folgten, indem sie ihre Kritiken widerriefen und Psycho nachträglich neu bewerteten (Kapsis 63). Trotz der im Juni noch verheerenden Kritik an den altmodischen Schockeffekten führt Crowther Psycho in seiner Liste „The Year's Best Films“ auf, die am 25. Dezember in der New York Times erscheint. In seiner Neubewertung deutet er den Horror, den er zuvor noch als „old-fashioned melodramatics“ bezeichnete, als „,new and frightened look“":

Old-fashioned horror melodrama was given a new and frightening look in this bold psychological mystery picture. Sensual and sadistic though it was, it represented expert and sophisticated command of emotional development with cinematic techniques. (Crowther nach Kolker 59)

Dieser Kritik ging ein Briefwechsel mit Hitchcock voraus, in dem sich Crowther in Anerkennung der Originalität des Films für seine schlechte Kritik entschuldigt (Rebello 171). Exemplarisch steht diese Neubewertung für die generelle Tendenz im Jahr 1960, in dem viele Kritiker ihre abwertenden Positionen gegenüber dem Film redigieren, Neubewertungen vornehmen und Psycho nachträglich als originellen Film ausweisen, wie es Sarris, Wood und Douchet als erste getan haben. 
Noch bis zum Ende des Jahres 1960 führt Psycho damit zu einer veränderten öffentlichen Wahrnehmung, die ihn als einen der besten Filme des Jahres preisen. Während sich Hitchcock angesichts des Überraschungserfolgs mit Psycho auf internationale Werbetour begibt, setzt eine Diskurswende ein, die noch während der Kinoauswertung Psycho's generische Verschiebung vom Randphänomen zum Genreklassiker vorzeichnet. Für die nachfolgende film- und genrehistorische Diskursivierung ist die kontrovers und umfangreich im öffentlichen Licht der Filmkritik geführte Debatte überaus zuträglich. Indem hitzig über den Film gestritten wird, setzt sich die Kritik intensiver und ausführlicher mit dem Film auseinander, was für damalige Genre- und Massenunterhaltungsfilme, vor allem im Horrorbereich, eigentlich unüblich ist, wie Rebello betont (168). Dieses kulturell wenig anerkannte Genre erfährt bis dato kaum öffentliche Aufmerksamkeit von Seiten der etablierten Kritik, obwohl es sich gerade bei einem jüngeren Publikum äußerster Beliebtheit erfreut. ${ }^{20}$ Der Diskurs der Filmkritik sorgt 1960 letztlich dafür, dass Psycho nicht nur einer der meist rezensiertesten Filme wird, sondern auch einer der wenigen Horrorfilme darstellt, die seinerzeit im Bereich des breiten Unterhaltungssegments laufen und Besprechungen erhalten.

Auch wenn Genrediskurse, sowohl generelle Systematiken als auch spezifische Theorien des Horrorfilms, in filmkritischen Diskursen noch keine zentrale Rolle spielen, agiert die Filmkritik 1960 dennoch im Bewusstsein der praktischen Relevanz von Genrekonzepten, die sie für die Produktion und insbesondere das Hollywoodkino und das Publikum einnehmen. Dieses Genrewissen lässt sich da herauslesen, wo die Duschszene nicht nur als Mordszene, sondern in Anerkennung der auf Schockeffekte zielenden Inszenierung als „one of the bloodiest murders ever filmed" (Dyer 195) explizit ,abgewertet" wird. Die Drastik an Gewalt und die Ausstellung von Sexualität werden missbilligend als Effekthascherei wahrgenommen, weil Psycho in erster Linie nicht als Horrorfilm gesehen wird, sondern als ,Hitchcock'-Film, der sich zur Überraschung der Filmkritik, aber weniger des Publikums, diesem Genre sehr eng verpflichtet fühlt. Inwiefern dies sowohl auf den Produktionskontext und die mediale Persona Hitchcock als auch auf die sensationellen Werbepraktiken, die spezifische Genremarkierungen für ein Horror- und Hitchcock-Publikum bereithalten, zurückzuführen ist, wird im Folgenden anhand der Psycho Policy deutlich.

${ }^{20}$ Siehe Doherty, insbesondere 63-89. 


\subsection{Die Psycho Policy: Genrekino als New Sensationalism}

Der Vermarktung von Psycho kommt retrospektiv der filmhistorische Ruf zu, eine der bestorganisiertesten ihrer Zeit gewesen zu sein und noch vor dem Internet, der Digitalisierung und umfangreichen Social Media-Kampagnen mit CrossmediaPromotion, Spoilerwarnungen und Fake News gearbeitet zu haben. Wurde der Fokus bislang auf den Diskurs der Filmkritik von 1960 gelegt, um diese ,gegen den Strich' auf Diskursivierungen des Horrorgenres zu lesen, zielt dieses Kapitel darauf, weitere populäre Genrediskurse herauszuarbeiten, die über spezifische Markierungen innerhalb der Kampagne gesetzt sind. Neben einem Hitchcockaffinen ,Thrill and Suspense'-Publikum, das Hitchcock aus Film und Fernsehen kennt, lockt das Marketing ein jüngeres Publikum an, das sowohl mit Horrorfilmen vertraut ist als auch auf die öffentlichkeitswirksame Werbekampagne , anspringt ${ }^{\star}$. Gerade weil in vielen Kritiken Vorbehalte gegenüber der irregulären Pressepolitik, der lautstarken Werbung und dem Horrorgenre festzustellen waren, verdeutlicht der Blick auf das Marketing zu Psycho, wie aufmerksamkeitsökonomisch gezielt über generische Markierungen Publika adressiert werden. Diese bieten den zuvor anhand von Neale betonten Zugang zu Genrediskursen eines Films („Questions“ 185). In der Gegenüberstellung der Diskurse der Filmkritik und der Materialien zeichnet sich zudem ein interessanter Unterschied in Bezug auf die Duschszene ab. Während diese in der Filmkritik auf ein übergreifendes Entsetzen stößt, markiert sie in den Materialien erst noch ein Geheimnis, bevor sie zur medialen Chiffre zukünftiger Folgeaufführungen und Zweitauswertungen wird. Inwiefern der Genrediskurs der Materialien über konträre Praktiken produktiv mit dem der Filmkritik ineinandergreift, wird am Ende des Kapitels deutlich.

Die Kampagne hantiert mit drei wesentlichen Bausteinen: der Kinopolitik, Hitchcocks Persona und einer Sensationalisierung, die im Folgenden zwar aus analytischen Gründen getrennt voneinander betrachtet werden, aber in einem zusammenhängenden Diskurs aufgehen, indem sie sich gegenseitig verstärken. Die neuartigen Kinopolitiken mit dezidierten Ankündigungs- und Aufführungsregeln, Hitchcocks populärer Persona und die Sensationalisierung von Gewalt und Sexualität - so die These dieses Kapitels - erzeugen einerseits ein generisches Setting, das verschiedene Genrekonzepte einbezieht und Quereffekte zwischen Genrepublika erzielt, und anderseits ein breites mediales Interesse, das die Werbekampagne selbst zur Sensation macht. Beides bringt für Genrekonzepte im Allgemeinen und den nachfolgenden Genrediskurs von Psycho im Besonderen erhebliche Verschiebungen mit sich. Um den aktuellen Genrestatus des Films nachzuvollziehen, aber auch den filmkritischen Verriss zu verstehen, ist also 
ein historischer Rückblick auf das Marketing und die damalige Kinosituation zu werfen. Dafür wird zuerst der Produktions- und Genrehintergrund von 1960 skizziert, der eine ungewöhnliche Genrekonstellation aufweist, bevor die Aufführungspraktiken der Psycho Policy beleuchtet werden. Diese implementiert aber nicht nur neue Einlass- und Vorführpraktiken, sondern setzt auch die Persona Hitchcock als prominentes Aushängeschild und generischen brand ein. Als weitere diskursive Bausteine der Policy werden der Trailer und das Plakatdesign betrachtet, aus denen sich Exploitationpraktiken des Horrorkinos herauslösen lassen. Inwiefern die Psycho Policy im Kontext des New Sensationalism selbst für Aufmerksamkeit sorgt und eine neue Publikumsdisziplinierung bewirkt, wie es Williams konzeptualisiert, wird abschließend diskutiert.

\subsubsection{Genre- und Produktionshintergrund}

Alfred Hitchcock agiert 1960 als namenhafter Regisseur bereits ,unabhängiger' innerhalb von Hollywood und bewegt sich mit seiner Krimi-Reihe Alfred Hitchcock Presents auch im neuen Medium des Fernsehens überaus erfolgreich. Seit dem Paramount-Urteil von 1948 unterliegt Hollywood organisatorischen Umstrukturierungen. Die Auflösung der vertikalen Integration führt unter anderem dazu, dass die großen Studios weniger Filme produzieren und häufiger nur als Verleih auftreten. Der Rückgang großer Produktionen sorgt in den 1950er Jahren für einen Aufschwung des Low-Budget-Genrekinos, welches nach Heffernan mehrere Strategien nutzt, um die entstandene Programmleere vor allem in den kleineren Kinos zu kompensieren: „cultivation of the youth audience, exhibitor financing of production, sensationalist advertising“ (65). Neben den Produktionsveränderungen und der neuen Konkurrenz mit dem Fernsehen bewirken die ,Babyboomer'-Generation und die Suburbanisierung, dass sich das Publikum ,verjüngt' und von den Stadtzentren in die Vorstädte abwandert. Vor dem Hintergrund dieser sich allmählich abzeichnenden Krise Hollywoods resultiert Hitchcocks Popularität aus einer frühzeitigen Reaktion auf die Veränderungen des Mediensystems: Nach dem siebenjährigen Exklusivvertrag mit David O. Selznick geht Hitchcock keine Exklusivverträge mehr ein, sondern produziert parallel zum Paramount-Vertrag sowohl mit Warner Bros. als auch mit MGM, sodass sein Name als Unterscheidungskriterium wichtiger wird als das Studio, für das er arbeitet. Zeitgleich wird er über das Fernsehen einem breiteren amerikanischen Publikum bekannt (Nitsche 194 f.). Für dieses besetzt Hitchcock mit seinem Namen unterhaltsame Kriminalgeschichten, die seiner erfolgreichen ,Thrill and Suspense“-Weise folgen und einen Sinn für das Makabre aufweisen, 
aber vor allem bereits erste Anleihen vom Horrorfilm einfließen lassen: „the sinister and terrifying lurked within the everyday“ (Jancovich, „Rational Fears“ 258). Zwar werden Hitchcock (noch) keine künstlerische Stilistik, aber dafür geschickte Techniken eines versierten Handwerkers zugeschrieben.

Mit der Adaption von Robert Blochs Novelle Psycho, die 1959 herauskommt, bewegt sich Hitchcock einerseits abseits seines bisherigen Images, das er durch kritik- und publikumsfreundliche Filme als Teil seiner Selbstvermarktung kultiviert, wie im Folgenden anhand seiner Persona noch ausführlicher dargestellt wird. Anderseits nimmt er sich eines Genres an, das wie oben erwähnt als filmkritisch wenig wertvoll und beachtenswert gilt und von großen Studios sowie seinem üblichen Kinopublikum gemieden wird. Es verwundert daher nicht, dass der damalige Studiopartner Paramount nicht in die Produktion einsteigt und Hitchcock in Eigenproduktion, für die Paramount nur als Verleih fungiert, kostengünstig drehen muss. Da er dies bereits aus seiner Fernsehreihe kennt, greift er für Psycho größtenteils auf das Fernsehteam zurück (Kapsis 57). Im Kontext der Fernsehreihe lässt sich Psycho mit Jancovich sogar als vorhersehbares Projekt deuten, das nicht nur die bereits in der Serie erprobten Horrorelemente fortsetzt und auf das Fernsehteam zurückgreift, sondern auch mit Bloch, der zwischen 1955 bis 1961 mehrere Drehbücher für die Serie schrieb, eine weitere Kontinuität aufweist (,Rational Fears“ 258). Zugleich passt die Wahl eines Low-Budget-Horrorfilms in Schwarzweiß wiederum sehr gut in Hitchcocks bisherige Bemühungen, auf Veränderungen des Mediensystems zu reagieren und mit Psycho den neuen lukrativen Markt des Low-Budget-Genrekinos zu betreten. ${ }^{21}$ Während des klassischen Hollywoods der 1930er und 1940er Jahre haben Horrorfilme, wie Doherty bemerkt, mit den Universal- bzw. RKO-Produktionen Frankenstein (1931), Dracula (1931), Cat People (1942) und I Walked With a Zombie (1943) zwar ,a steady and respectable, albeit minor, place in studio production. But following World War II the horror film ,proper' all but

${ }^{21}$ Im Laufe der 1950er Jahre werden Genreproduktionen von Independents nach Heffernan bei kleinen wie großen Studios immer gefragter: „By the end of the decade, genre films were serving a number of functions for distributors. Exhibitor-backed companies such as Howco and McLendon were primarily interested in filling out playdates in their own theaters. Major studios including Columbia, Twentieth Century-Fox, and Paramount contracted with independent producers to ensure a year-round supply of product, releasing these films, often in double-feature packages, to downtown houses between major films or directly to neighborhood theaters.“ (76) Dass Paramount Psycho also als „Independent-Produktion“ einkauft, entspricht der damals üblichen Praxis großer Studios. Zur weiteren Geschichte des Genrekinos der 1950er Jahre siehe Heffernan, insbesonders 64-89. Zur Geschichte des B-Movies vor dem Hintergrund des Paramount-Urteils und den Veränderungen in Hollywood siehe auch Davis, insbesonders $108 \mathrm{ff}$. 
disappeared from the American screen“ (143). Mit der Rückkehr von Horrorfilmen in den 1950ern wird das Genre zu einem erfolgreichen Exploitationkino für das ,neue “ jugendliche Publikum, für das B-Movies mit ,a much smaller investment, a high-concept title, and energetic exploitation of the teen audience" (146) von größeren Studios produziert werden. Besonders erfolgreich in der Produktion von „horror teenpics“, wie Doherty sie nennt, sind vor allem das Independent-Studio American International Pictures (AIP) (153 ff.), aber auch die importierten Horrorproduktionen der britischen Hammer Film Studios, die dem jüngeren amerikanischen Publikum blutige Gewaltbilder bereits in Technicolor vorführen. $^{22}$

Dieser kurze Abriss des Genre- und Produktionskontextes verdeutlicht die für Psycho spannende Verkettung von Genrediskursen und Herstellungssituation: Aufgrund der genrespezifischen Produktionsumstände muss Psycho nicht nur unabhängig, sondern mit einer Gesamtsumme von nur ca. 800.000 Dollar (Rebello 53) auch relativ billig produziert werden. Daher weist Psycho im Verhältnis zu Hitchcocks vorherigen Filmen und anderen HollywoodGroßproduktionen der 1950er Jahre relativ geringe symbolische Verkaufswerte auf, wie es große Stars oder hohe Produktionskosten bereithalten (Naremore, „Filmguide“ 19). Bis auf Janet Leigh, die über Hauptrollen unter anderem in Filmen von Josef von Sternberg (Jet Pilot 1957) und Orson Welles (Touch of Evil 1958) einen größeren Bekanntheitsgrad erlangt hat und durch die Heirat mit Tony Curtis auch die damaligen Boulevardblätter füllt, werden mit Vera Miles als Lila Crane und Anthony Perkins als Norman Bates zwei ParamountVertragsschauspieler/innen engagiert. Der eigentliche Star bildet Hitchcock selbst, der statt Janet Leigh das Marketing dominiert. Angesichts dieser Ausgangslage wird deutlich, dass dem Marketing von Psycho nicht nur die zentrale Aufgabe zukommt, die fehlenden symbolischen Verkaufswerte zu kompensieren, sondern auch zwischen mehreren Genrepublika zu vermitteln. Dies funktioniert über Hitchcocks (ironische) Selbstinszenierung, eine restriktive Presse- aber zugleich öffentlichkeitswirksame Einlasspolitik und eine genrespezifische Gestaltung von Plakat und Trailer, die allesamt nicht nur den Film, sondern die Kampagne selbst zur Sensation machen.

\footnotetext{
${ }^{22} \mathrm{Zu}$ den Horrorfilmen der Hammer Studies siehe Heffernan, insbesondere 43-62, und Kendrick, ,Hollywood Bloodshed“.
} 


\subsubsection{Hitchcocks Einlasspolitik im Kino}

Hitchcocks Popularität geht aus einer „,intermedialen Formation“ hervor, die „nicht allein aus seinen Kino- oder Fernseherfolgen (resultiert), sondern das Ergebnis der intensiven Inszenierung seiner Figur" (Nitsche 100) darstellt. Folglich nutzt Hitchcock nicht erst bei Psycho seine Popularität und mediale Persona, um Einfluss auf die Wahrnehmung seiner Filme auszuüben. Im Bewusstsein um den ökonomischen Kontext seiner Arbeit und aus den eigenen Erfahrungen aus Nebentätigkeiten in der Werbebranche professionalisiert Hitchcock seine Werbeaktivitäten in den 1930er Jahren mit der Gründung der Produktionsfirma Hitchcock-Baker Productions, die sich auch um die produktionsgesteuerte Presseund Öffentlichkeitsarbeit kümmert (Staiger, „Creating the Brand“ 40 f.). Ziel seiner Werbebestrebungen ist es, dass seine Filme bei Publikum und Kritik stets über seinen Namen wahrgenommen werden und er als kommerziell erfolgreicher Regisseur eines populären Unterhaltungskinos wiedererkannt wird. Früh setzt er dabei auf die eigene Selbstvermarktung:

We make a film succeed [...]. The name of the director should be associated in the public's mind with a quality product. Actors come and go, but the name of the director should stay clearly in the mind of the audience. (Hitchcock nach Staiger, „Creating the Brand“" 40; Herv.i.O.). ${ }^{23}$

Obwohl Hitchcock 1960 (noch) nicht zu Regiegrößen wie Orson Welles oder William Wyler zählt, führt die früh auf seine Person und Erscheinung ausgerichtete (Selbst-)Vermarktung dazu, dass sein Name weltweit Aufmerksamkeit genießt und zum Aushängeschild für ein kommerziell erfolgreiches Unterhaltungskino, insbesondere eines Genrekinos, wird. Während seine britischen Thriller ihn in den 1930er Jahren international bekannt machen und nach Hollywood führen, sorgt der Erfolg seiner amerikanischen Film- wie Fernsehproduktionen dafür, dass sein Name zum Innbegriff spannender Thriller und Krimiunterhaltung, sogenannten ,Thrill and Suspense', mit einem Sinn für das Makabre avanciert und ihm den Titel ,Master of Suspense` einbringt. ${ }^{24}$

The single name is enough to tell people what type of film they can expect. Hitchcock: the only director whose name alone can sell a film and very often save it from otherwise bad box-office. Few directors ever achieve the status of a superstar with their

${ }^{23}$ Das Zitat findet sich u. a. bei Spoto, „,The Dark Site“ 73; Kapsis 16; McGillan 86 f. Die Äußerung geht auf das Jahr 1927 zurück (Montagu nach McGillan 86 f.).

${ }^{24}$ Zum Humor von Hitchcock siehe Naremore, ,Hitchcock and humor“. 
name above the title. Americans have always considered the thriller, the mystery, the suspense film, and the black comedy to be plebeian. Hitchcock took these genres, gave them dignity, and made them acceptable as art forms. (Harris/Lasky 16)

Neben diesem kultivierten Genre-Image steigt Hitchcock in den 1950er Jahren für das amerikanische Publikum vor allem durch seine populäre Fernsehreihe Alfred Hitchcock Presents zu einer „,wahren Ikone der Popkultur“ (Fischer, „Einführung“ 12) auf. $^{25}$ Mit den über 400 Anmoderationen institutionalisiert er nicht nur seine Auftritte als ,Master of Ceremonies', der im schwarzen Anzug und mit süffisanter (Selbst-)Ironie in die mit makabren Pointen und Horroranleihen gespickten Kriminalgeschichten einführt, sondern auch sein generisches branding. Bereits während seiner britischen Produktionszeit arbeitet Hitchcocks an der Wiedererkennbarkeit von Name und Erscheinung, für die er 1927 eine eigene zeichnerische Karikatur entwickelt und als Puzzle im Rahmen eines Weihnachtsgrußes verschickt (Deutelbaum/Poague 64). Diese noch heute bekannte und genutzte Zeichnung braucht nur neun Striche, um Hitchcocks markante Köperund Gesichtszüge im Seitenprofil anzudeuten: die korpulente Statur, die spitzen Lippen, die lange Nase und der kahle Kopf. Zur ikonischen Erscheinung wird die Silhouette aber erst mithilfe seiner Fernsehreihe Alfred Hitchcock Presents, die die Silhouette nicht nur jeder Folge voranstellt, sondern Hitchcocks selbst ,hineintreten` lässt (Abb. 3.1).

Abb.3.1 Alfred Hitchcock

Presents, „Hitchcocks

Silhouette", USA

1955-1965

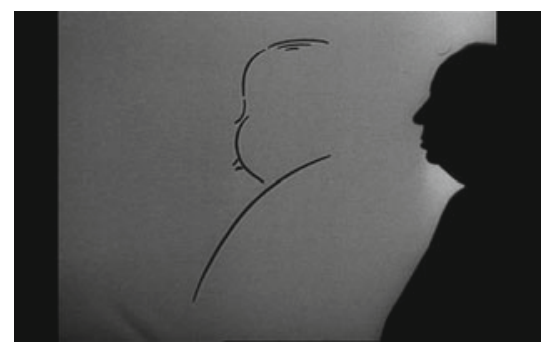

Diese (selbstironische) Inszenierung von Name und Persona steht stellvertretend für Hitchcocks generelle Vermarktungstaktik und gezielte Genrearbeit, die er für

\footnotetext{
${ }^{25}$ Neben der Fernsehreihe findet sich Hitchcocks Name auch auf Zeitschriften- und Taschenbuchreihen wieder wie auf Alfred Hitchcock's Mystery Magazine und die bei Random House erschienene Suspense-Anthologiereihe, die unter anderem den Titel Alfred Hitchcock Presents Stories My Mother Never Told Me führt, die das generisches Branding weitertreiben (Harris/Lasky 16).
} 
Psycho marketingtechnisch auf die Spitze treibt. Hitchcocks Persona durchzieht das gesamte Marketing crossmedial: Von Aufstellern, Aushängen, Handreichungen über Durchsagen bis zu Printanzeigen, Plakaten und Kinotrailer gerinnt Hitchcock zur omnipräsenten Werbefigur, die Indikationen eines ,Thrill and Suspense'-Kinos mit sich führt, um der (auf den ersten Blick) ungewöhnlich wirkende Einlass- und Pressepolitik entgegenzuwirken.

Bevor Psycho im September landesweit in den Kinos anläuft, finden im Juli und August 1960 erste Aufführungen in ausgewählten Städten statt, unter anderem in New York, Boston, Philadelphia, Chicago, London und Los Angeles. Mit diesen vorgezogenen, aber auf wenige Großstädte begrenzten Vorpremieren zielt der Verleih auf eine erste Medienaufmerksamkeit, ohne auf eine landesweite Auswertung zu verzichten. ${ }^{26}$ Dies hat System, denn auch wenn das Prerelease nicht den erhofften Schneeballeffekt produziert hätte, die Publikums- und Kritikresonanz nur verhalten oder sogar (auf beiden Seiten) miserabel ausgefallen wäre, hätte in Hitchcocks Namen genügend Zugkraft bestanden, um ausreichend Kinobesucher für zwei Wochen anzulocken, sodass selbst etwas Profit hätte eingespielt werden können (Kapsis 59). Doch selbst nach den regulären neun Wochen bleibt Psycho im Programm der Manhattaner Vorpremierenkinos, obwohl der Film bereits in den Umgebungskinos anläuft, was für Kapsis eine ungewöhnliche Buchungspraxis darstellt. Den Grund dafür macht er in dem außergewöhnlichen Kassenerfolg Psycho's aus: Statt den üblichen 10-20-prozentigen Absatzeinbrüchen, die normalerweise nach einem ersten Aufführungswochenende erfolgen, läuft Psycho vom ersten Tag an unter fast kompletter Ticketauslastung und sorgt landesweit für überdurchschnittlich lang ausverkaufte Kinos (59).

Während die Auswertung an gängige Verleihpraktiken anknüpft, weicht der Verzicht auf Pressevorführungen und Vorab-Interviews mit dem Cast von der üblichen Pressepolitik ab. In den Verleihverhandlungen akzeptiert die ParamountFührung den Verzicht auf Probe-, Vorab- und Pressevorführungen. Lew Wassermann erwirkt für Hitchcock zudem eine 60-prozentige Gewinnbeteiligung

\footnotetext{
${ }^{26}$ Eine landesweite Auswertung ist wesentlich einträglicher als die zeitaufwendige stufenweise Auswertungsspanne. Denn gerade bei stufenweisen Auswertungen muss das Publikum in kleineren Städten und in kleineren Kinohäusern lange warten, bis die Kopien die Großstadtkinos bespielt haben und für das lokale Kinoprogramm verfügbar sind. Für Psycho werden mit mehreren tausend sogar überdurchschnittlich viele Kopien gezogen, um nicht nur die urbanen Ballungszentren, sondern gleichzeitig das in vorstädtische und ländliche Regionen abgewanderte Publikum zu erreichen (Rebello 148). Zum US-amerikanischen Vermarktungs- und Distributionssystem siehe Donahue.
} 
(Rebello 29) und rät zum landesweiten Verleih (ebd. 270 f.). ${ }^{27}$ Die eher ungewöhnlichen Zugeständnisse von Paramount, die Presse zu umgehen, sind erneut auf den Genre- und Produktionskontext zurückzuführen: Mit diesem eher ,kleinen' Film erwartet Paramount weder einen Box Office Hit noch geht der Verleih ein besonders großes Verlustrisiko ein. Allerdings ist Paramount über die Werbeund Aufführungspläne, die bereits zur Vorpremiere greifen sollen, nicht informiert. Die Voraufführungen im Vorfeld des nationalen Kinostarts dienen letztlich weniger einer Testphase für den Film selbst, sondern sollen vielmehr eine neue Einlasspolitik und begleitende Werbekampagne erproben, die bei Erfolg für die gesamte nationale Auswertung übernommen werden soll (ebd. 272). Diese Einlasspolitik sieht einige strikte Regeln vor: Erstens darf niemand mehr nach dem Start der Projektion in den Kinosaal hineingelassen werden - die Türen müssen geschlossen werden, sobald die Vorführung beginnt. Und zweitens muss nach dem Filmende der Saal für 30 Sekunden dunkel bleiben, bevor das Licht angeht und das Publikum den Saal verlassen kann. Diese Instruktionen führt Hitchcock in der eigens verfassten Handreichung „The care and handling of Psycho" dezidiert auf. Zusammen mit Presseberichten über die Vorpremieren, Auflistungen der Werbematerialien und weiteren dezidierten Anweisungen ist die Handreichung Bestandteil des Paramount Press Book, das Kinobetreibende von den umfangreichen Werbemaßnahmen überzeugen soll.

Zusätzlich produziert Hitchcock einen 12-minütigen Verleihtrailer - das Press Book on Film - der Aufnahmen von der New Yorker Vorpremiere zeigt, um die erfolgreiche Umsetzung der Psycho Policy zu demonstrieren. Im Stile eines ,Newsreel' wird Psycho im Verleihtrailer als außergewöhnliches kulturelles Ereignis angepriesen, dessen erfolgreiche Vorpremieren in New York, Boston, Philadelphia und Chicago vor allem durch die Aufführungspolitik ermöglicht werden, die nicht nur einen geordneten Umgang mit dem Publikumsandrang bei den Vorpremieren sichern, sondern auch einen zukünftigen Andrang versprechen und regeln. Aufnahmen des DeMille-Kinotheaters in New York, in dem Psycho zuerst vorgeführt wird, zeigen die langen Publikumsschlangen, Absperrungen und Wächter, die den Andrang und Einlass zu den Kinovorführungen koordinieren, als

\footnotetext{
${ }^{27}$ Lew Wasserman galt als einflussreichste Person in Hollywood. Er war Präsident von MCA, die nach dem Paramount-Urteil 1948 hauptsächlich als Schauspieler- und RegieAgentur agierte, und bekannt für sein Verhandlungsgeschick mit erfolgreichen Gewinnbeteiligungen. Als ehemaliger Agent von James Stewart verschaffte er ihm eine 50-prozentige Gewinnbeteiligung an dem Film Winchester'73 (1950) bei Universal, dessen enormer Gewinn letztlich nicht nur Stewart, sondern auch Wasserman reich machte und eine Lawine an Gewinnbeteiligungen losbrach (Rebello 148).
} 
auch die für das Publikum sichtbaren Hinweise auf die Einlasspolitik (Abb. 3.2a3.2b). In nahezu allen (Werbe-)Materialien - von Printanzeigen in Zeitungen über Aufsteller und Megafon-Einspieler im Kinofoyer bis zum offiziellen Kinotrailer wiederholt Hitchcock seine Anweisungen: „We won't allow you to cheat yourself! You must see Psycho from beginning to end to enjoy it fully. Therefore, do not expect to be admitted into the theatre after the start of each performance of the picture. No one - and we mean no one - not even the manager's brother, the President of the United States, or the Queen of England (God bless her)!" (Abb. 3.2c) Noch vor den heutigen omnipräsenten ,Spoiler Alert'-Warnungen und inzwischen standardmäßig geschlossenen Non-Disclosure Agreements verstärken diese Secrecy Policy-Hinweise zu Psycho die Erwartungen auf ein sensationelles Filmerlebnis im Vorhinein: „After you've seen Psycho please don't tell your friends its shocking secrets." (Abb. 3.2d) Zur weiteren Zeugenschaft der gelungenen und gewinnbringenden Maßnahmen lädt im Verleihtrailer Georg Weltner, Vizepräsident von Paramount und Vertriebsstratege für den Weltvertrieb, die Manager der Vorpremierenkinos zur Zeugenschaft, um mit ihren Erfahrungsberichten letzte Zweifel bei etwaigen skeptischen Kinobetreibenden auszuräumen:

The results were wonderful. We did more business with Psycho than any other picture has done in our town in the past 30 years. I hardly recommend for every exhibitor that he follows the policy of Psycho if he wishes to do as well as we did. (Kinomanager Mill Miller im Verleihtrailer)

Der strikte Einlass spielt innerhalb der Psycho Policy eine wichtige Rolle. Das Publikum gilt zu der damaligen Zeit als Laufpublikum, das zu jeder Zeit in jeden Film während der gesamten Vorführung gehen kann, bei Psycho aber zum pünktlichen Erscheinen im Kino gezwungen wird. ${ }^{28}$ Wer verspätet zum angekündigten Aufführungsbeginn kommt, wird nicht mehr in den Kinosaal gelassen. Zur Sicherstellung der Forderungen werden Wächter aufgestellt, um das Publikumsaufkommen und die Warteschlangen vor dem Kino sowie den Filmstart zu ,regeln ${ }^{29}$ Dabei erfüllten diese weniger eine praktische denn eine doppelte

\footnotetext{
${ }^{28}$ Bereits für Les Diaboliques (1955) von Henri-Georges Clouzot musste das Publikum pünktlich im Kino erscheinen, wollte es den Film sehen. Der überraschende Erfolg des Films wird unter anderem auf die strikte Einlasspolitik zurückgeführt (Nitsche 198). Aber erst Psycho setzt dies als neue Kinopraktik durch, wie Williams mit Verweis auf Peter Bogdanovich, der dies 1963 bereits bemerkte, unterstreicht („Discipline and fun“ 363).

${ }^{29}$ Meist waren es Angestellte, die sich als Wächter verkleideten. Angeblich ließ Hitchcock zusätzlich Krankenschwestern vor den Kinos auftreten, die bei möglichen gesundheitlichen Problemen im Zuge der Kinovorführung von Psycho erste Hilfe leisten konnten (siehe Younker). In Anbetracht der Geläufigkeit dieser Gimmicks für das Low-Budget-Horrorkino ist
} 

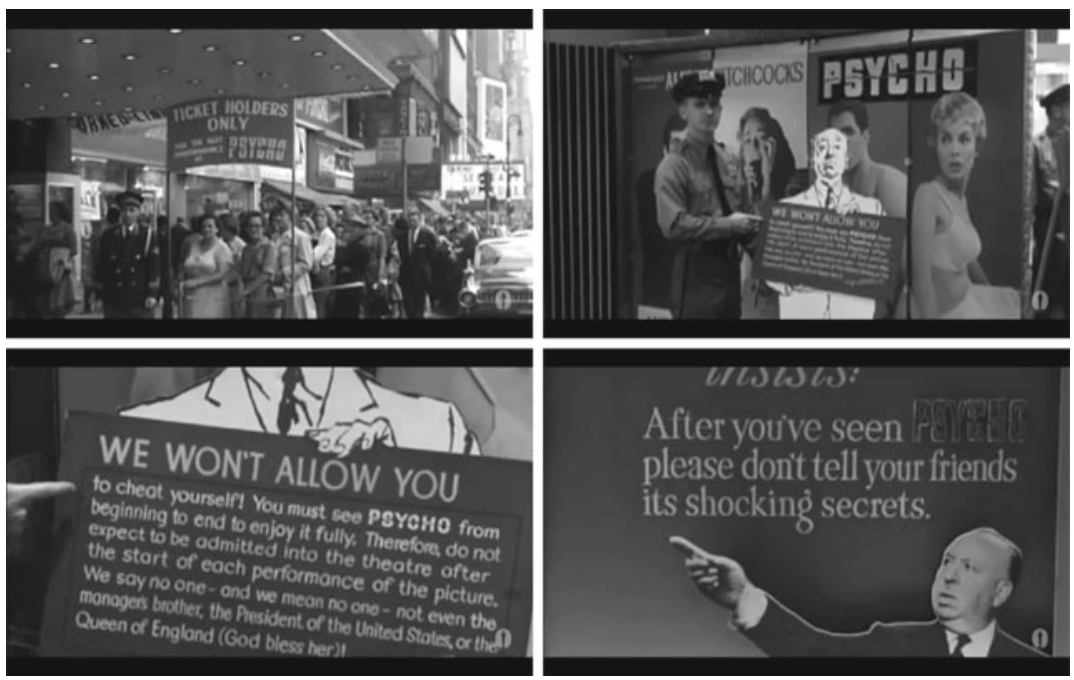

Abb. 3.2a-d Press Book on Film, „Die Psycho Policy“, USA 1960

Genrefunktion: Für Hitchcock-Informierte verweist der Polizist nicht nur auf Hitchcocks, Thrill and Suspense-Kriminalgeschichten, sondern auch auf seine aus der oben beschriebenen Legende rührende Angst vor der Polizei. Als zusätzliche ,Gimmicks‘ produzieren die Wächter den aufregenden Nebeneffekt, während dem Warten auf den Einlass ,überwacht` zu werden, was die Vorfreude auf unterhaltsame Weise hinauszögert. Für das damalige, ältere und weniger horrorgeübte Publikum bilden diese Gimmicks, die Secrecy Policy und Auffordungsrhetoriken im Zusammenhang mit einem Hollywood-Film eher unkonventionelle Praktiken. Im Kontext des Horrorgenres allerdings ist diese sich als ungewöhnlich anpreisende Einlasspolitik für ein jüngeres Publikum keineswegs provokativ und neu. Zum Low-Budget-Genrekino der 1950er gehören, wie Heffernan herausstellt, bereits aufwändige Werbekampagnen, die Horrorfilme wie I Was a Teenage Werewolf (1957), The Screaming Skull (1958) oder Horrors of the Black Museum (1959) ,with an unusual emphasis on their topical or horrific content“ (64) vermarkten und ungewöhnliche Werbe-Gimmicks wie ,,ambulances, uniformed nurses, decapitated dummies in water tanks, blood-trenched tableaux and coffins

dies durchaus vorstellbar. Des Weiteren würde es nicht verwundern, wenn auch ,Patienten und Patientinnen' engagiert worden wären, die angeblich durch den Besuch von Psycho verursachte Herzinfarkte hätten. 
in theater lobbies“ (Doherty 172) einsetzen. Wie mit Doherty und Heffernan geschlussfolgert werden kann, nutzen Low-Budget-Produktionen insbesondere im Horrorbereich bereits Ankündigungen, wie sie Psycho derart prominent platziert, als Teil ihrer Exploitationstrategien, zu denen ebenfalls das landesweite „saturation booking" und Fernseh- wie Radiowerbung zählen (Doherty 170). ${ }^{30}$ Auch Kapsis führt dazu aus: ,,such gimmicks were nothing new to young people familiar with the promotional strategies accompanying the release of other low-budget horror films of that period." (58) Da sich Teenager und ein jüngeres Publikum zudem über Anzeigen, Plakate und Trailer informieren und weniger auf Vorberichterstattungen durch die Filmpresse zurückgreifen (ebd. 62), stößt Psycho gerade bei diesem Publikum auf einen hohen Zuspruch und erfährt einen derartigen Erfolg: „Apparently, for the young horror-film fan, Psycho was a film that really delivered." (60)

Die umfangreiche und detaillierte Gesamtinszenierung aus Kinoanleitungen, Einlasspolitik und Secrecy Policy gestaltet den Kinobesuch zu einem besonderen Erlebnis, welches Warteschlangen, Wächter und weitere Gimmicks bereithält. Diese können als ein verlängerter Arm des Genrediskurses verstanden werden, der bereits den Wartemoment vor dem Kino als zu erwartendes ,Horrorkino“ genrespezifisch markiert. Gerade für das jüngere und horroraffine Publikum sind diese Attraktionen als spezifische Horrormarkierungen sehr deutlich im Marketing zu lesen, ohne dass sie konkret benannt werden müssen. Tatsächlich findet sich in den Printanzeigen, Hinweisen, Kinoaufstellern und Plakaten kein dezidierter Genrebegriff, der Psycho als ,Horrorfilm` benennt, anders als beispielsweise das Plakat zu Horror of Dracula (1957), das mit „love that horror“ wirbt (Doherty 166), oder Invasion of the Body Snatchers (1956), dessen Plakat ein „,nightmare of terror" verspricht (Heffernan 80). Dennoch markieren die Vermarktungspraktiken deutlich ein generisches Setting. Der Verzicht auf konkretere Begriffe rührt aus Hitchcocks populärer Kinoposition her, die eine explizite Horrorbenennung bewusst kaschiert, um das Hitchcock-affine Publikum nicht abzuschrecken und Psycho vor allem als Hitchcock-Film zu bewerben, wie Williams bemerkt:

But audiences who first went to see it did not go to see a slasher horror film; they went to see a Hitchocck thriller with a twist - about which there was a great deal of excitement and quite a bit of mystery. (,Discipline and fun” 359)

\footnotetext{
30 Ähnliche Spoiler Alert-Hinweise finden sich z. B. auch bei Invasion of the Body Snatchers, für den das Plakat bittet: „Please don't tell what the ,body snatchers“ do to their victims.“ (Heffernan 80)
} 
Dies korrespondiert zudem mit der damaligen Genrepraxis, wie sie Clover für den Horrorbegriff aufzeigt. Dieser wurde in Bezug auf Low-Budget-Produktionen verwendet, wohingegen teurere Produktionen eher mit den Genrebegriffen Drama und Suspense arbeiteten (5 f.).

\subsubsection{Trailer und Plakat: „The most horrible event"}

Seit North By Northwest (1959) tritt Hitchcock in Trailern zu seinen Filmen selbst auf. ${ }^{31}$ Erscheinen im Trailer zu North by Northwest noch in klassischer Weise Ausschnitte aus der Filmhandlung, verzichtet Hitchcock innerhalb des 6minütigen Kinotrailers zu Psycho komplett auf Filmmaterial und legt diesen wie eine kurze ,Newsreel'-Dokumentation an, in dem er Psycho selbst vorstellt und durch die Kulissen des Filmsets führt. ${ }^{32}$ Der Trailer gleicht einem Monstrositätenkabinett, in dem Hitchcock vor dem Filmset des Motels posierend und mit makabrer Ironie sowie vieldeutigen Anspielungen den Tourenführer durch das ,House of Horror" spielt, wo das „quiet little“ und „perfectly harmless" wirkende Motel als „,a scene of a crime“ eine traurige Berühmtheit erfahren habe (Abb. 3.3a). Doch bevor es zum ersten Tatort in einem der Motelzimmer geht, führt er zum alten Haus hinauf, welches auf einem Hügel neben dem Motel thront (Abb. 3.3b). Während Hitchcock fortfährt zu erklären, dass das Haus „,a little more sinister looking, less innocent than the motel itself" sei und sich dort „the most dire horrible events" ereignet haben, gleitet die Kamera näher heran und erfasst Hitchcock in einer Nahaufnahme mit dem Haus im Hintergrund. In schlenderndem Gang weist Hitchcock innerhalb des Hauses mit Handbewegungen auf Mordschauplätze und erzählt im Plauderton, wie sich der zweite Mord zugetragen habe (Abb. 3.3c). Dabei deutet er delikate Details rhetorisch nur an und lässt Sätze bewusst unvollendet, um sie bedeutungsschwanger aufzuladen.

\footnotetext{
${ }^{31}$ Auftritten von Regisseuren innerhalb von Trailern waren zuvor eher unüblich und finden sich nur bei D. W. Griffith während der Stummfilmära und bei Cecil B. DeMille, die ähnliche Zugkraft hatten wie Schauspielstars (Hediger, „Verführung zum Film“17). Im Trailer zu North by Northwest kündigt Hitchcock seinen Film ähnlich einem Pitch als Urlaubsziel an, bevor Szenen aus dem Film mit Hitchcocks Ausführungen alternierend montiert werden. Diese Auftritte führt Hitchcock in den Trailern zu The Birds (1963), Marnie (1964) und Frenzy (1972) fort (siehe dazu Nitsche 99 f.).

${ }^{32}$ Neben diesem langen Trailer wurden noch zwei kurze Teaser veröffentlicht, die auf den Einlass und die Secrecy Policy hinweisen (Rebello 152). Im Fokus steht hier aber Hitchcocks Präsenz im längeren Kinotrailer. Das Script dazu stammte von James Allardice, der für Hitchcock bis 1964 die Trailerscripts schrieb und auch für die Einführungstexte der Fernsehreihe verantwortlich war.
} 
Nach der Besichtigung des Schlafzimmers, in dem die ominöse Frau wohne, die für den zweiten grässlichen Mord verantwortlich sei, verkündet Hitchcock zwar verheißungsvoll ,the weirdest and the most...", spart aber auch dieses Satzende aus (Abb. 3.3d). Zurück im Motel verweist er auf den Lieblingsraum des Sohnes, das Hinterzimmer des Empfangs. Mit weiteren offenen Anspielungen auf Figuren (,After all, being dominated by an almost maniacal woman was enough to drive anyone to the extreme of...") und Handlungen (,,There was a private supper here, and... by the way, this picture has great significance, because...") gibt Hitchcock mehr Rätsel auf als er Anhaltspunkte liefert. Schließlich führt er in das Badezimmer des Motelzimmers 1, wo sich der blutigste aller Morde zugetragen habe: „You should have seen the blood. The whole, the whole place was... Well it's, it's too horrible to describe. Dreadful. And I tell you, there's a very important clue [that] was found here. Down there. Well the murderer, you see, crept in here very slowly, of course the shower was on, there was no sound, and..." Als Hitchcock sich langsam dem Duschvorhang nähert (Abb. 3.3e) und ihn zur Seite zieht, stößt Vera Miles mit Perücke zur einsetzenden Filmmusik von Bernard Herrmann und zum eingeblendeten Filmtitel einen kreischenden Schrei aus (Abb. 3.3f). Damit schließt die Tour und der Trailer endet mit den Hinweisen auf die Psycho Policy: „The picture you MUST see from the beginning... or not at all!... for no one will be seated after the start of... Alfred Hitchcock's Greatest Shocker Psycho a Paramount Picture".

Mit dieser damals gewagten Filmvorschau inszeniert Hitchcock die Vorschau selbst als einen großen, makabren, aber unterhaltsamen Scherz, bei dem er ganz im Sinne seiner Suspense-Theorie zwar verrät, dass etwas Schlimmes und Grausames passieren wird, aber bewusst konkretere Hinweise auslässt, sodass in der Antizipation des Schocks und Horrors Anspannung und Aufregung steigen. Miles' Schrei funktioniert hierbei weniger als intermedialer Verweis auf den Duschmord, sondern ihr Schrei steht vielmehr für das Genreversprechen, das sich auch die Thrill-Erfahrungen des Publikums in Schreien äußern werden. Hitchcocks Selbstinszenierung im Trailer kündigt nach Jancovich Psycho weniger als Film desjenigen Regisseurs an, der zuvor North by Northwest, Vertigo (1958) und Rear Window gemacht hat, sondern vielmehr als Film desjenigen ,Alfred Hitchcock', den das Publikum aus der Fernsehreihe Alfred Hitchcock Presents kennt (,Rational Fears“ 258). Zugleich finden sich die Horroranleihen, die Jancovich in der Serie bereits entdeckt, in einer deutlichen Horrorrhetorik (,,sinister looking“, „horrible events“, ,too horrible to describe“) wieder. Der komödiantische Tonfall setz dem taktisch die Gegenrhetorik entgegen, dass der Film und die Horrormarkierungen nicht zu ernst zu nehmen seien. Passenderweise agiert Hitchcocks im Trailer wie ein ,roly-poly ringmaster of a macabre circus of horror" 

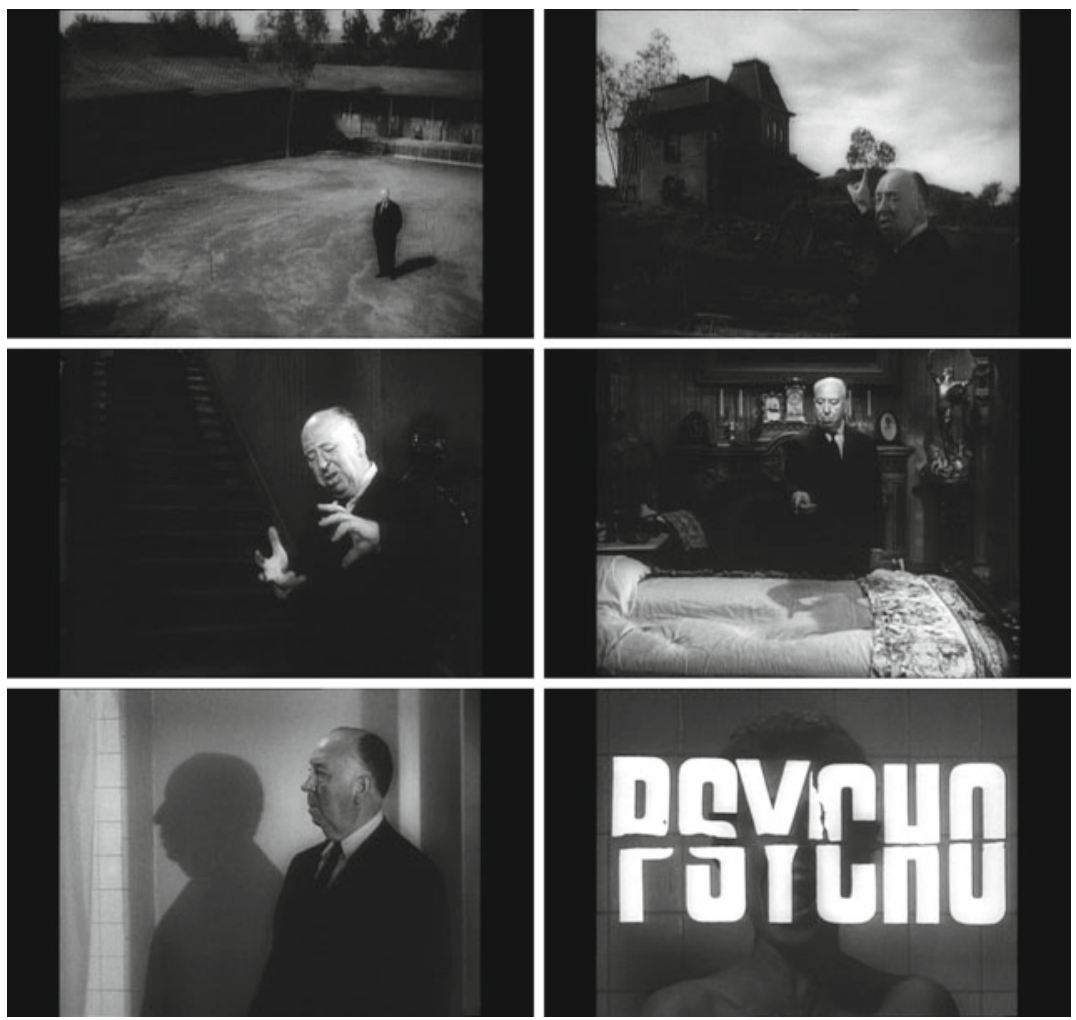

Abb.3.3a-f Trailer zu Psycho, „Das House of Horror“, USA 1960

(Rebello 149), der den Film sowohl als Horrorfilm ausstellt, aber zugleich ironisch davon distanziert. Dieser ironische Umgang mit der eigenen Genresignatur kann letztlich als gezielte Strategie angesehen werden, um die geringe kulturelle Wertschätzung für das Horrorgenre zu umgehen, ohne auf genrespezifische Schokelemente zu verzichten. Vor allem für Hitchcocks älteres Publikum bietet eine solche Gegenlektüre die Möglichkeit, Psycho als Film des ,Master of Suspense“ zu lesen.

Auch wenn die Gesten und Mimiken, die Beschreibungen wie ,most horrible event" und „too horrible to describe“ begleiten, komische Effekte erzeugen, 
bleiben Merkmale des Schocks, Thrills und Horrors als zu erwartende Wahrnehmungserlebnisse erhalten, die in ihrem affektiven Ausmaß eben nicht ,nacherzählt' werden können, sondern ,erlebt' werden müssen. In diesem Erleben, das Williams als „sensational fun“ (,Discipline and fun“ 353) beschreibt, wird der komödiantische Tonfall wiederum zum Horrorversprechen, dem es eben weniger um kohärente Figuren und Handlungen geht als vielmehr um das Vergnügen an der Angstlust, auf das nachfolgend noch einmal eingegangen wird. Zuvor erfolgt ein Blick auf die Plakate, die entlang einer dichten Semantik explizitere Genrebezüge vornehmen.

Auf den Plakaten bildet eines der auffälligsten visuellen Elemente das Design des Filmtitels, das nicht nur im Plakat vorkommt, sondern auch auf allen anderen Materialien zu Psycho prominent platziert ist. Das Design stammt ursprünglich von Tony Palladino, der Teil einer jungen Generation an Werbegestaltern war, die Mitte der 1950er Jahre, inspiriert vom Bauhaus und Abstrakten Expressionismus, eine neue moderne Werbeästhetik hervorbrachten. Seine Gestaltung wurde von der New York Times in einem 2014 anlässlich seines Todes erschienen Artikel als „one of the most iconic typographic titles in publishing and film history“ (S. Heller) beschrieben. Palladinos Konzeption des Psycho-Titels erscheint zuerst auf dem Buchcover von Robert Blochs gleichnamigem Roman, bevor sie in horizontaler Ausrichtung auch für Psycho übernommen wird. Die Titelgestaltung erinnert in ihrer Ästhetik an ein Erpressungsschreiben, bei dem die zerrissenen Großbuchstaben wieder zusammengeklebt wurden. Das Titeldesign übersetzt den mörderischen Wahnsinn der Hauptfigur Norman Bates in eine zerfetzte Buchstabenästhetik, in der sich die zerrissene Identität und die , slashing'-Gewalt seiner Messerangriffe widerspiegeln. In der syntaktischen Knappheit des Worts lässt sich ein semantisches Bedeutungsspektrum ausmachen, das von einer psychosozialen Störung bis zu mörderischen Dimensionen reicht. Diese hängen stark mit der Diskursgeschichte des Lustmords und seiner psychoanalytischen Diagnostik zusammen, die seit dem 19. Jahrhundert als kriminologisches Phantasma forensische, psychiatrische und psychologische Diskurse befeuern und zu einem kulturellen Phänomen aufgestiegen sind. Auch wenn, wie Irina Gradinari herausarbeitet, die psychosexuelle Deutung von Serienmorden in der Kriminologie und Psychiatrie wie Psychologie längst nicht mehr zur gängigen Praxis gehört, bildet sie in der Populärkultur weiterhin einen beliebten Topos („Lust an Gewalt?“, insbesondere $46 \mathrm{ff}$.). Die Syntax und Gestaltung des Titels rufen dieses Topoi semantisch auf, das sich über die wiederholte Platzierung in den Materialien zu einem visuellen Reizbild verknüpft und ähnlich der Produktwerbung ein narratives Image prägt (Hediger, ,Verführung zum Film“ 173). 
Plakate, Trailer, Printanzeigen und Aushangfotos bauen den Titel zu einer übergreifenden genrespezifischen Schlüsselsemantik im Sinne eines key artSymbols auf, das Psycho auf ein Schlüsselmotiv reduziert und eine unmittelbare Wiedererkennung und genrespezifische Identifizierung ermöglicht (ebd. 174). Im Laufe der Zeit gewannen die Semantik und mediale Präsenz dieser Titelästhetik zudem an historischer Bedeutung. Die Sequels Psycho II-IV und das Remake Psycho von Gus Van Sant ziehen dieses Titeldesign der filmischen PsychoTitelsequenz von Saul Bass vor. Die zerrissenen Buchstaben tauchen nun nicht mehr nur im Trailer und auf den Plakaten auf, sondern auch in den filmischen Titelsequenzen der Sequels und auf allen DVD- und Blu-ray-Editionen zu Psycho, den Sequels, dem Remake, den Dokumentationen Psycho Legacy sowie 78/52 und dem Biopic Hitchcock (Abb. 3.4). Die hohe generische Semantik des Titel generiert sich aber nicht allein aus der diskursiven Anknüpfung an populäre Diskurse des Lustmords. In ihrer marketingstrategischen Nutzung wie auch in der späteren historischen Funktion steht sie in Verbindung mit weiteren audiovisuellen Elementen und Semantiken, die weitere Genremarkierungen bereithalten.

Abb. 3.4 Das zerrissene

Titeldesign

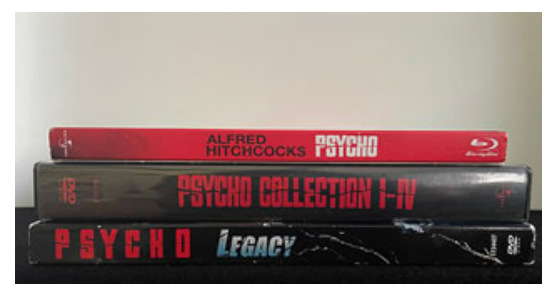

Innerhalb der Plakate korrespondiert der Titelzug mit Szenenbildern, Castsowie Regie-Credits und weiteren Schriftzügen, die wie Bildfetzen collagenartig montiert sind (Abb. 3.5). Die Szenenbilder bestehen aus gerasterten Halbtonaufnahmen von Janet Leigh und John Gavin, beide halbnackt in Unterwäsche bekleidet beziehungsweise mit freiem Oberkörper, sowie Werbeporträtaufnahmen von Anthony Perkins und Vera Miles, die mit vor dem Mund gehaltenen Händen Schreie unterdrücken. In den von Entsetzen gezeichneten Gesichtern von Perkins und Miles werden die dargestellten Angstschreie - äquivalent zum Schrei aus dem Kinotrailer - visuell ,hörbar'. ${ }^{33}$ Sie veranschaulichen darin stellvertretend für das Publikum eine zu erwartende Aufregung. „A New - And Altogether Different - Screen Excitement" verspricht der Schriftzug hierbei nicht nur im

\footnotetext{
${ }^{33}$ Das Bild von Vera Miles findet sich zudem auf dem Frontcover der Reclam-Ausgabe zum Horrorfilm (Vossen) wieder.
} 
Sinne des Grauens, sondern auch der Erotik: „These photographs, besides being unambiguous, were to shatter taboos by becoming the first blatantly ,suggestive" photographic images ever to advertise a mainstream Hollywood feature." (Rebello 152). Mit dieser offenen Ausstellung gestalteten sie Sex, der im Film letztlich nur einen geringen Anteil einnimmt, zu einer weiteren Attraktion auf den Plakaten.

Abb. 3.5 Plakat zu

Psycho, 1960 Paramount

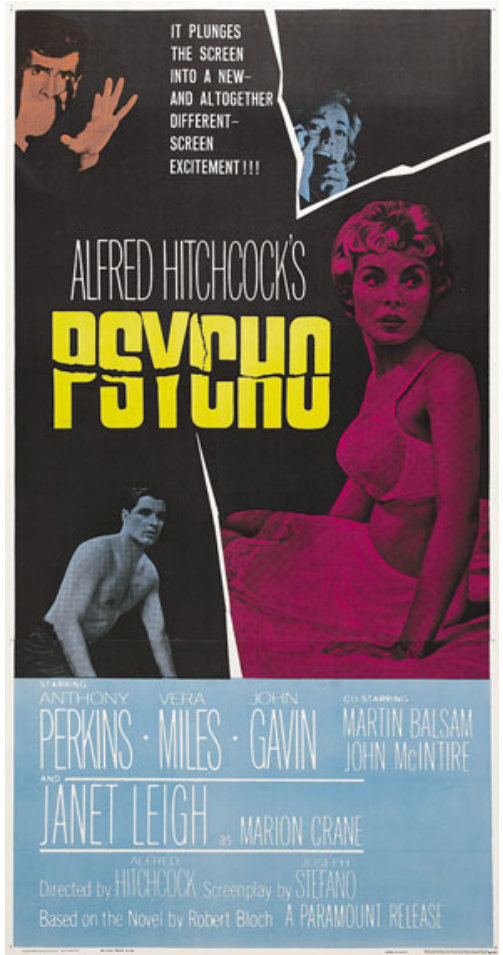

Insgesamt nehmen der Trailer und das Plakat mehrere genrespezifische Markierungen vor, in dem sie mit unbeschreiblichen Schockeffekten rhetorisch (Hitchcock), auditiv (Trailer) und visuell (Plakat) werben. Diese Exploitationpraktiken des Horrorkinos greifen des Weiteren (populär-)kriminologische Diskurse und den damaligen Sensationsjournalismus auf, der um reale Serienmörder wie Ed Gein betrieben wurde und auch die Vorlage für Blochs Roman bildet. Werden den Horrormarkierungen im Trailer Hitchcock-affine Konventionen der Suspense 
und des Makabren gegenübergestellt, erfolgt in den Plakaten eine genrespezifische und sexualisierte Ausweitung des Exploitativen durch ,hörbare' Schreie und halbnackte Darstellungen. Hierbei zeigt sich, wie sich gerade das Horrorgenre als Bezugsgröße durch die Materialien zieht und die Markierungen über Bezüge auf bestehende Werbepraktiken und populäre Diskurse rhetorisch und semantisch konstruiert sind. Inwiefern die Psycho Policy insgesamt einer generellen Tendenz des Kinos zum Sensationellen unterliegt, bei der die Werbekampagne selbst zur besten Werbung für den Film wird, soll abschließend diskutiert werden.

\subsubsection{Disziplinierungsmaßnahmen und Aufmerksamkeitsgeneratoren}

Auch wenn die Marketingstrategien nicht so unkonventionell sind wie dies in den Werbematerialien angepriesen wird - gerade für ein jüngeres Publikum, das sich mit Low-Budget-Horrorfilmen auskennt - erfüllen sie die Konventionen, um als ,reißerische“ Genremarkierungen wahrgenommen zu werden. Zwar fällt der Film selbst im Vergleich zu den besonders auf Plakat und im Trailer ausgestellten Schockmomenten aus Gewalt und Freizügigkeit viel gesitteter aus. Dennoch bleibt Psycho angesichts von Hitchcocks kritik- und publikumsfreundlichem Image eine ungewöhnliche Genrewahl; ,significantly, with the lowest budgeted film of his American career and the least glamorous stars" (Paul 33). Aus diesem Grund muss Hitchcock sicher gehen, dass seine Reputation als ,Entertainer' eines unterhaltsamen Krimi- und Suspense-Kinos nicht die Wahrnehmung von Psycho verstellt und einen Kinoerfolg verhindert, wie es zuvor bei Vertigo (1958) geschehen war. Mit der Psycho Policy verlieren zuerst Presse und Filmkritik an Privilegien und Vormachtstellung, bevor Hitchcock entlang eines gezielten ,Genre-Setting' nicht nur verschiedene Publikumsgruppen anspricht, sondern die Werbekampagne selbst zur Sensation macht. Der Erfolg der Kampagne spiegelt sich in den Einnahmezahlen wieder: Laut IMDb spielt Psycho 30 Millionen Dollar an den US-amerikanischen Kinokassen ein und weltweit sogar 50 Millionen, womit er das Vielfache seiner Produktionskosten wieder hereinholt („Psycho“). Die gezielte Ausrichtung der Kampagne entlang genrespezifischer Praktiken und Semantiken geht auf. Die Psycho Policy steigert das nationale sowie internationale Interesse für einen Horror- und Thrill-SuspenseFilm, weil sie ein soziales Ereignis kreiert, das es nicht zu verpassen und an dem es teilzuhaben gilt. Angezogen von diesem sozialen Ereignis lassen sich die Zuschauer willentlich auf feste Anfangszeiten disziplinieren, um sich den versprochenen Horror- und Thrill-Effekten auszusetzen. Die vermittelte Notwendigkeit, 
den Film von Anfang an zu sehen, implementiert feste Regeln für den Kinobesuch, aus denen zwei wesentliche Konsequenzen abzuleiten sind: Zum einen steuert sie das Kinoverhalten des Publikums hin zu einem pünktlichen Erscheinen, in dem die Aufführungszeit zu einem fixen Ereignis werden, nach dem sich das Publikum zu richten hat, wenn es die Vorführung besuchen will. Zum anderen verkehrt sie die Freiheiten des Publikums, das zuvor als Laufpublikum zu jeder Zeit in eine Filmvorführung gelassen wird, in eine disziplinierte Verhaltensweise um (Williams, „Discipline and fun“ $364 \mathrm{ff}$.). Indem sich das Publikum diesen Disziplinierungsmaßnahmen unterwirft, ergeben sich neue Kinoformationen in Form langen Warteschlangen. Das wartende Publikum, die engagierten ,Wächter' und die lebensgroßen Hitchcock-Aufsteller arrangieren nicht nur die Abläufe des Kinobesuches auf diese Weise neu, sondern führen auch zu veränderten Erfahrungs- und Erlebnisstrukturen und bewirken einen neuen Grad an Affektivität (Williams, „Discipline and fun“ 372).

Historisch gesehen lassen sich an Psycho mehrere wichtige Wendepunkte verdeutlichen. Für Williams geht mit Psycho eine Verquickung aus Disziplinierung und Angstlust einher, die bereits Ende der 1950er Jahre bei den neuen Achterbahnen in Disneyland in Form langer Warteschlangen zu beobachten war:

Just as the newly thematized roller coasters such as the Matterhorn and the later motion-simulation roller coasters such as Star Tours base their thrills on destabilizing movement through real, or simulated, narrativized space, so a film such as Psycho introduced, long before the Blockbusters Schatz describes as defining the New Hollywood, what might be called a roller-coaster concept to the phenomenon of film viewing. (Ebd. 358)

Innerhalb der Geschichte des amerikanischen Kinos nimmt Psycho des Weiteren eine historische Stellung ein, in der das Mainstreamkino angesichts der zunehmenden Konkurrenz mit dem Fernsehen und den Freizeitparks neue visuelle Attraktionen schuf: „In this moment visual culture can be seen getting a tighter grip on visual pleasures of film spectators though the reinstitution of a postmodern cinema of attractions.“ (Ebd. 367) Psycho steht damit im Kontext eines neuartigen Kinos der Sensationen, das in den Materialien eine spannungsgeladene Mordgeschichte mit nervenzerreißenden Horroreffekten und ausgestellter Sexualität zusammenführt und dem Publikum diese als grenzüberschreitende Erfahrungen aus Thrill und Schock anbietet. Die Durchsetzung von festen Anfangszeiten, die mit Psycho etabliert werden und die durchlaufende Aufführungspraxis ablösen, ist für diese neue Kinoerfahrung des ,sensational fun" entscheidend. Die dabei so prominent in den Materialien geführten Attraktionswerte aus Schock, Gewalt und Sex gehen in Psycho eine verhängnisvolle 
Verbindung ein, bei der mit der Auflösung des Mordes auch das sexuelle Geheimnis gelüftet wird. Dieser neue Sensationalismus schreibt nach Williams eine Mischung aus Sex und Gewalt fest, die für Slasherfilme paradigmatisch geworden ist:

Psycho thus needs to be seen not as an exceptional and transgressive experience working against the classical norms of visual pleasure but rather as an important turning point in the pleasurable destabilizing of sexual identity within what would become the genre of slasher horror: it is the moment when the experience of going to the movies began to be constituted as providing a certain generally transgressive sexualized thrill of promiscuous abandonment to indeterminate, ,other“ identities. (,Discipline and fun“ $361 \mathrm{f}$.)

Innerhalb der Filmvermarktung ist also eine weitere Schlüsselstelle auszumachen, weil Psycho für ein Mainstreamkino unkonventionelle Werbestrategien salonfähig macht und Disziplinierungspraktiken für den Kinobesuch durchsetzt. Dabei haben die Materialien zu Psycho gezeigt, wie diese Strategien und Praktiken genrespezifische Konventionen eines Low-Budget-Genrekinos darstellen, mit denen gezielt Genremarkierungen quer durch das Marketing eingesetzt wurden. Dabei orientiert sich die Platzierung an den publikumsspezifischen Informations- und Kinopraktiken, indem Hitchcocks generisches branding als ,Thrill and Suspense'-Regisseur samt seiner makabren Komik vor allem innerhalb der Printanzeigen und im Trailer vorkommen. Dagegen markiert der Trailer zusätzlich ein effektvolles Horrorkino als erwartbare Wahrnehmungserlebnisse, das auf den Plakaten semantisch aufgeladen wird und mit der Secrecy Policy und den Wächtern horrortypische Gimmicks bereithält. In diversen Formen wie Titeln, Bildern, Persona und Rhetoriken lassen sich also Genremarkierungen finden, die durch die gegenseitigen Bezugnahmen und transmedialen Verbindungen einen doppelten Genrediskurs aus einem Low-Budget-Horrorfilm und einem Mainstream-Suspense-Kino aufbauen. In der Zusammenführung öffnen diese Genres wechselseitig Publika, sodass Horror einem breiteren Publikum und Hitchcock einem jüngeren Publikum zugänglich wird, während zugleich das Horrorgenre wieder für Hollywood attraktiver wird und sich der Standard für Low-Budget-Schwarzweiß-Schocker komplett verändert (Heffernan 105). Über die sensationsgeladene Aufbereitung im Marketing erhalten nicht nur Psycho, sondern auch die Genrekonzepte eine medienwirksame Aufmerksamkeit, wodurch sie eine ,verquickende“ neue Dynamik entfalten und Psycho paradigmatisch für die Genres werden lassen.

$\mathrm{Zu}$ dem neuen kollektiven Kinoerlebnis, das Psycho schuf, zählt also nicht nur die im Kino konkret zu erfahrende neue ,Angstlust ${ }^{\text {', }}$ sondern insbesondere die Materialien der Psycho Policy sorgen für eine genrespezifische und antizipierende 
Erwartungshaltung. Denn erst das Wissen um den zu erwartenden Effekt und das Warten - sowohl vor dem Kino als auch im Kinosaal - auf das eintretende Schockmoment bewirken die richtige Anspannung im Vorhinein, die sich dann in gesteigertem Ausmaß entladen kann. Inwiefern die nachfolgenden Genrediskurse diese ,Entladung ' beschreiben und Psycho als Genreproduktion diskursivieren, wird im nächsten Kapitel deutlich.

\subsection{Psycho im Spiegel seiner Genrediskurse und Genresignaturen}

Indem sich in Psycho, ähnlich wie auch im gleichzeitig erschienenen britischen Film Peeping Tom (1960), die Figur des Norman Bates als psychisch gestörter Täter herausstellt, wendet sich der Film wie eingangs hervorgehoben von den bis dato für den Horrorfilm genretypischen übernatürlichen Monstern, Zombies, Geistern, Dämonen und Vampiren ab, die aus weiter Ferne in die heile Welt eindringen. Zugleich führt der Film ein Verwirrspiel mit den Zuschauenden, denn bevor Norman Bates als ,neue' Hauptfigur und spätere mörderische Persönlichkeit den Fokus des Films einnehmen kann, muss erst noch der Star des Films sterben. ${ }^{34}$ Dafür vollzieht der Film in der ersten Hälfte eine in narrativer wie ästhetischer Hinsicht radikale Wendung, die sich mit dem Mord an Marion Crane in der berühmt gewordenen Duschszene des ,Stars` entledigt und die Perspektive auf den schüchternen Motelbesitzer Norman Bates verschiebt. ${ }^{35}$ Es ist nicht allein der Bruch mit der zur damaligen Zeit geläufigen Regel, dass der Star niemals vor der letzten Filmrolle zu sterben hat (Palmer 18), sondern auch die Drastik an Gewalt, mit der dieser Regelbruch zelebriert wird und als ,one of the bloodiest murders" für Aufsehen bei Publikum und Filmkritik sorgt. Inzwischen gilt die Duschszene als ,the greatest shock effect in the history of cinema" (Naremore, „Filmguide“ 24) und ,one of the most analysed sequences in all American film“ (Williams, „Discipline and fun“ 360). Trotz der genrespezifischen und formalästhetischen Nonkonformität der Duschszene und ihres diskursiven Aufsehens bemerkt William Rothman jedoch noch Anfang der 1980er Jahre kritisch, dass viele analytische Herangehensweisen an die Duschszene rudimentär bleiben:

\footnotetext{
${ }^{34}$ Der hier gewählte Sprachgebrauch von ,Zuschauenden“ markiert eine geschlechtsneutrale Analysekategorie jenseits heteronormativer Inskriptionen.

35 Der Duschmord erfolgt erst in der 46. Minute, was bei einer Gesamtlänge von 104 Minuten fast in der Mitte des Films angesiedelt ist.
} 


\begin{abstract}
Although the shower murder is perhaps the most celebrated sequence in all Hitchcock's work, it has never, to my knowledge, been subjected to more than rudimentary analysis. Most critics have gone little beyond expressions of astonishment at the number of shots crammed into its minute or so of screen time, failing to note the basic facts about its structure and significance. („Hitchcock“ 292)
\end{abstract}

Mit der frühen Diskursivierung der ästhetischen Grenzüberschreitung als „the grisliest murder scenes", ,the goriest thing" oder auch ,the messiest, most nauseating murders" ist in den Filmkritiken bereits ein Horrordiskurs angelegt. Anders formuliert lassen sich die Kritiken retrospektiv mit dem Horrorgenre als eine zelebrierte Form ästhetischer wie affektiver Grenzüberschreitung (Podrez, „Der Horrorfilm“ 6 ff.) bereits genrespezifisch lesen, was im Folgenden in Bezug auf die theoretisch-analytischen Diskurse zu Psycho ausgeweitet wird. Hierbei steht nicht mehr nur die Duschszene im Fokus, sondern der gesamte Film und die in den Diskursen identifizierten Genremarkierungen und -semantiken. Denn nicht nur in der Duschszene, sondern im gesamten formalen Arrangement erscheinen für Kolker experimentelle Züge offensichtlich:

This is what makes Psycho such an important film. It was an experiment in form that was a commercial success. It was built to generate an emotional charge that cannot be ignored not matter how often it is seen. Few films before it had such a shocking effect on their audience. (,Introduction“ 24)

Ein heutiger genreanalytischer Blick auf Psycho kann jedoch weder im wissenschaftlichen noch im populären Kontext mehr unabhängig von theoretischanalytischen und historischen Diskursivierungen erfolgen. Aus diesem Grund richtet sich die Genreanalyse von Psycho auf die bereits erfolgten diskursiven Durchdringungen des Films, die nicht nur die Duschszene als großes Schockmoment beschreiben, sondern weitere generische Markierungen wie unter anderem das Liebespaar, das gestohlene Geld, die Ermittlungen, weitere Morde und „Mothers" Stimme fokussieren. ${ }^{36}$ Im Spiegel der ausgewählten Analysen zeigt sich nicht nur - so die These dieses Kapitels - wie Psycho als generischer Text auch das Ergebnis dieses wissenschaftlichen Genrediskurses darstellt, sondern die Genrediskurse sich zugleich aus der Semantisierung textueller Markierungen generieren. Dafür wird die folgende Diskursanalyse auf diejenigen Texte eingegrenzt, die ein theoretisch-analytisches Erkenntnisinteresse auf der Mikroebene

\footnotetext{
${ }^{36}$ Die Schreibweise von „Mother“ bezieht sich auf Normans psychopathologische Imagination und Verkörperung seiner (toten) Mutter als lebendige und mit ihm interagierende Persönlichkeit hin. Die doppelten Anführungszeichen referieren auf Normans Anrufung seiner Mutter als „Mother“.
} 
von Einzelanalysen verfolgen. Dazu gehören allerdings nur wenige dezidiert genretheoretische Analysen zu Psycho, die zudem meist nur einige Seiten umfassen (Höltgen 162-174; Jancovich „Rational Fears“ 295-301; S. Koebner; Mecke; Pabst; Seeßlen, „Filmwissen: Thriller“ 144-151). Das Manko an genretheoretischen close readings ist auf die diskurshistorische Entwicklung der Genretheorie zurückzuführen, die systematische Züge erst Ende 1960er Jahre annimmt und zum Horrorfilm erst ab den 1980er Jahren umfangreichere Studien hervorbringt; zwar zementieren diese Psycho's prototypischen wie ikonischen Genrestatus, aber greifen für close readings auf gegenwärtigere Fallbeispiele zurück. ${ }^{37}$ Psycho's generischer Vormachtstellung fehlt es bemerkenswerterweise an einer entsprechenden Diskursivierung, die auf der Mikroebene exemplarischer Genreanalysen operiert. Aus diesem Grund werden close readings aus anderen theoretischen Feldern herangezogen, die Psycho ausführlicher analysieren, und diese entlang einer ,diskursanalytischen Genreanalyse ' operationalisiert. Von den autorenbezogenen Studien werden neben dem Vorreiterbuch von Wood (,Hitchcock's Films“), Naremores Handbuch (,Filmguide“) und Rothmans ausführlicher Einzelbildanalyse von Psycho (,Hitchcock“), die vorherigen Arbeiten noch analytische Defizite bescheinigt, zusätzlich die deutsche Einführung von Heller (,Hitchcock") herangezogen. Mit Elisabeth Bronfens Kulturgeschichte des Nabels und Slavoj Žižeks Lektüre von „Lacan mit Hitchcock“ werden ,psychoanalytisch orientierte“ Kulturtheorien der jüngeren Diskursgeschichte einbezogen. ${ }^{38}$ Während Bronfen eine Umschreibung der psychoanalytischen Theorie vornimmt und Psycho als eine postmoderne Version des König Ödipus liest (55-73), kehrt Žižek die psychoanalytische Interpretation von Hitchcocks Filmen um und verdeutlicht anhand filmischer Beschreibungen Lacansche Konzepte (Umschlag). Die ausgewählten Texte werden entlang von zwei Aspekten strukturiert: Einerseits wird eine generische Metaperspektive eingenommen, bei der die jeweiligen Theoreme und Differenzen in den Hintergrund treten, um aus den filmisch ausgemachten Detailbefunden genrespezifische Beschreibungssemantiken herauszuarbeiten. Anderseits bildet der Film selbst den roten Faden, sodass keine diskurshistorische Chronik wiedergegeben wird, sondern vielmehr die multiplen Genremarkierungen und ihre genrespezifische Diskursivierung im Zentrum stehen. Ziel ist es, einen

\footnotetext{
${ }^{37}$ Häufig steht die Ebene des Genrekonzepts im Vordergrund (Clover; Modleski; Tudor, „Monsters“; Seeßlen/Jung).

${ }^{38}$ Siehe auch Bellour, Klinger und Modleski. Dabei schließen sich die Lektüren keinesfalls aus. Insbesondere die Horrortheorie weist eine Reihe psychoanalytisch orientierter Ansätze auf (u. a. von Creed und Williams). Ebenso versuchen psychoanalytische Kulturtheorien Dimensionen des Abjekten (u. a. bei Kristeva) zu erklären, die wiederum zu beliebten Topoi des Genres geworden sind.
} 
weiteren Genrediskurs von Psycho herauszuarbeiten und in seinen Semantisierungen aufzuschlüsseln, um neben der generischen Ausgangssituation, der Filmkritik und den Materialien ein weiteres Puzzleteil innerhalb der gesamten diskursiven Anordnung aufzudecken: den wissenschaftlichen Genrediskurs auf der Ebene der Genreproduktion. Hierbei gerät auch die Duschszene wieder in den Fokus. Bereits in den vorherigen Diskursen lässt sich ein vielfältiger Umgang beobachten, der die Duschszene einerseits als generische Ausnahme hervorhebt (Filmkritiken), anderseits als generisches Geheimnis behandelt (Materialien), demgegenüber markiert sie in der Genregeschichte eine generische Wende- und Ausgangsstelle. Bevor die Duschszene entlang der Diskursivierung ihrer Thrill- und Schockaffekte ins Zentrum rückt und den Anfang einer Reihe weiterer Horrormomente bildet, erarbeitet die Analyse zuerst die im Film identifizierten multiplen Genremarkierungen. Die psychiatrische Diagnose und die doppeldeutigen Bilder im Filmende bieten schließlich eine Semantik des Unheimlichen an, die als lose Erklärungsmuster für den dargestellten Wahnsinn erfasst werden. ${ }^{39}$ Inwiefern die multiplen Genremarkierungen und -semantiken in einem übergeordneten Genrespiel aufgehen, das gezielt Erwartungen und Verwerfungen unterliegt, wird abschließend beleuchtet.

\subsubsection{Generische Markierungen und Verwerfungen}

Am „Friday December the Eleventh“ um „Two Forty-Three P.M.“ - wie der Film zu Beginn über Luftaufnahmen von Phoenix exakt verrät - gleitet der Kamerablick hinab zu einem Gebäudefenster und dringt mit einem „natural appetite“ (Rothman, „Hitchcock“ 252) durch die Jalousien hindurch in die Privatsphäre des noch halbnackten Paares Marion Crane und Sam Loomis ein. ${ }^{40}$ Angesichts der willkürlich erscheinenden Wahl dieses Fensters, das auch ein anderes hätte sein können und das gleichermaßen zufällig und alltäglich erscheint wie auch Stadt und Uhrzeit, stellt Robin Wood fest: „Arbitrary place, date and time, and now an apparently arbitrary window: the effect is of random selection: this could be any place, any date, any time, any room: it could be us.“ („Hitchcock's Films“" 106; Herv.i.O.). Mit dieser Eröffnungsfahrt zieht der Film in eine Liebesgeschichte hinein, die in ihrem normalen Setting zwar „ordinary enough“ (ebd. 107) ist, sich als generisches Angebot aber als aussichtslos darstellt. Sams Insistieren gegen die

\footnotetext{
${ }^{39}$ Zum Diskurs des Unheimlichen siehe Lehmann.

${ }^{40}$ In William Rothmans Einzelbildanalyse des gesamten Films kommt der Kamera eine physische Präsenz, eine „corporeal presence“, zu, deren Bewegungen über eine auffällige Eigendynamik verfügen und die Rothman als „,body“ und „the camera's natural appetite“ beschreibt (,Hitchcock“ 251 f.).
} 
gemeinsame Heirat verweigert ihm eine Rolle als „,romantic hero of the film“, die für Wood darin besteht, über die miserablen finanziellen Umstände hinwegzusehen und „to accept things as they are for the sake of the relationship“ (ebd. 107). Stattdessen erhält der Film mit Sams romantischem Versagen, noch bevor Marion das Geld stehlen kann, eine erste räuberische Dynamik: „This is the first step in our complicity in the theft of the 40.000 dollars. It is Sam's fault that Marion steals the money, which has no importance for her." (Ebd.) Nach Georg Seeßlen beginnt Psycho noch wie ein „konventioneller Thriller“, bei dem sich mit ,dem Heraustreten aus der kleinbürgerlichen Identität“ eine gefährliche Wendung andeutet (,Filmwissen: Thriller“ 145). Marion entwendet das Geld, statt es auf die Bank zu bringen. In ihrer Wohnung liest es Elisabeth Bronfen als „Markierung für den Schnitt der Gesetzesübertretung von Marion und Cassidy, mit dem beide gesellschaftliche Kodes über Bord geworfen werden“ (57). ${ }^{41}$ Immer wieder rückt das in einem Briefumschlag gesteckte Geld ins Visier der Kamera, die, den prüfenden Blick von Marion aufnehmend, das Geld von allen Seiten betrachtet und als zu verfolgendes Diebesgut visuell einkreist, bevor es in der Handtasche verschwindet (Abb. 3.6a-3.6e). Das nunmehr, illegale Geld“ ist nicht nur zu einem für Bronfen psychoanalytischen Repräsentanten des symbolischen Gesetzesbruchs geworden, sondern auch als generisches Objekt für den nach Seeßlen beginnenden Thriller wiederholend markiert worden. Mit dem Diebesgut ist Marion zur Flucht gezwungen, durch die bei Williams eine romantische Hoffnung auf eine doch noch ,slightly tawdry love story of Marion and Sam“ aufkommt, die im hypothetischen Imaginationsbereich der Zuschauenden bestehen geblieben ist (,Discipline and fun“ 355). Auf der Flucht mit dem unterschlagenen Geld ist die Heldin, ob in Form des bedrohlichen Polizisten mit Sonnenbrille oder der schlechten Sicht durch die verregnete Windschutzscheibe, immer wieder Irritationen und Ängsten ausgesetzt, welche die Zuschauenden mit ihr in dieser „Apotheose des B-picture-Thrillers“" teilen (Seeßlen, „Filmwissen: Thriller“ 148). Hierbei wird auch das Geld zu einem sichtbaren Medium dieser Ängste: als der Polizist sie auf dem Highway kontrolliert, beim Kauf des neuen Autos und später im Motelzimmer, wenn sie es in Zeitung geschlagen auf den Nachtisch legt (Abb. 3.6f-3.6h).

Zeitgleich zu der Ablage auf dem Nachtisch ertönt erstmals „Mothers“ Stimme aus dem Haus über dem Motel, was für Rothman in eine unheimliche Simultanität mündet: „At the precise moment they lay the paper down, we hear a woman's voice, loud but muffled by distance. [...] The simultaneity of the intrusion of this voice and Marion's guilty gesture is uncanny, as though the voice emanated from Marion's imagination.“ („Hitchcock“274) Diese Verbindung zwischen Diebesgut

${ }^{41}$ Die Lesart des doppelten Gesetzesübertritts findet sich auch bei Jancovich: „Cassidy himself has no more right to the money than Marion.“ (,Rational Fears“ 298) 

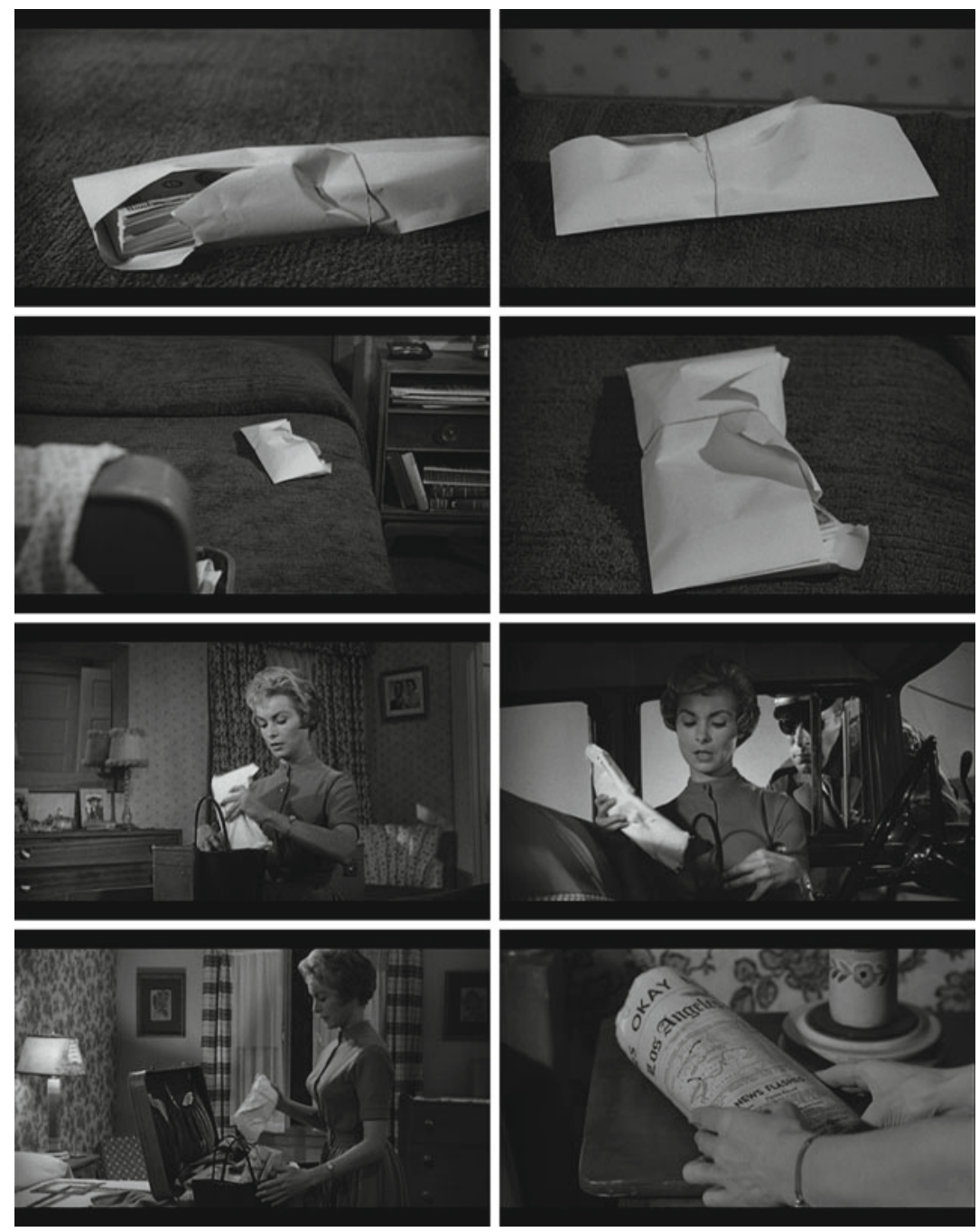

Abb. 3.6a-h Psycho, „Das ,illegale“ Geld als generisches Objekt“, USA 1960 
und „Mother" deutet auf einen ersten Übergang des Thrillers in eine Horrorgeschichte, ,,a turn of violence“ (ebd. 276), denn „Mothers“ wüste Beschimpfungen bleiben keine leeren Drohungen (ebd. 275), sondern überführen die im Kinotrailer anklingende mütterliche Dominanz (,,being dominated by an almost maniacal woman") und späteren voyeuristischen Blicke von Norman (Abb. 3.7a und 3.7b) in eine destruktiv-monströse Semantik:

„Mother”: No! I tell you no! I won't have you bringing some young girl in for supper! By candlelight, I suppose, in the cheap, erotic fashion of young men with cheap, erotic minds! [...] Go on, go tell her she'll not be appeasing her ugly appetite with my food... or my son! Or do $I$ have to tell her because you don't have the guts! Huh, boy? You have the guts, boy?

Nach dem Duschmord wird die Kamera auf das in Zeitungspapier eingeschlagene und auf dem Nachttisch sichtbar liegende Geld erneut zufahren und es ein letztes Mal fokussieren, bevor Norman Marions Leiche und Habseligkeiten in ihrem Auto verstaut. Mit dem eingeschlagenen Geld, das Norman fast übersieht, aber als letzten Gegenstand doch noch rechtzeitig entdeckt, löst sich für Wood Marions letzte ,Spur' auf: „the last lingering trace of Marion [...]: the money, becomes now a mere squalid bundle of paper, an ironic reminder of her life, her desires, her relationship with Sam.“" (110) Mit dieser ,Spur' werden mehrere generische Geschichten als endgültig begraben angesehen: die Raubgeschichte des Thrillers und die Liebesgeschichte.
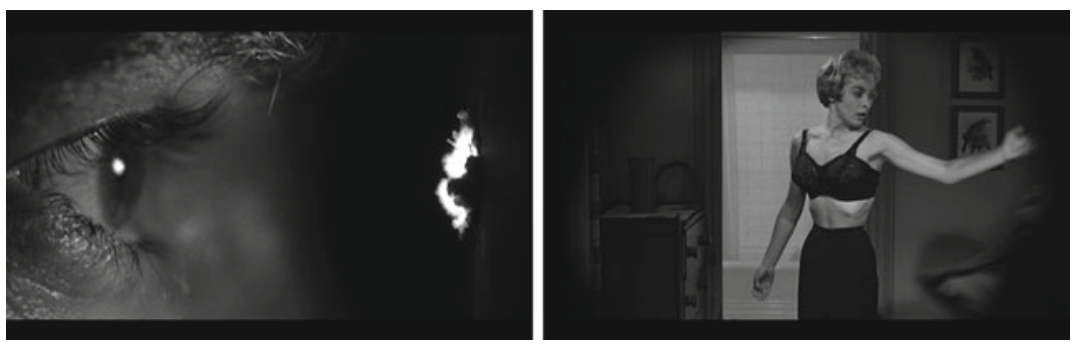

Abb. 3.7a und b Psycho, „Normans voyeuristischer Blick auf Marion“, USA 1960

Zu spät kommt Sams Einsicht, dass ihre Liebe die finanziellen Hürden überwinden kann. Mit der abrupten Aufkündigung der räuberisch-romantischen Heldin 
ist sein Brief sinnlos geworden und seine Figur als ,romantic hero“ ins Tragische verkehrt worden (Abb. 3.8). Psycho führt die potentielle ,Liebesgeschichte mit schrecklichem Ausgang“ (Seeßlen, „Filmwissen: Thriller“ 149) ad absurdum. Das Geld, was die Heldin genommen hat, hätten sie eigentlich nicht gebraucht. Mit Normans Aufschrei „Mother! Oh, God, Mother! Blood! Blood!“ setzt das analytische Gegenstück zum Mord und Verschwinden von Marion ein, das sich im Auftritt von Lila Crane zur Detektivhandlung entwickelt (Jancovich, „Rational Fears“ 299). Bis zu ihrem Erscheinen in Sams Einrichtungsgeschäft in Fairvale aber wirkt der Horror der Duschszene nach, der durch mehrere Umstände nicht nur überaus brutal, sondern auch unerwartet die Hauptfigur und die mit ihr einhergehenden generischen Markierungen auflöst, wie im Folgenden ausgeführt wird.

Abb.3.8 Psycho, ,Sams romantische Einsicht kommt zu spät“", USA 1960

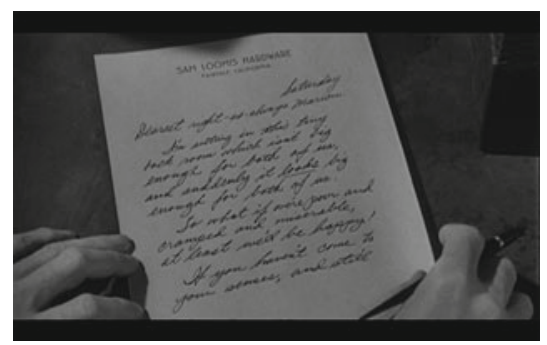

\subsubsection{Die Duschszene im Zentrum des Horrors}

Für das Verständnis der Horrorwirkung muss noch vor dem brutalen Tötungsakt und dessen audiovisueller Rhythmik angesetzt werden. Der Duschszene gehen Marions Autofahrt und ihre Ankunft am Motel voraus, die Franziska Heller als atmosphärischen und emotionalen Vorlauf deutet, bei dem sich das Gefühl der Verunsicherung bereits in audiovisuellen Wahrnehmungsstrukturen ausdrückt: „Wir sehen Marion, wie sie in die Nacht hinein fahrend, geblendet von entgegenkommenden Autos, immer wieder die Augen zukneift. Die Lichter verzerren sich surreal im Zusammenspiel mit dem an den Scheiben abperlenden Regen." (,Hitchcock“ 128) Die Leuchtbuchstaben des „Bates Motel“ (Abb. 3.9), die sich schließlich hinter der verregneten Frontscheibe diffus abzeichnen und für Marion „the only port in this storm“ darstellen (Spoto, „The Art of" 365), erscheinen nach Heller ,trotz aller Merkwürdigkeiten im ersten Moment als eine Beruhigung“ (,Hitchcock“ 129). Dieser surreal hervortretende Ort der Beruhigung bildet das kontradiktorische Setting, in das der Duschmord unerwartet einfällt und das 
in seiner Wirkung durch den vorherigen Umstand der Ruhe verstärkt wird. Der Duschmord kommt nach Williams zudem für diejenigen Zuschauenden gleichsam unerwartet, die der Liebesgeschichte (mit schrecklichem Ausgang) zwischen Marion und Sam folgen. Für Wood ist es die Bedeutungslosigkeit, aus der der Mord ebenso irrational und nutzlos erfolgt wie der Diebstahl:

It is not merely its incomparable physical impact that makes the shower-bath scene probably the most horrific incident in any fiction film. The meaninglessness of it (from Marion's point of view) completely undermines our recently restored sense of security. The murder is as irrational and as useless as the theft of the money. It also constitutes an alienation effect so shattering that (at a first viewing of the film) we scarcely recover from it. Never - not even in Vertigo - has identification been broken off so brutally.“ („Hitchcock’s Films“ 109, Herv.i.O.)

Abb.3.9 Psycho, ,Das

Motel als surrealer Ort der Beruhigung“, USA 1960

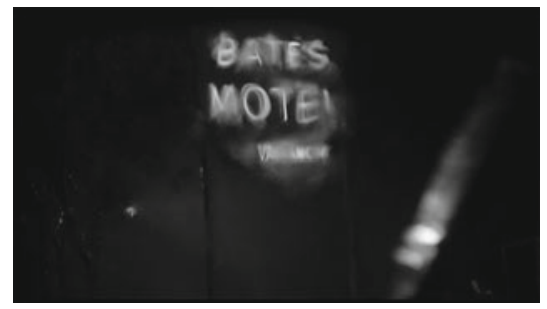

Noch im Gespräch mit Norman beschließt Marion, das Geld zurückzubringen. Mit diesem Entschluss, mit dem sie nach Rothman gegenüber den „oppressive conditions of her existence“ resigniert („Hitchcock“ 294), ist die anschließende Dusche häufig als symbolische Reinigung beschrieben worden, mit der sie sich von Tat und Sünde reinwäscht (S. Koebner 150). Jedoch ist es für Jancovich irreführend, ihre kriminelle Tat mit ihrer Sexualität zu assoziieren. Der Diebstahl richtet sich weniger gegen das Patriachat, sondern folgt vielmehr den patriachalen Wertvorstellungen nach einer , anständigen“ Beziehung (,Rational Fears“ 298). Marions Tötung entspricht demnach keiner Bestrafung im psychoanalytischen Sinn: „To read her killing as a punishment for her sexuality is to claim that women are responsible for men's sexual violence against them, a position which is never encouraged by the film itself." (Ebd.) Eher ist mit Seeßlen der Mord als Strafe für ein begangenes Unrecht zu lesen, aber auch ,diese Deutung wird durch die Absurdität der Motive wieder ad absurdum geführt“ („Filmwissen: Thriller“ 148). Abseits dieser Semantiken kennzeichnet die Dusche einen Ort des Alltäglichen und Privaten, sodass ein ebenso intim-erotischer wie auch ungeschützter Raum zum Schauplatz des Verbrechens wird. In der Dusche ist Marion durch den Duschvorhang, den Rothman als „safety curtain“ (,Hitchcock“ 299) bezeichnet, 
komplett umschlossen (Abb. 3.10a). Mit ihr werden auch die Zuschauenden vom aus dem Duschkopf herausschießenden Wasser umspült (Abb. 3.10b): „We can all but feel the water coursing over our bodies, awakening and arousing us, all but feel Marion's own pleasure, all but become Marion. The shower head's stream and the views of Marion that flow over us are all but one."(Ebd. 295) Marion ist in der Dusche nicht nur von vorn, sondern von beiden Seiten zu sehen (Abb. 3.10c und 3.10d). Den Bildern schreibt Heller eine intensive Wahrnehmungspräsenz zu, in der ,das Rauschen der Dusche allgegenwärtig“ und das Wasser „zum raumgreifenden Element“ wird, das ,(d)urch seine Bewegung und seine Affizierung des Blicks, durch seine diaphane Struktur [...] ständig auf der eigenen Präsenz zu insistieren (scheint)“ („Filmästhetik des Fluiden“ 159). Alles herum erscheint ausgeblendet, durch den Duschvorhang performativ , abgesichert" und durch das gleichmäßige Rauschen und Fließen des Wassers intensiviert.
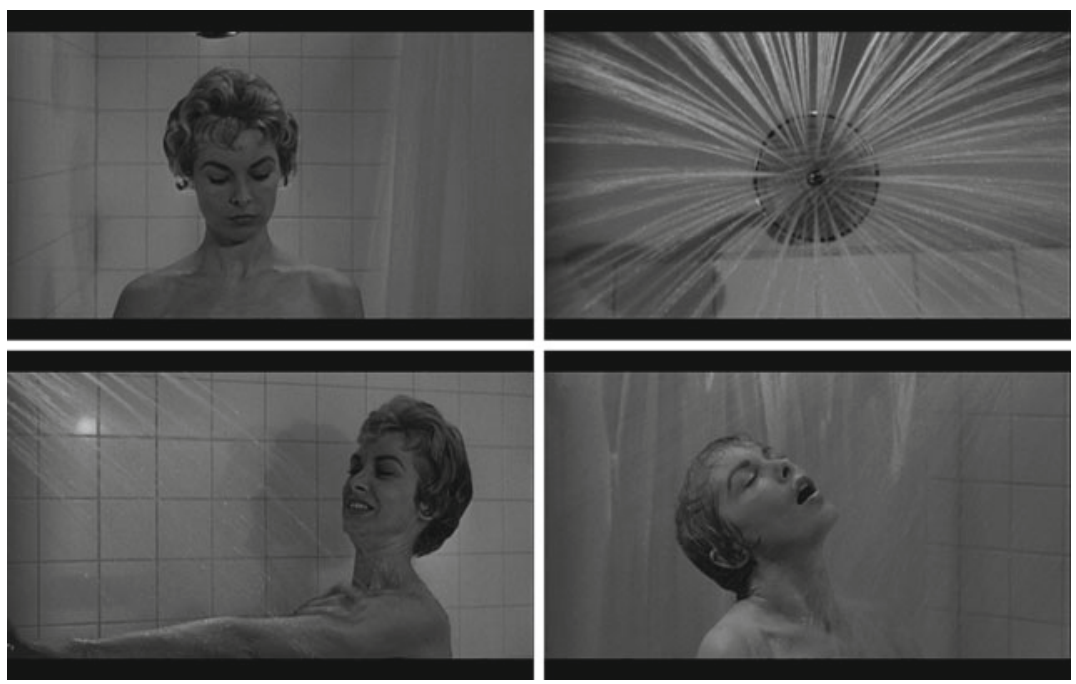

Abb.3.10a-d Psycho, ,Marion in der Dusche“, USA 1960

In dieses beruhigende und berauschende Moment dringt der Mord auf drastische Weise ein. Dabei ereilt die Zuschauenden wenige Sekunden zuvor eine bedrohliche Vorahnung, als sich die Badezimmertür öffnet und eine Gestalt nähert (Abb. 3.11a). Indem die Kamera in der Dusche zwar von Marion weg, aber leicht vorwärts fährt, während die dunkle Gestalt hinter dem Vorhang näherkommt, entsteht für Heller aus dieser beidseitigen Annäherung ,ein Gefühl der Umzingelung, der bedrohlichen räumlichen Fokussierung Marions“ (ebd. 159). Die langsame 

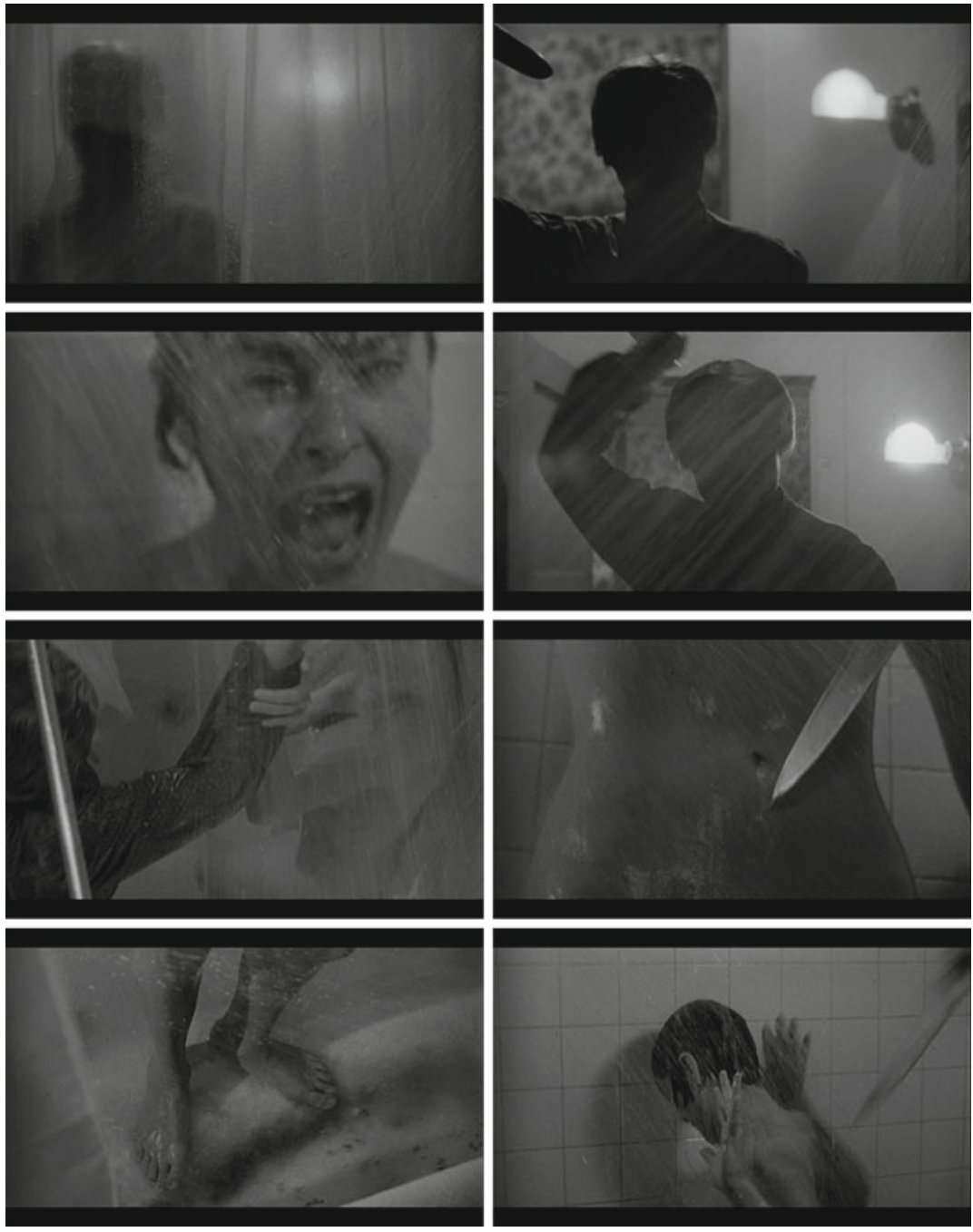

Abb. 3.11a-h Psycho, ,Die , audiovisuelle Tötungssinfonie“ der Duschszene“, USA 1960 
Kamerabewegung scheint das Monströse anzukünden, denn was nach Rothman noch als "safety curtain“ von der äußeren Welt trennt, öffnet sich in einer theatralen Geste und bringt ,,a nightmarish fantasy“ (,Hitchcock“ 299) hervor: Statt einem furchterregenden Gesicht wird nur eine dunkle Silhouette sichtbar (Abb. 3.11b), als würde ein Schatten auf die Leinwand fallen (ebd.): „This moment is authentically terrifying because it succeeds in provoking us to the nightmarish fantasy that the scene of murder now commencing is real, and that we are the murderer's intended victim. We are face to face with our own murderer, confronting the imminent prospect of our own death." (Ebd.) In der doppelten Annäherung (Gestalt und Kamera), der theatralen Öffnung des Vorhangs und der unbestimmten alptraumhaften Erscheinung wird den Zuschauenden auf selbstreflexive Weise der Spiegel vorgehalten, der sie mit dem Alptraum vom eigenen Tod konfrontiert. Die Attacke gilt also in erster Linie den Zuschauenden, an deren Blick der Horror ausgerichtet ist, denn sie bezeugen nicht nur den nahenden Terror, sondern bilden selbst Opfer des Angriffs, für den Marions Körper stellvertretend niedergestochen wird. ${ }^{42}$ Die Horrorvision wird in einer außerordentlich pointierten Brutalität vorgeführt, die vor allem über eine gezielte audiovisuelle Rhythmik funktioniert (Heller, „Hitchcock“ 130 f.). Mit dem Auftritt der mordenden Schattengestalt setzen die aufreibend hohen Streicher-Glissandi von Bernard Herrmanns Filmmusik ein, die sich wie messerscharfe ,Violinenschreie' mit den schrillen Schreien Marions und der schnellen Montage des immer wieder in ausholender Bewegung schwungvoll auf Marions Körper einstechenden Messers zu einer audiovisuellen Tötungssinfonie orchestrieren und eine zerstörerische Wirkung entfalten (Abb. 3.11c-3.11h). Der Schrecken wird zwar filmästhetisch an Marions Körper, vorgeführt', aber die spürbare Gewalterfahrung greift am Körper der Zuschauenden: „Not just the body of Marion is to be ruptured, but also the body on the other side of the screen: our witnessing body." (Clover, „Men, Women" 52) Alternierend werden die Zuschauenden sowohl in die Position Marions als auch der Täterin versetzt, sodass sie nach Georg Seeßlen und Fernand Jung „die Furcht des Opfers durch seine Augen“ wahrnehmen (701). Erst durch die Übernahme beider Seiten dieses Terrors, der Angreifenden und der Angegriffenen, entfaltet sich für Clover das ,wahre 'Erlebnis im Horrorfilm: „the force of the experience, in horror, comes from ,knowing " both sides of the story. “43 (,Men, Women” 12)

\footnotetext{
${ }^{42} \mathrm{Zu}$ dieser stellvertretenden Verkörperung im Horrorfilm siehe Williams, „Film Bodies“.

${ }^{43}$ Diese identifikatorische Dopplung bildet bei Clover den Ausgangspunkt ihrer genderbezogenen Theorie des Slashergenres, in dem sowohl mit dem Serienmörder als auch mit dem Final Girl mitgefiebert wird.
} 
Auch während der Tötungsszene ist das kontinuierlich fallende Wasser weiterhin präsent, das für Heller nicht nur visuell eine „Diffusion der Blickstrukturen“ bewirkt, sondern akustisch unter der schrillen Musik gleichförmig weiterrauscht: „so als läge unter dem auditiv quälenden Horror eine fast alltägliche Indifferenz der Umwelt.“ („Filmästhetik des Fluiden“, 160; Herv.i.O.) Diese indifferente Subebene geht nach der Brutalität des Duschmordes in eine filmische „Gleichgültigkeit“ über, in der das Wasser kontinuierlich weiterfließt und -rauscht, „,so als wäre nichts passiert“ (Heller, „Hitchcock“ 131). Die Kamera folgt langsam und ebenso gleichmäßig den fließenden Bewegungen des Wassers, bis links im Bild ein glänzender Abfluss ins Bild kommt, der wie eine ,fluide Spirale eine soghafte Dynamik“ (ebd. 130) erzeugt (Abb. 3.12a). In dieser Gleichgültigkeit und Sogwirkung verkehrt sich der laute und brutale Horror in ein stummes Entsetzen darüber, das die Zuschauenden ihrer Identifikationsfigur beraubt werden: „,Führerlos ' geworden, kämpfen wir um Orientierung, suchen nach Hoffnungen und Auswegen, genießen doch den Strudel [...].“ (Seeßlen, „Filmwissen: Thriller“ 151) Die Wucht der erlebten Tötung und der Schock von Marions Tod verkehren sich zu einer vernichtend gleichgültigen Metaphorik. Mit dem Blut des toten Leinwandkörpers werden auch alle bisherigen generischen Erwartungen förmlich den Abfluss hinuntergespült, wie es Sarris bereits 1960 in seiner Kritik formulierte: „flushed down the drain“ (,Movie Journal“ 6).

Psycho markiert mit der Duschszene einen Erfahrungsraum des Horrors, in dem sich ein bewusstes Thrill- und Schockerlebnis entlädt. „Pointierter Wahnsinn und gleichförmige Alltäglichkeit“ („Hitchcock“ 131) formen in der Duschszene nicht nur für Heller einen nachhaltigen destabilisierenden Effekt, den der Film anschließend nicht mehr einzuholen vermag. Auch für Jancovich bleibt die Schwierigkeit bestehen, Marions Tod als final und definitiv zu akzeptieren: „Whatever one may know about the narrative, there is still a sense of disbelief and an expectation that Marion will somehow return from the dead.“" (Rational Fears“ 299) Wenn dann in das tote Auge von Marion überblendet wird, aus dem in einer spiralförmigen Drehung herausgefahren wird (Abb. 3.12b und 3.12c), übersetzt sich die Desorientierung der Zuschauenden in ein lebloses Auge, das unfähig geworden ist zu sehen und von dem nur noch ein leerer Blick übrig bleibt (Williams, „Discipline and fun“ 355). Mit dem Tod von Marion evoziert der Film eine narrative Leerstelle, bevor die Perspektive auf Norman wandert. Aus einer selbstreferentiellen Bewegung heraus, sich ihrer selbst bewusst und „no longer masked“ (Rothman, „Hitchcock“ 310), löst sich die Kamera von Marions totem Blick und bewegt sich eigenständig durch den Raum bis zum Blick auf das Haus (Abb. 3.12d), aus dem schließlich Normans Aufschrei „Mother! Oh, God, Mother! Blood! Blood!“ erfolgt. Mit einer ähnlichen Gleichförmigkeit wie das 

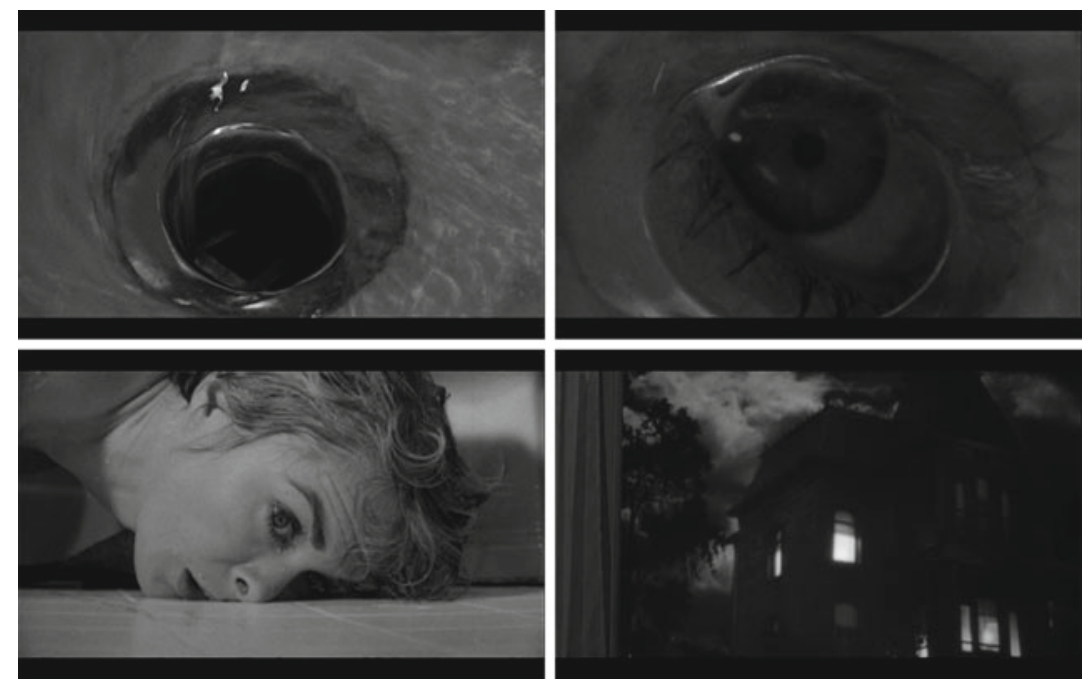

Abb. 3.12a-d Psycho, ,Abfluss und totes Auge“, USA 1960

rauschende Wasser kümmert sich Norman ,fast routiniert“ (Mecke 162) um die Säuberung des Badezimmers und die Beseitigung von Marions Leiche und ihren Habseligkeiten. Bevor ihre Spuren mitsamt der Raub- und Liebesgeschichte vollständig im Sumpf verschwinden, verlockt für Mecke der kurze Moment, in dem der Wagen stecken bleibt (Abb. 3.13a und 3.13b), dazu, mit Norman zu bangen und sich erneut ,,auf die moralisch falsche Seite“ zu schlagen (ebd.).
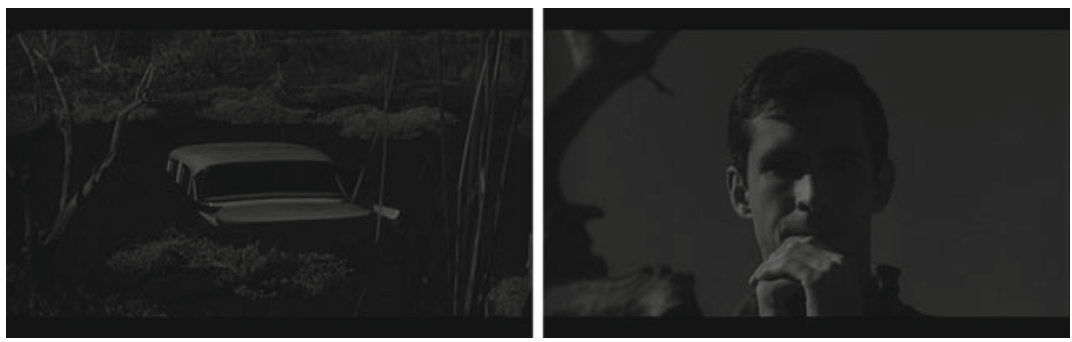

Abb.3.13a und b Psycho, ,Die Verführung mit der ,falschen“ Seite“, USA 1960 
Im weiteren Verlauf wiederholen sich zwar die Schockerlebnisse mit den folgenden Attacken auf den Privatdetektiv Milton Arbogast und Marions Schwester Lila Crane. Sie erreichen aber nicht mehr den explosiven Grad, den der Duschmord in seiner filmästhetischen Drastik und narrativen Plötzlichkeit wie Widersinnigkeit noch hervorbrachte. Für das Publikum ist eine Rückkehr in eine entspannte Haltung nicht mehr möglich, wie Williams feststellt:

This baroque movement, down the drain' and back out of a dead eye, unseeing eye, enacts a spectatorial disorientation that was one of the most striking features of watching Psycho. In a moment this abyss will be filled by a new focus on Norman who will enter to clean up the mess and protect ,Mother'. But from this point on, the audience cannot comfortably settle into a conventional narrative trajectory. (,Discipline and fun” 355)

Für Williams beginnen die Zuschauenden nach diesem Mord, eine antizipierende Position einzunehmen und sich den Rhythmus aus ,anticipation, shock, and release“ (,Discipline and fun“ 356) einzuverleiben, die mit der gezielten Orchestrierung des Duschmords geliefert wurde und sich in den folgenden Mordattacken fortsetzt. ${ }^{44}$ Auf diese sind die Zuschauenden vorbereitet, sodass die Wahrnehmung der weiteren Detektivhandlung von dem (vermeintlichen) Wissen über die destruktiv-monströse Gefahr der Mutter determiniert ist. Die Erlebnisstrukturen des Duschmords durchziehen die Detektivhandlung mit einer genrespezifischen Anspannung, die bis zur Auflösung aufrechterhalten wird. Die Detektivhandlung betrachtet Jancovich als funktionale Rahmung für die nach dem Duschmord stattfindende Ausdifferenzierung der Geschichte, die mit der Figur der Lila Crane ein ,surrogate for the audience's supposed desire for an explanation of the mystery" (299) bereithält, aber sonst kaum identifikatorische Tiefe anbietet (,Rational Fears“ 299) ${ }^{45}$ Diese fehlende Tiefe ist nach Williams für den Thrill nicht nötig („Discipline and fun“ 356). Die detektivische Handlung zielt schließlich in den Mord(versuch)en auf Arbogast und Lila für Jancovich auf zwei zentrale Schockmarkierungen („Rational Fears“ 299).

Den zweiten Mord an Arbogast sieht Slavoj Žižek im Gegensatz zum Überraschungsmoment des Duschmords als Schockmoment in einem ,geometrischen Grundriß“ (213) ausgespielt: „Die Lektion dieser Mordszene besteht darin, daß

\footnotetext{
44 Während bis zum Duschmord 46 Minuten vergehen, dauerst es nur weitere 25 bis zu Arbogasts Treppensturz und weitere 23, bis Norman als „Mother“, mit einem Messer bewaffnet, Lila angreift. Diese Abfolge macht das Kalkül deutlich, wie es Williams beschreibt.

45 Jancovich sieht darin die Ursache, dass sich die meisten Analysen auf die erste Filmhälfte beschränken (,Rational Fears“ 299).
} 
wir den brutalsten Schock dann erleiden, wenn wir Zeugen der exakten Realisierung dessen werden, worauf wir uns freuten [...].“ (Ebd.) Der Top Shot im Inneren des Hauses irritiert in seiner senkrechten Ausrichtung für einen Augenblick die Wahrnehmung, weil er die Szenerie zu einer Fläche umformt, auf der die Figuren wie Schachfiguren gerückt werden. Ihm geht wiederum ein Spannungsaufbau voraus, der den Zuschauenden ,einen entscheidenden Wissensvorsprung gegenüber den handelnden Figuren verschafft“ (Pabst 81): Arbogast steigt langsam in das obere Stockwerk (Abb. 3.14a), was einem „Tabubruch“ gleichkommt, „gilt dieses doch in angelsächsischen Wohngebäuden als unzugängliche private Zone“ (S. Koebner 149). Mit dem sich öffnenden Türspalt zu einem der oberen Zimmer (Abb. 3.14b) steigt die Vorahnung, die schließlich, wie Žižek es formuliert, ,geometrisch realisiert" wird (Abb. 3.14c) und im anschließenden Wechsel in die frontale Perspektive ausgespielt wird: Zusammen mit Arbogast fallen die Zuschauenden die zuvor hochgestiegenen Treppen hinunter und blicken in ein von Angst und Schrecken gezeichnetes Gesicht, dessen Wahrnehmung in der Rückprojektion zudem zeitlich und subjektiv gedehnt wird (Abb. 3.14d).
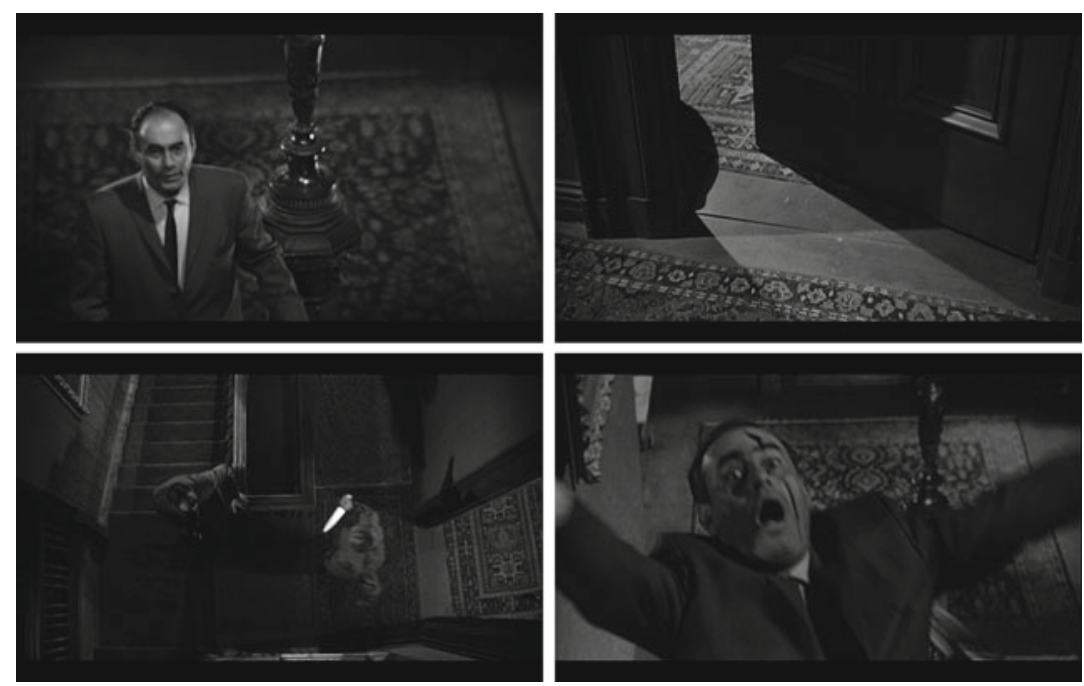

Abb. 3.14a-d Psycho, ,Der Mord an Arbogast in der Treppenszene“, USA 1960

Wenn Lila sich langsam dem Haus nähert, dieses betritt und schließlich in den Keller steigt, geht ihr mit dem Wissen, dass Norman seine Mutter in den Keller 
gebracht hat, nicht nur der gleiche Spannungsaufbau voraus, sondern ihr kommt auch das Wissen um die tödliche Gefahr im Haus zuvor. Doch statt Normans Mutter im Schaukelstuhl vorzufinden, blicken die Zuschauenden dem mumifizierten Tod ins Gesicht (Abb. 3.15a): ,the eyes of the living death“ (Wood 112). Rothman verortet diese ,figure of death“ zwischen Alptraum-Vision und Erkenntnis (,Hitchcock“ 327), auf die unmittelbar eine weitere Bedrohungsvision folgt: Norman tritt , verkleidet" als seine Mutter und mit einem Messer bewaffnet durch die Kellertür ein (Abb. 3.15b). Aber statt einer Alptraum-Fantasie des eigenen Tods (Duschmord) und statt einer geometrisch realisierten Attacke (Treppenmord) präsentiert sich mit Normans „menacing pose“ (ebd. 328) ein als "gender shock“ (Williams, „Discipline and fun“ 358) ausgespieltes Schockmoment. Nach der Verhinderung dieses dritten und letzten Angriffs, bei dem Sam Norman überwältigen kann, geht Psycho zum aufklärerischen Moment des Kriminalfilms über, bei dem „wir uns auf der sicheren Seite des Genres bei den Aufklärern (bewegen), die das Verbrechen enthüllen und den Täter stellen werden“ (Mecke 162). Dies trägt aber nicht zur genreüblichen Beruhigung bei, wie sich im Folgenden zeigt.
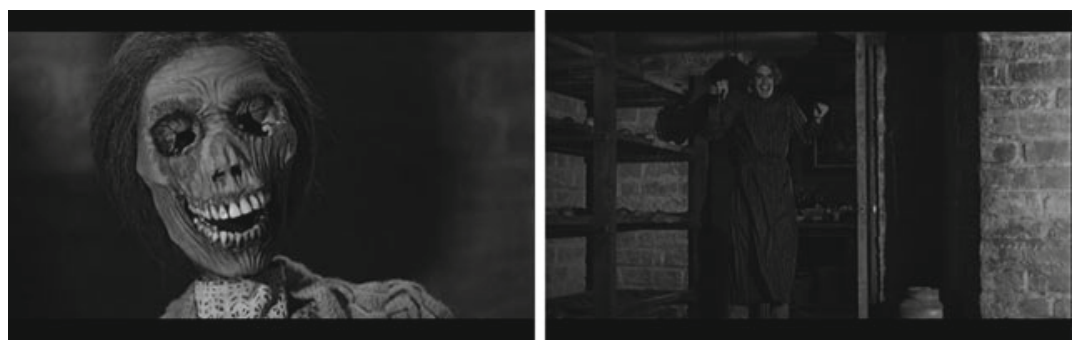

Abb. 3.15a und b Psycho, ,Das mumifizierte Leichengesicht und Normans Verkörperung von Mother“", USA 1960

\subsubsection{Der unheimliche Nachhall des Wahnsinns}

Auf dem Polizeirevier berichtet der Psychiater von Normans befremdlicher Vorgeschichte mit seiner dominanten Mutter und stellt fest: „Norman Bates no longer exists.“ 
Psychiater: He was already dangerously disturbed, had been ever since his father died. His mother was a clinging, demanding woman... and for years the two of them lived as if there was no one else in the world. Then she met a man and it seemed to Norman she ,threw him over' for this man. That pushed him over the thin line... and he killed them both. And because he was so pathologically jealous of her, he assumed she was as jealous of him. Therefore, if he felt a strong attraction to any other woman, the mother side of him would go wild. When Norman met your sister, he was touched by her... and aroused by her. He wanted her. And this set off his ,jealous mother' and..., mother killed the girl'.

Die pathologischen Ausführungen des Psychiaters im Film hält Seeßlen für ,hanebüchen“ (Seeßlen, „Filmwissen: Thriller“ 147), weil sie sich auf „die Mythen der Psychologie (nicht die Psychologie selber)“ (ebd. 149) beziehen, die wenn überhaupt als ,pop-Freud at best“ (Tudor, „Monsters“) bezeichnet werden können, aber keine kohärente psychologische Theorie ergeben. ${ }^{46}$ Vielmehr stellt die Figur des Psychiaters „,noch einmal alles auf den Kopf, was wir an Erklärungsversuchen parat hatten [...]“ (,Filmwissen: Thriller“ 150) und kann daher kaum aus dem „Bann der Faszination“ (ebd.) befreien, in den die Duschszene, die vorherige Todesfigur und der Gender-Schock die Zuschauenden gezogen haben. Dennoch bietet Psycho erstmals eine Semantik des psychopathologischen Wahnsinns an, bei der es weniger um die psychiatrischen Erklärungen einer Psychose an sich geht, sondern vielmehr um den gesamten filmischen Versuch, den monströsen Wahnsinn im Horrorfilm als ,Symptom' zu verhandeln und eine lose Reihe an Erklärungsmustern anzubieten. ${ }^{47}$ Normans voyeuristische Blicke auf Marion, die sexuelle Konnotation der Morde und der Gender-Schock seiner Erscheinung als „Mother“ werden über die destruktiv-monströse Semantik einer dominanten Mütterlichkeit gerahmt, die sich in gewaltsamen Tötungen und einer sexuellen Indifferenz äußert. Die Erklärungen des Psychiaters fügen sich in dieses semantische Deutungsangebot ein, beruhigen darin auch für Mecke aber keineswegs, denn „der rational erklärende Psychiater hat nicht das letzte Wort“ (162).

In Psycho zeigt sich „the most unbearable horrible in the film“ (Wood „Hitchcock's Films 113) erst am Ende: Auf der Polizeiwache wird „Mothers“

\footnotetext{
${ }^{46}$ Dagegen greift Bloch in seiner Romanvorlage, wenn auch unterkomplex, deutlicher auf Freuds „Ödipus-Komplex“ zurück, dem sich der Täter im Roman sogar bewusst ist (Höltgen 167 f.).

${ }^{47} \mathrm{Zu}$ dieser ab 1960 mit Psycho einsetzenden Entwicklung an psychotischen Ideenkreisen im Horrorfilm siehe Tudor, ,Monsters“, insbesondere 185-210.
} 
Stimme erstmals sichtbar an den Körper von Norman geheftet, der in eine Decke gehüllt auf einer Polizeipritsche sitzt (Abb. 3.16). Während die Kamera langsam an den stillen Norman heranfährt, legt „Mother“ ihre Sicht dar, die in ihrer vermeintlichen Harmlosigkeit die eigene Monstrosität markiert:

„Mother": It's sad... when a mother has to speak the words that condemn her own son... but I couldn't allow them to believe that I would commit murder. They'll put him away now... as I should have... years ago. He was always... bad. And in the end, he intended to tell them I killed those girls... and that man. As if I could do anything except just sit and stare... like one of his stuffed birds. Well, they know I can't even move a finger. And I won't. I'll just sit here and be quiet. Just in case they do... suspect me. They're probably watching me. Well, let them. Let them see what kind of a person I am. I'm not going to swat that fly. I hope they are watching. They'll see... they'll see... and they'll know... and they'll say..., why, she wouldn't even harm a fly..."

Abb.3.16 Psycho, „Mothers Inbesitznahme von Norman“, USA 1960

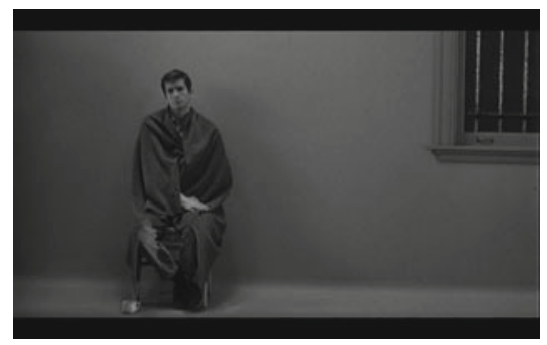

Während „Mother“ hier über Norman spricht, existierten ihre Drohungen zuvor nur außerhalb des filmisch Sichtbaren und herrschten - gerade weil sie keinem eindeutig sichtbaren Körper zuzuordnen war - in ihrem bestechend strengen Klang über dem Haus im Sinne von Michel Chions Theorie des Acousmêtre mit einer akusmatischen Präsenz. ${ }^{48}$ Für Bronfen bildete die mütterliche Stimme einen „Fremdkörper, der jeglicher Materialität beraubt““ wurde und als ,ein verlorener

\footnotetext{
${ }^{48}$ Zur Theorie des Acousmêtre bei Michel Chion siehe The Voice in Cinema, insbesondere 17-29.
} 
Körper“ (59) auf den Muttermord verweist. ${ }^{49}$ In der nun sichtbaren Zusammenführung der mütterlichen Stimme mit Normans Körper sieht Bronfen ein „psychotisches Moment“: Norman ist vollständig zu „Mother“ geworden (61). Zwar entspricht die Zusammenführung von Stimme und Trägerkörper einer Deakusmatisierung nach Chion, in der die Zuschauenden den Träger der Stimme erblicken und identifizieren, aber damit geht in Psycho keine Entmachtung der Stimme einher. „Mothers“ Stimme wird zwar zu dem Körper, aus dem sie stammt, hingeführt, aber „die Wirkung hier (ist) völlig gegensätzlich zur Zähmung“ (218), wie Žižek feststellt: „Die Stimme hat sich an den falschen Körper geheftet, so dass das, was wir erhalten, ein wahrer Zombie ist [...]." (Ebd.) Das Ende in Psycho markiert Normans ,endgültige Gefangenschaft im psychotischen Universum“ (ebd.), das von "Mother" beherrscht wird. Machtvoll hat sie nicht nur von Normans Körper Besitz ergriffen und spricht nun aus ihm heraus, sondern scheint auch durch ihn hindurch. Hinter Normans Lächelns zeichnet sich das Gesicht des mumifizierten Leichenkörpers ab (Abb. 3.17a). Die Überlappung der Gesichter ergibt den verstörenden Anblick eines totenschädelähnlichen Fratzengesichts, ,a skull-like Grimace“ (Wood, „Hitchcock's Films“ 113), ,the grinning death-face“ (Rothman, ,Hitchcock“ 339), das ebenso ambivalent wie zombieartig eine fremdartige Gestalt angenommen hat und in dieser „absoluten Andersartigkeit“ für Žižek umso unheimlicher wirkt (218). ${ }^{50}$ Für Noël Carroll markiert der Anblick einen spezifischen Horror, weil die identitären und existenziellen Verhältnisse von Norman aufbrechen und uneindeutig werden:

He is Nor-man: neither man or woman but both. He is son and mother. He is of the living and the dead. He is both victim and victimizer. He is two persons in one. He is abnormal, that is, because he is interstitial. In Norman's case, this is function of psychology rather than biology. Nevertheless, he is a powerful icon of impurity, which is, ultimately, why I submit that commentators are prone to classify Psycho as a horror film. (,The Philosophy of“ 39)

\footnotetext{
${ }^{49}$ Für Bronfen ist in der mütterlichen Stimme der Muttermord als traumatische Separation kodiert, wobei sie innerhalb von Normans psychischem System, repräsentiert durch das Haus, existiert und hier ständig an das Trauma erinnert und für die missglückte Verdrängung des mütterlichen Körpers steht. (59)

${ }^{50}$ Die unheimliche Andersartigkeit der Stimme in Psycho kann mit Linda Williams' Konzept der body genres auch als eine genrespezifische Affektwirkung beschrieben werden. Stimmen gehören in Form schreiender, wimmernder und kreischender Figuren zum Darstellungsrepertoire des Horrorgenres, wo sie affizierend eingesetzt werden (,Film Bodies“). Zur Materialität der Stimme siehe aber auch Silverman, ,Acoustic Mirror“, und Barthes, „Grain of the Voice“.
} 
Aus dieser Ambivalenz schält sich schließlich die letzte Einstellung des Films heraus, in der Marions Auto über eine Eisenkette aus dem Sumpf herausgezogen wird (Abb. 3.17b). Wenn dieses letzte Bild schließlich vollständig aufblendet, ist der Film nicht zu einem erzählerisch logischen Endpunkt gekommen, sondern kehrt zu Marion zurück: „The film's final image then, echoes, the equally cryptic conclusion of the shower murder sequence.“ (Rothman, „Hitchcock“ 430) Damit vollzieht der Film eine virtuelle Kreisbewegung, die nicht nur zur Sumpfszene zurückführt, sondern für Heller bis an den Anfang des Films zurückreicht, weil das Bild nicht nur auf den Duschmord, sondern auf Marion, ihre Flucht, ihren Tod und das Versenken ihres Autos verweist. Das Ende hält jedoch keine Lösung bereit. In Psycho bietet sich nicht die gefundene Leiche von Marion an, sondern nur der Kofferraum als ,visuelle, wahrnehmungsbildliche Hülle“ (,Filmästhetik des Fluiden“ 163 f.). In der Verweigerung einer Lösung steckt aber nicht nur ein selbstbezogener Zirkelschluss, sondern es bietet sich ein offenes Ende, das ,mit der Gewissheit (entlässt), dass mit Untergründigem jederzeit wieder zu rechnen ist" (Mecke 162). Auch für Naremore hallen die Bilder des Duschmords und des Fratzengesichts nach: „,ertain images haunt us“ („Filmguide“ 78). In Psycho's Bildlichkeit hat sich eine Semantik des Monströsen und Unheimlichen eingeschrieben, die derart nachwirkt, dass sich auch die von Hitchcock kultivierte Legende lange hält, dass das Publikum nach Psycho wochenlang Angst vor dem Duschen hatte: „He (Alfred Hitchcock; K.K.) feels his pièce de résistance was achieved by what he did to the hundreds of millions of people who viewed Psycho, many of whom were afraid to take showers for weeks after." (Harris/Lasky 5)
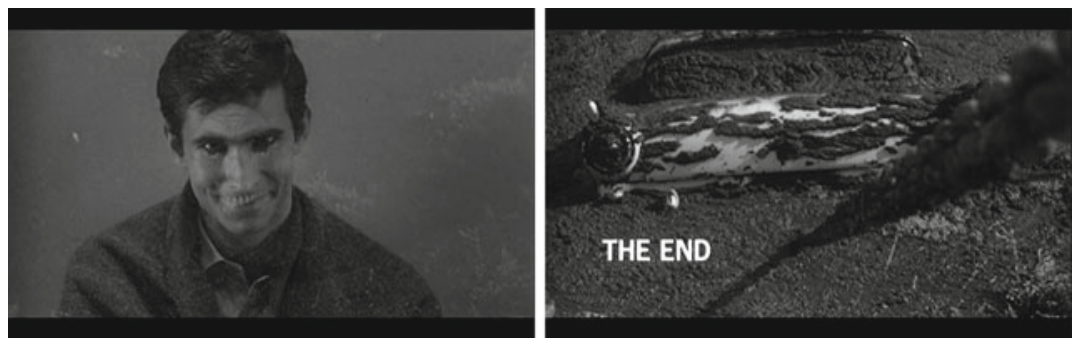

Abb. 3.17a und b Psycho, „Das unheimliche Fratzengesicht und Marions Auto“, USA 1960 
Diese Lesarten des Endes verdeutlichen, wie „Mothers“ Stimme, das Fratzengesicht und der Kofferraum als genrespezifische Markierungen und unheimlicher Nachhall diskursiviert werden, die sich in eine Semantik des Monströsen einfügen. Was zuvor über die Duschszene, den Treppenmord und die Entdeckung der mumifizierten Leiche und Normans Erscheinung als „Mother“ an Horror erfahren wurde - die Bedrohung und Angst, aber ebenso die beiden Seiten des ausgeübten Terrors - wird hier einer destruktiv-monströsen Mütterlichkeit und sexuellen Andersartigkeit zugeschrieben, die als Quelle des Horrors zu einer nachhaltigen Verunsicherung beiträgt. Der Terror entspringt keiner rationalen Erklärung, sondern einem psychotischen Universum (Bronfen, Žižek), das den terrorisierten wie terrorisierenden Zuschauenden (Clover) mit einer unheimlichen Stimme (Žižek), einem ambivalenten Fratzengesicht (Carroll, Wood, Rothman), in ein offenes, unsicheres Ende (Heller) entlässt, in dem zwischen Leben und Tod, Mutter und Sohn, weiblich und männlich nicht mehr eindeutig unterschieden werden kann.

Wie die Ausführungen zeigen, lassen sich entlang der eingenommenen generischen Metaperspektive eine Reihe genrespezifischer Diskursivierungen aus den wissenschaftlichen Texten herausziehen, die, ob autorenbezogen oder psychoanalytisch, phänomenologisch oder genretheoretisch modelliert, filmische Details genrespezifisch beschreiben und in Psycho multiple Genremarkierungen identifizieren. Während das unterschlagene Geld, die Flucht, der bedrohliche Polizist und die Verfolgungsängste als Markierungen des Thrillers semantisch aufgeladen werden, führen das Paar, die Motivation der Heldin und Sams Brief die hypothetische Imagination einer Liebesgeschichte mit sich, wobei sich die generischen Semantiken gegenseitig in Widersinnigkeiten verstricken, denn erst der romantische Wunsch führt zum Diebesgut, das sich letztlich zu spät als unnötig erweist. Mit der Auflösung dieser generischen Angebote werden die Figuren des Privatdetektivs und der Lila Crane, aber auch der Psychiater, im Rahmen einer Detektivhandlung und Aufklärung innerhalb des Kriminalgenres gelesen. Die Beschimpfungen von „Mother“, das surreale Motel, die Morde und Attacken, „Mothers“ Stimme und Normans Fratzengesicht dagegen werden über den Horrorfilm in ihren bedrohlichen Inszenierungen, schockierenden wie unheimlichen Wirkungen und monströsen Erscheinungen semantisiert. In den so herausgearbeiteten Signaturen von Psycho zeigt sich aber auch eine semantische Flexibilität, die Markierungen im Kontext verschiedener Genres beschreibt. Die verregnete Windschutzscheibe kennzeichnet Momente subjektiver Irritation und Verunsicherung, die einerseits im Kontext der Raubgeschichte des Thrillers als mit der Heldin geteilte Angst gelesen werden (Seeßlen). Zugleich bildet diese subjektive Verunsicherung den emotionalen Vorlauf und das kontradiktorische Setting für die Schockwirkung des Horrors (Heller). So erhalten die audiovisuellen 
Detailbefunde zwar eine gleiche Semantik, werden aber als unterschiedliche Markierungen identifiziert, ohne dass die einbezogenen Genrekonzepte in Widerspruch zueinander geraten. Vielmehr verdeutlichen sie, dass Texte auf vielfache Weise generisch markiert sind und an mehreren Genrekonventionen teilnehmen, sodass von den Genresignaturen von Psycho mitunter dynamische Genreeffekte ausgehen, wie die tragische Verbindung von Liebes- und Thrillerhandlung, die subjektive Ebene zwischen Thriller- und Horroreffekten oder die Verwerfungen innerhalb der Duschszene (Williams).

Die diskursanalytische Genreanalyse offenbart zudem, dass die Duschszene nicht die einzige generische Wendestelle des Films bildet. Bereits zuvor werden an mehreren Stellen im Film Wendungen beschrieben, als mit der Unterschlagung des Geldes eine räuberische Dynamik beginnt (Seeßlen) oder "Mothers“ Beschimpfungen eine bedrohliche Wendung ankündigen (Rothman). Ebenso finden sich diese in der zweiten Filmhälfte, wenn die eingeführte Detektivhandlung zum analytischen Gegenstück avanciert (Jancovich) oder im Polizeirevier auf die Seite der Aufklärung gewechselt wird (Mecke). Dennoch sind an der Duschszene besonders viele Wendungen hervorgehoben worden, die von einem abrupten Eindringen in das beruhigende und berauschende Moment der Dusche über die generische Verwerfung von Thriller und Liebesgeschichte bis zum identifikatorischen Wechsel von Marion zu Norman reichen. Sie werden im Kontext eines audiovisuell radikalen Schockmoments diskursiviert, das ebenso unerwartet wie drastisch kommt und besonders affizierend gestaltet ist. Die zerstörerische Wirkung zielt auf den Körper der Zuschauenden, der bezeugt wie erleidet und letztlich völlig destabilisiert und desorientiert in keine sichere Haltung mehr zurückkehren kann, sondern einen Rhythmus aus ,,anticipation, shock, and release" (Williams) verinnerlicht. Sowohl die Beschreibungssemantiken der in der Duschszene greifenden Affektsteuerung als auch die innerhalb der Szene identifizierten Markierungen des Horrors zeigen, dass die Duschszene nicht , an sich eine Genresignatur des Horrors bildet, sondern aus mehreren generischen Elementen zusammengesetzt ist. Diese greifen auf mehreren Ebenen und erfüllen visuell wie akustisch, emotional und affektiv kontradiktorische Genrefunktionen: das beruhigende, quälende wie gleichgültige Wasserrauschen (Heller), der sichere wie alptraumhafte Duschvorgang (Rothman), die Brutalität aus Violinenschreien, Messer und Marions Stellvertreterkörper (Heller, Clover), aber auch die destabilisierende Symbolik von Abfluss und totem Blick (Heller, Seeßlen, Williams, Jancovich). Die Wirkung der Duschszene entsteht nicht allein durch die pointierte Brutalität dieser ,Bausteine'. Sie generiert sich gleichermaßen aus dem generischen Vorlauf, wie sie über die nachfolgenden Schockmomente sogar noch an Steigerung erfährt. Psycho zieht so in einen Bann des Schreckens, aus dem 
eine Befreiung weder möglich noch angelegt ist. „Mothers“ wüste Beschimpfungen, Normans voyeuristische Blicke wie routinierte Beseitigungen und die psychiatrischen Aufklärungen der Psychose legen um den filmisch erlebten Terror eine Semantik, die zwar in der dominanten Mutter eine erste Erklärungsfigur für den mörderischen Wahnsinn anbietet, in der Ambivalenz und Andersartigkeit von Norman jedoch das eigentlich Monströse verortet, das als destabilisierender Faktor unheimlich nachwirkt.

\subsection{Die antizipierenden und sensationsgeladenen Genresignaturen der Genrediskurse}

Die drei analysierten Genrediskurse verdeutlichen, wie Psycho als generischer Text über diese Diskurse erzeugt wird, indem verschiedene genrespezifische Markierungen nicht nur im Film, sondern bereits in den Materialien gesetzt werden, um entscheidend Einfluss auf die Diskursivierung des Films zu nehmen. Bereits im Diskurs der Filmkritik lässt sich in der gespaltenen Wahrnehmung ein implizites Genrewissen herauslesen, das in der Duschszene gezielte Schockeffekte eines Horrorkinos erkennt. Die kulturelle Geringschätzung als ,the goriest thing seen on film in a long time" (Callenbach 48) rührt aus einem Low-Budget-Genrekino her, bei dem bereits vor den Kinosälen sensationsgeladene Genremarkierungen zu finden sind. Trotz der restriktiven Pressepolitik und entsprechend schlechten Filmbesprechungen bewirkt die Psycho Policy ein langanhaltendes und übergroßes Interesse beim Publikum, das auf mehreren Ebenen von den Sensationen eines ,neuen“ Genrekinos angezogen wird, das sich als gar nicht so neuartig herausstellt. Eine Einlasspolitik mit dezidierten Ankündigungs- und Aufführungsregeln, eine Secrecy Policy, Gimmicks wie Wächter und eine reißerische Horrorrhetorik werden bereits zuvor in der Vermarktung von Low-Budget-Genrefilmen der 1950er Jahre benutzt und locken als sensationsgeladene Genrepraktiken erfolgreich ein Publikum in die Kinos. Ebenso greift Hitchcocks omnipräsente Persona auf einen generischen brand zurück, den er seit der frühen britischen Produktionszeit geschickt vermarktet und der seit seiner Fernsehreihe und seinen Auftritten als ,Master of Ceremonies' auch einem breiten amerikanischen Fernsehpublikum bekannt ist. Indem die Psycho Policy sowohl Hitchcocks mediale (Fernseh-)Persona eines Mainstream-Suspense-Kinos als auch gängige Praktiken des randseitigen Horrorkinos in einem doppelten Genrediskurs zusammenführt, entstehen zwischen den Unterhaltungsbereichen und Publikumsgruppen verstärkende Quereffekte. Die exploitative Ausgestaltung von Hitchcocks Persona sowie der ironischen Horrorrhetorik und mörderischen Semantik zog derart erfolgreich 
beide Publika an, dass sich mit den langen Warteschlangen neue ,Kinoformationen' ergaben und die Werbekampagne selbst zur Sensation wurde. Die Breite der medialen Öffentlichkeit, die Psycho als Hitchcocks Film trotz geringer symbolischer Verkaufswerte zukommt, bewirkt, dass die in den Materialien funktionalisierten Kinopraktiken und präsentierten Sensationswerte zu Genresignaturen eines ,Thrill and Suspense'-Unterhaltungskinos werden, das nicht mehr auf das Low-Budget-Horrorkino reduziert ist, sondern seitdem auch ein Mainstreamkino hinsichtlich einer genrespezifisch antizipierenden Erwartungshaltung markiert.

Die Orchestrierung der Zuschauerwahrnehmung unterliegt damit also nicht nur einem ,anticipation, shock, and release“-Rhythmus, wie es Williams nach der Duschszene für die zweite Filmhälfte beschreibt (,Discipline and fun“ 355), sondern greift bereits vor dem Kino. Indem die Genresignaturen ein generisches Setting vor dem Kino abstecken, sorgen sie für die richtige Anspannung im Vorhinein, um sich anschließend in einem gesteigertem Ausmaß entladen zu können. $\mathrm{Zu}$ dieser Orchestrierung zählen auch die Genresignaturen des wissenschaftlichen Diskurses. Die identifizierten Markierungen rufen verschiedene Genrebezüge auf, um einerseits in einem Genrespiel gegeneinander , ausgespielt " und verworfen zu werden. Anderseits gehen sie in einer übergreifenden Semantik des Horrors auf, um nicht nur nach dem ersten Schock, sondern auch nach dem Ende des Films noch anzuhalten. Zwischen diesen antizipierenden und nachhallenden Genresignaturen bildet die Duschszene dennoch die zentrale Genresignatur eines ,neuen“ Horrors. In dem audiovisuell pointierten Zusammenspiel aus fließendem Blut, verstörenden Soundeffekten und alternierenden Bewegungen zwischen Messer und Körper erzeugt die Szene die suggestive Illusion einer ,slicing and physical penetration", mit der Psycho eine anschauliche Gewaltdarstellung im Mainstreamkino eingeführt hat (Kendrick, „Hollywood Bloodshed“ 43). Dies zeigt sich auch noch 1964, wie Paul aufzeigt, als die geplante Fernsehausstrahlung von Psycho verboten wird und es deshalb 1965 (und noch einmal 1969) zur Wiederaufführung im Kino kommt (Abb. 3.18a):

Psycho had already extended the boundaries for graphic violence four years before, so its unfitness for television made clear that movie theatres were the appropriate venue for such explicitness. Appropriately, the denial of its television showing immediately led to a full-scale rerelease of Hitchcock's film. Throughout the $1960 \mathrm{~s}$, graphicness came to be associated with theatrical features. (Ebd. 9) 

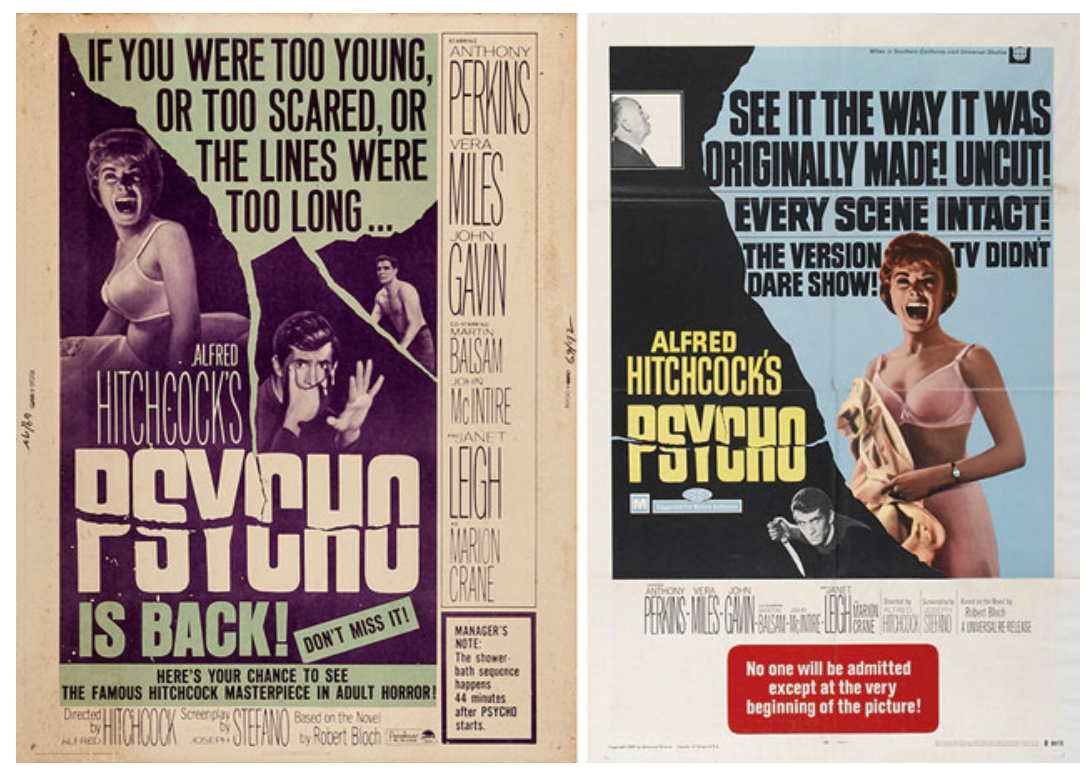

Abb. 3.18a und b Plakate zu den Kino-Wiederaufführungen von Psycho, Paramount 1965 und Universal 1969

Psycho steht damit als markantes Beispiel für eine neue Kinoära, in der das Publikum den Nervenkitzel und Kick im Kino sucht und mit pointierten Mordszenen und Attacken, zombiehaften Erscheinungen, Gender-Überraschungen und unheimlichen Stimmen wie Gesichtern in einer Form geliefert bekommt, die den Wiederaufführungen erneute Sensationen beschert, denn noch 1969 wirbt das Plakat mit ,the TV didn't dare show" (Abb. 3.18b). Bevor aber Psycho innerhalb genrehistorischer Diskurse als markanter Vorläufer und wichtiger Wendepunkt herausgestellt wird, führt die mediale Popularität der Slasherfilme in den 1980er Jahren zu drei Fortsetzungen. Bereits 1983, nur drei Jahre nach Hitchcocks Tod im Jahr 1980, erscheint mit Psycho II das erste Sequel, das bereits 1986 von einem weiteren begleitet wird. Inwiefern die Sequels einen Genrediskurs auf der Ebene des Genrekonzepts herausbilden, indem die generisch-seriellen Wechselverhältnisse nicht nur Bezüge auf Psycho herstellen, sondern dessen Genresignaturen fortführen und verändern, wird im folgenden Kapitel im Kontext des Slashergenres untersucht. 
Open Access Dieses Kapitel wird unter der Creative Commons Namensnennung 4.0 International Lizenz (http://creativecommons.org/licenses/by/4.0/deed.de) veröffentlicht, welche die Nutzung, Vervielfältigung, Bearbeitung, Verbreitung und Wiedergabe in jeglichem Medium und Format erlaubt, sofern Sie den/die ursprünglichen Autor(en) und die Quelle ordnungsgemäß nennen, einen Link zur Creative Commons Lizenz beifügen und angeben, ob Änderungen vorgenommen wurden.

Die in diesem Kapitel enthaltenen Bilder und sonstiges Drittmaterial unterliegen ebenfalls der genannten Creative Commons Lizenz, sofern sich aus der Abbildungslegende nichts anderes ergibt. Sofern das betreffende Material nicht unter der genannten Creative Commons Lizenz steht und die betreffende Handlung nicht nach gesetzlichen Vorschriften erlaubt ist, ist für die oben aufgeführten Weiterverwendungen des Materials die Einwilligung des jeweiligen Rechteinhabers einzuholen.

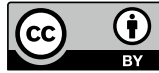

